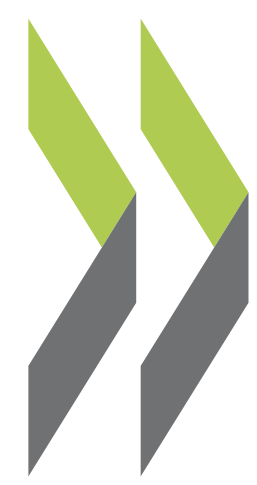

OECD Local Economic and Employment Development (LEED) Papers 2012/09

Skills for Competitiveness: A Synthesis Report

\section{Francesca Froy,}

\section{Sylvain Giguère,}

\section{Michela Meghnagi}




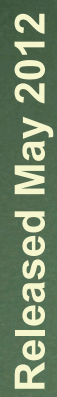

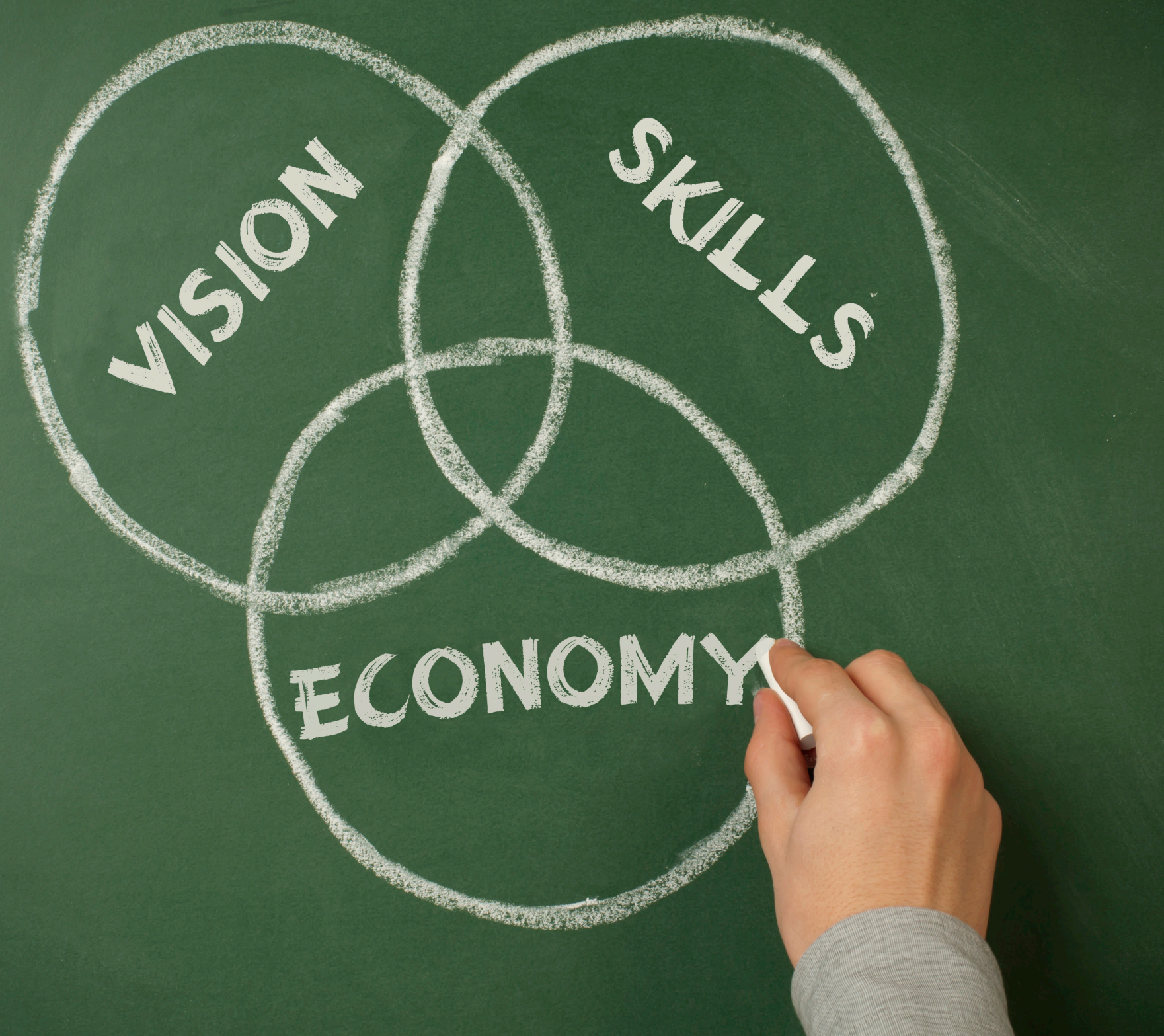

\section{Skills for Competitiveness}

\section{A Synthesis Report}

F.Froy, S.Giguère and M. Meghnagi 


\section{FOREWORD}

It is broadly agreed that investing in skills will play a key role in helping OECD countries to return to growth following the global economic crisis. In order to rebuild successful and productive economies, all OECD countries will need skilled people who can adapt to change, think innovatively, and identify the new products and processes which will help firms to corner new markets. At the same time, ensuring that more people share the skills necessary for an active participation in the labour market will be crucial for ensuring a more equitable and sustainable growth.

The work of the LEED Programme over recent years on Designing Local Skills Strategies, Breaking out of Policy Silos and Leveraging Training and Skills Development in SMEs has demonstrated that strategies to boost skills require the participation of many different actors, not just in the field of education, but also in employment, economic development, migration and social welfare. It is not just policy makers that need to play a role but also business and the not-for-profit sector. And it is at the local level that the work of such actors needs to be joined up to ensure that investment in skills meets business needs and helps to contribute to broader economic development strategies.

The study on Skills for Competitiveness demonstrates that it is not just investment in the supply of skills which counts, but also work with employers to ensure that human potential is effectively harnessed and skills fully utilised. Too many managers waste the potential of their staff, from customer service to the shop floor, to problem solve, innovate and develop new solutions to production problems from the bottom up. Many of today's workforce remain frustrated in jobs which do not make the most of their skills, in firms which remain unproductive, and which contribute little to local economies. The economic downturn has revealed that employment in such firms is dangerously unsustainable at a time of increasing global competition.

The project was carried out through a strong collaboration with LEED member countries and a network of academics specialist in the field. It represents a key element in LEED's contribution to the OECD Skills Strategy (2012). I would like to warmly thank the following organisations for their active participation and support in the study: DG Employment and Social Affairs at the European Commission, the UK Commission for Employment and Skills, Human Resources and Skills Development (HRSDC) in Canada, and the Institute for the Development of Vocational Training for Workers (ISFOL - Istituto per lo Sviluppo della Formazione Professionale dei Lavoratori) in Italy. We hope that the findings and recommendations will be of use to national and local governments alike.

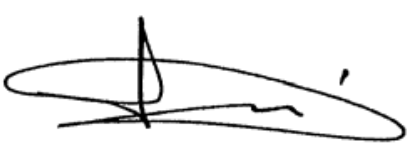

Sergio Arzeni, Director, OECD Centre for Entrepreneurship, SMEs and Local Development 


\section{ACKNOWLEDGEMENTS}

The project has been carried out in collaboration with the European Commission and has benefited from the support and active participation of staff from the UK Commission for Employment and Skills, Human Resources and Skills Development (HRSDC) in Canada, and the Institute for the Development of Vocational Training for Workers (ISFOL - Istituto per lo Sviluppo della Formazione Professionale dei Lavoratori) in Italy. Important contributions were made by Robert Strauss from the DG Employment and Social Affairs at the European Commission; Mike Campbell, Lesley Giles and Katherine Chapman from UKCES; Lawrence Buhagiar, Jeff Perrault, Francois Rivet, Mark Roe, Lucas Mcall, Joanne Winter, Nina Ahmed and Sharif Mohammad at HRSDC; Matthew Lee from the Ontario Ministry of Training, Colleges and Universities and Claudio Tagliaferro, Simona Acunzo, Valeria Iadevaia and Christian Poggi at ISFOL. The fieldwork research was carried out in collaboration with the following experts in each country:

- Anne Green, Professorial Fellow University of Warwick; with additional expertise from Professor David Finegold, Rutgers Institute, New Jersey and Professor Peter Lloyd, independent expert;

- Professor Sergio Destefanis, University of Salerno, with additional expertise from Professor Chris Warhurst, University of Sydney;

- Professor Anil Verma, Rotman School of Management, University of Toronto with additional expertise from George Erickcek, Senior Regional Analyst at the Upjohn Institute for Employment Research, United States.

The project also formed an international advisory group of the following experts (see Table 1. below).

Table 1. Skills for Competitiveness Expert Advisory Group

\begin{tabular}{|l|l|l|}
\hline \multicolumn{1}{|c|}{ Expert } & \multicolumn{1}{c|}{ Institution } & \multicolumn{1}{c|}{ Country } \\
\hline Valentine Bilsen & Idea Consult & Belgium \\
\hline Gerhard Bosch & $\begin{array}{l}\text { Institute for Work, Skills and Training, University of Duisberg- } \\
\text { Essen, Germany }\end{array}$ & Germany \\
\hline John Buchanan & Workplace Research Centre, University of Sydney, Australia & Australia \\
\hline Randall Eberts & Upjohn Institute, Michigan, United States & United States \\
\hline David Finegold & The State University of New Jersey, United States & United States \\
\hline Anne Green & $\begin{array}{l}\text { Institute for Employment Research, University of Warwick, } \\
\text { United Kingdom }\end{array}$ & United Kingdom \\
\hline Peter Lloyd & ECOTEC Research and Consulting & United Kingdom \\
\hline Geoff Mason & $\begin{array}{l}\text { National Institute of Economic and Social Research, United } \\
\text { Kingdom }\end{array}$ & United Kingdom \\
\hline Ken Mayhew & $\begin{array}{l}\text { The ESRC Centre on Skills, Knowledge and Organisational } \\
\text { Performance (SKOPE) }\end{array}$ & United Kingdom \\
\hline Mark Troppe & National Institute of Standards and Technology, United States & United States \\
\hline
\end{tabular}

The authors would like to thank colleagues in the LEED Programme for their assistance in delivering the project including Jonathan Barr, Debra Binks, Helen Easton, Damian Garnys, Francois Iglesias and Emma Mooney. 
TABLE OF CONTENTS

INTRODUCTION

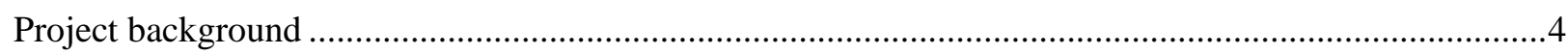

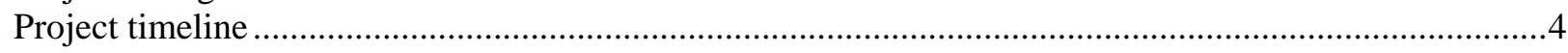

MAPPING SKILLS SUPPLY AND DEMAND: THE DIAGNOSTIC TOOL ..........................................

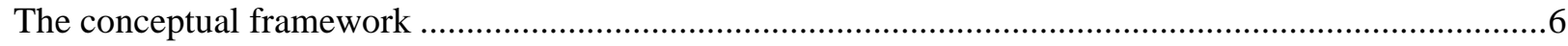

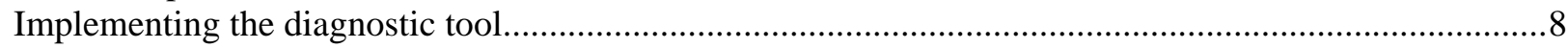

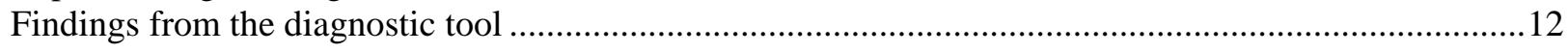

RESPONDING TO AND SHAPING SKILLS DEMAND: POLICY LESSONS .......................................34

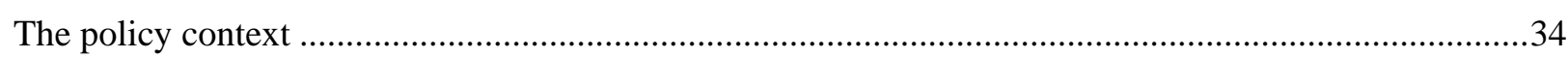

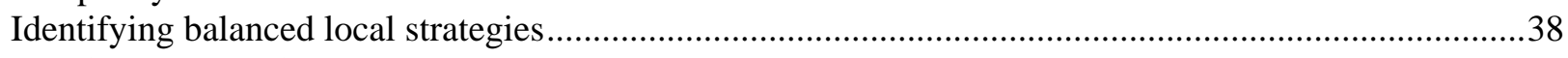

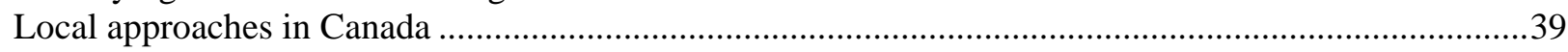

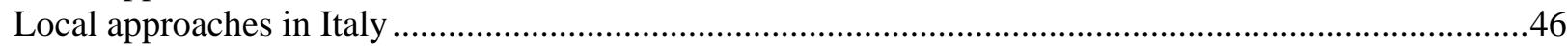

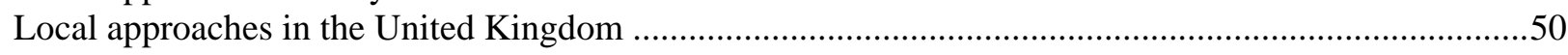

GOVERNANCE OF STRATEGIES TO RAISE SKILLS SUPPLY AND DEMAND ..............................54

Taking a sectoral or a place-based approach ......................................................................................54

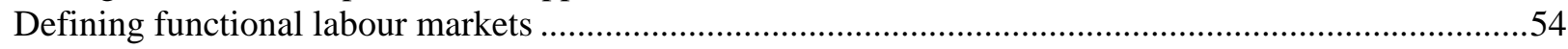

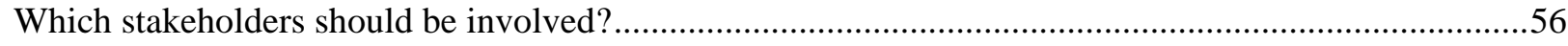

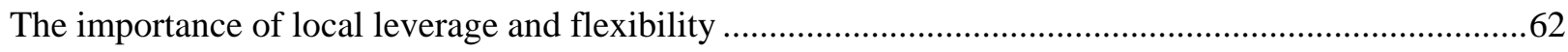

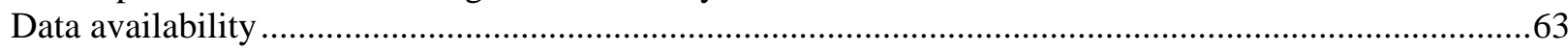

CONCLUSIONS AND ISSUES FOR CONSIDERATION …...............................................................64

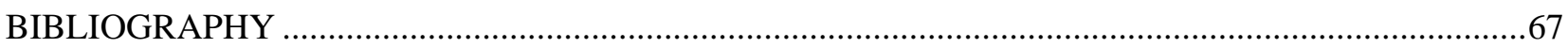




\section{INTRODUCTION}

\section{Project background}

To be successful in today's knowledge economy, communities need to boost not only the skills of local people but also the utilisation and deployment of these skills by employers. By ensuring that skills are utilised effectively, local economies can become more competitive and host better quality and better paid jobs, while simultaneously improving living standards and stimulating innovation.

The OECD LEED Skills for Competitiveness project has reviewed the tools and governance mechanisms which policy makers are putting in place to tackle this policy area in three LEED member countries, Canada, the United Kingdom and Italy, with information on a wider set of policies and measurement tools being collected through an international literature review. Data has also been analysed on the supply and demand for skills at the sub-regional level (OECD territorial level $3^{1}$ ) in each country.

The research builds on the lessons learned from LEED's 2007-9 Designing Local Skills Strategies project, which showed that balanced skills strategies are important to raising local productivity and increasing socio-economic inclusion at the local level. It was clear that there is strong variation between local labour markets in terms of the relationship between skills supply and demand. While some regions exhibit characteristics of 'high-skills equilibrium,' with a strong supply of skills being matched by a strong demand for skills, others experience either an imbalance in skills supply and demand (leading to skills shortages or skills surplus) or a 'low-skills equilibrium' where low skills in the work force are matched by low demand for skills amongst employers. This means that depending on their local skills context, some regions will need to focus on raising both the supply and the demand for skills in order to have a chance of competing in today's knowledge economy.

Working on improving skills demand and utilisation is a relatively new area for policy makers in the field of workforce development and training, and it is an area where a number of other policy sectors (particularly economic development) and a number of different types of stakeholder (colleges, universities, employment services, unions, economic development agencies, social enterprise) have a role to play.

In order to start work in this area, local actors need first to be able to accurately identify the local skills context they are working within. A first step of this project has therefore been to develop a statistical diagnostic tool which exploits the limited indicators that are available locally to help policy makers to better understand the overarching skills issues affecting local labour markets and the extent to which these are differentiated. The aim is for the tool to be useful in its own right in helping policy makers to complete the evidence base for local skills and economic strategies, and as a follow up to the project data has been mapped against the tool in a broader set of OECD countries as part of the OECD Skills Strategy.

\section{Project timeline}

The project started in late 2009 with an international literature review. In 2010 and 2011 work focused on establishing and implementing the diagnostic tool, and carrying out fieldwork in the three participating

1. Regions in OECD member countries have been classified according to two territorial levels (TL) to facilitate international comparability. The higher level (Territorial level 2) consists of macro-regions, while the lower level (Territorial level 3) is composed of micro-regions. Territorial Level 3 is broadly comparable to NUTS 3 in the European nomenclature, specifying regions with populations of 150,000 800,000 . 
countries to test the viability and usefulness of the tool and to evaluate policy and practice. The structure of the project is summarised in Box 1. below.

\section{Box 1. Skills for Competitiveness Project structure}

\section{Stage 1: International literature review}

A team of experts from the Workplace Research Centre at the University of Sydney produced a literature review to identify (i) how skills demand and utilisation is being measured at the regional level and (ii) what efforts to improve skills utilisation at the local and regional level have been undertaken in OECD countries (Buchanan et al., 2010). An international expert advisory group was also established to review and feed into the findings of the project (see Table 1).

\section{Stage 2: Quantitative analysis}

A diagnostic tool was developed to assess the supply and demand for skills at Territorial Level 3 in OECD countries. The tool has been applied in Canada, Italy and the United Kingdom. For the United Kingdom and Italy data has been sourced from Labour Force Survey and National Accounts, and for Canada from the Census.

\section{Stage 3: Fieldwork in selected areas}

Field work has taken place in the above three countries, including interviews at national, regional and local level, e-questionnaires to policy makers and firms, case studies at local level and OECD study visits. In Canada the province identified for the fieldwork was Ontario, with local case studies taking place in Kitchener and Niagara. In Italy, the two regions chosen were Veneto and Campania, with local case studies in Treviso and Riviera del Brenta. In the United Kingdom, the regions and nations chosen were north west England and Wale, with local case studies in Blackpool, Manchester and Rhyl.

\section{Stage 4: Reporting}

The findings in each country have been summarised in a series of study reports with specific policy recommendations for national and local policy makers.

This LEED project has fed into the OECD Skills Strategy (2012), which is based around three key strands: ensuring an adequate supply of skills now and for the future; optimising the productive use of skills and the effective steering and funding of skills systems. 


\section{MAPPING SKILLS SUPPLY AND DEMAND: THE DIAGNOSTIC TOOL}

\section{The conceptual framework}

The labour market analyst Anne Green (see Green et al., 2003) proposes a useful typology to understand the complex relationship between skills and supply at the level of local economies. According to this typology, local economies can broadly fall into four different categories: those experiencing a lowskills equilibrium; those experiencing skills gaps and shortages; those experiencing a skills surplus; and, lastly, those experiencing a high-skills equilibrium (see Figure 1. below).

Figure 1. Moving from a low to high-skilled equilibrium (adapted from Green et al, 2003)

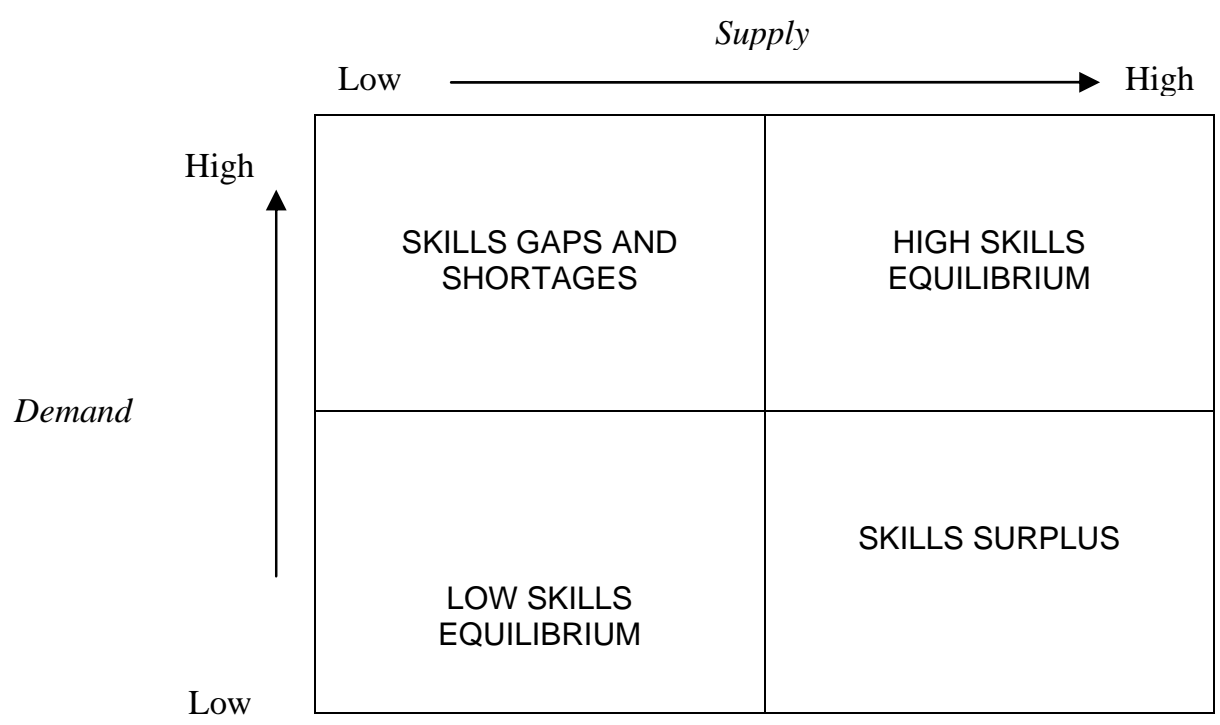

Source: Froy et al, 2009.

In the context of demographic change and mobility, many communities found themselves experiencing skills gaps and shortages before the economic downturn (the top left hand corner of the diagram) with such problems continuing today, despite higher unemployment rates. However, in other local economies (particularly rural ones) a low supply of skills is matched by a low demand for skills amongst local employers - the low-skills equilibrium. Not all businesses and not all communities progress as fast as others in terms of adopting new technologies and adapting to changing markets. Coyle (2001) identifies a lag time of roughly 50 years between the development of new technologies and the ability of societies and economies to fully take advantage of the potential they offer to improve productivity. In the meantime, employers can also achieve competitive advantage through keeping skills levels, and therefore salaries, at a minimum. Where such employers become concentrated in a particular region, a vicious circle can develop as individuals may see a limited incentive to remain in education if local companies are not seeking higher-level skills (Froy and Giguère, 2010a).

Simply improving the supply of skills locally in such regions will not necessarily lead to economic growth, as unless simultaneous attempts are made to improve demand, this may produce a skills surplus (the bottom right hand corner of the diagram), with trained people leaving the area at a young age to seek better quality employment opportunities elsewhere. In such cases, local policy makers often become 
diverted towards "fire-fighting" to fill labour shortages ${ }^{2}$, as opposed to skills shortages, as people are not available and/or willing to take up less attractive vacancies. These labour shortages are sometimes resolved through recourse to immigration, meaning that policy makers do not have an eye on the longer-term strategic need to improve the quality and knowledge intensity of local jobs and to increase the attractiveness of the labour market to residents and newcomers alike.

In such situations, if there is no supply for a given labour demand it is often a signal that the method of production of the good or service is unsustainable and that the job is in fact not viable in the longerterm. When public employment agencies "fire-fight" to fill such vacancies they are subsidising business activity in a way that leads to poor efficiency in the use of public resources (particularly as such placement often leads to poor job retention and labour market "churning") while also contributing to low productivity. In order to progress towards high-skills equilibrium there is rather a need for local stakeholders to collaborate together on improving both the supply and demand for local jobs.

\section{Defining the variables for the diagnostic tool}

For this project, OECD LEED has identified a statistical diagnostic tool for helping local policy makers to situate their local labour market on the above chart and see where they are relative to other subregions in terms of the balance between skills supply and demand. Data has been sought over time to see the trends of movement of local labour markets between one quadrant and another. In addition, work has been carried out to compare like areas with like, i.e. those with a similar industrial base (i.e. with dominant employment in primary, secondary or tertiary sectors) and degree of urbanisation. The diagnostic tool was initially trialled in British Columbia, Canada. On the basis of this pilot, the tool was refined and implemented in Italy, Canada and the United Kingdom.

\section{Indicators of skills supply and demand}

In order to help diagnose where sub-regions fall on the chart, local indicators have been sought for skills supply and demand. Table 2. lists a number of variables which policy makers may look at in relation to these themes:

2. Labour shortages occur when vacancies remain unfilled either due to a sheer lack of local people to fill them, or because people are not attracted by the pay, wage and job contract provisions or working conditions of the positions. 
Table 2. Examples of variables of skills supply and demand

\begin{tabular}{|c|c|}
\hline Skills supply & Skills demand \\
\hline 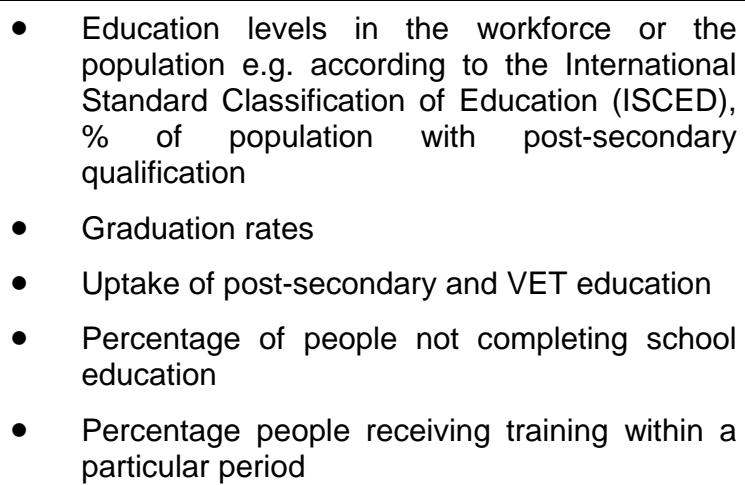 & $\begin{array}{l}\text { - } \text { Occupations within the workforce } \\
\text { - } \quad \text { Wage levels } \\
\text { - } \quad \text { Productivity } \\
\text { - Skills shortages and vacancies (in particular } \\
\text { unmet vacancies) } \\
\text { - Employee jobs in knowledge based } \\
\text { industries/high technology firms } \\
\text { Under-employment/over-qualification } \\
\text { workers }\end{array}$ \\
\hline
\end{tabular}

\section{Implementing the diagnostic tool}

While data for some of the above indicators (e.g. education levels, wage levels) is generally available from National Statistics Offices at a sub-regional or local level in OECD countries, others (such as skills shortages and vacancies, percentage of people recently receiving training) are harder to come by. In practice, in order to collect similar local data for this project across OECD countries it was necessary to use proxies for measuring skills supply and demand, supplemented where possible by country specific data.

In order to approximate the supply for skills at sub-regional level in Canada, Italy and the United Kingdom the study has used the percentage of the population having post secondary education as an indicator. No other variable is consistently available at the sub-regional level at present in the three countries, although richer data is available in specific countries.

In order to approximate the demand for skills the following two variables have been combined into a composite index:

- $\quad$ Percentage of employed residents in medium-high skilled occupations (all countries).

- $\quad$ Gross Valued-Added (GVA) per worker (UK and Italy), income from employment ${ }^{3}$ (Canada);

Medium-high skilled occupations are identified for the purpose of this study as those occupations requiring at least a post-compulsory education and managerial positions which require a relevant period of work experience. For Canada and the United Kingdom classifications of occupation by estimated required skills level are already available (i.e. the HRSDC National Occupational Classification for Canada and the ONS Standard Occupational Classification for the UK) and these have been used for this research. Italy has not yet developed of its own classification, therefore the LEED Programme has worked with ISFOL to develop a classification which has been aligned as far as possible with the classifications used in Canada and the United Kingdom.

3. Income from employment refers to total income received by persons 15 years of age and over, during a calendar year. It includes wages and salaries, commissions from employment, training allowances, tips and gratuities, and net self-employment income (business, professional, commission, farming and fishing income) (Source: Statistics Canada). 
GVA per worker and income from employment represent useful proxies for productivity, complementing information on medium-high skilled occupations by directly reflecting the intensity with which higher levels of skills are used at the workplace, which is normally mirrored by higher output and/or remuneration.

In combining the two demand variables into a composite index a weight equal to 0.75 has been allocated to the first variable and 0.25 to the second. GVA per worker is given a higher weight as it is a workplace-based variable which precisely refers to the area where the person actually works. On the contrary, employment in medium - high skilled occupations is residence-based ${ }^{4}$.

\section{Identifying the correct geographical level in each participating country}

This project is focusing principally on OECD Territorial Level 3 (TL3, which is comparable to NUTS 3 in the European nomenclature), with populations of 800,000 or less ${ }^{5}$, which can broadly be equated to local labour markets or 'travel to work' areas. The focus was hence on the NUTS3/TL3 regions in the United Kingdom, the provinces in Italy (which also equates to TL3) and the Employment Insurance (EI) regions in Canada.

An early challenge identified by the project was the fact that regional classifications do not always follow local labour market boundaries or 'travel to work' areas. A particular region may have a mismatch between skills supply and demand because skilled people are commuting out and being employed elsewhere. In recognition of this in Canada the Secretariat has worked with HRSDC to populate the 58 EI regions with census data for the first time. EI regions are designed to provide comparable EI benefits to Canadians residing in areas with homogeneous labour markets and similar unemployment levels. Except for the Northwest Territories, Yukon and Nunavut ${ }^{6}$, EI regions in Canada have a population size which is comparable to those of the NUTS3/ TL3 areas. They therefore incorporate travel to work areas and are particularly useful for this analysis.

It is important to recognise that disparities also exist in skills supply and demand beneath this level of analysis - while cities can often broadly be classified as areas of high-skills equilibrium (showing concentrations of both skilled people and high skills demand) they often host pockets of low-skilled people, which can have an important impact on employment rates ${ }^{7}$.

4. Note that these weights are indicative and others could be applied. For the sake of consistency the same weighting was allocated in all countries irrespective of whether GVA data or income data was used, despite the fact that income from employment is residence-based.

5. The OECD definition of a Territorial Level follows closely that of the Eurostat NUTS classification for European countries. In both cases, while population thresholds are identified for each level of the classification, there are some discrepancies which reflect the national administrative classifications applied in the different countries. For example in Italy, Rome and Milan are both classified as TL3/NUTS3 areas despite having populations greater than 3 million.

6. These EI regions were excluded from the analysis as they were not considered to represent local travel to work areas.

7. The European Urban Audit in $\mathbf{2 0 0 5}$ for example found that city residents were more likely to have tertiary education, but that three out of four cities studied had a lower employment rate than their country as a whole. 


\section{Computing the supply and demand indices}

For building indices it is necessary to bring the variables in a common unit (scale) of measurement using a standardisation method. It was decided to use the inter-decile range method which is not influenced to a great extent by outliers. See the formula below:

$$
\begin{array}{ll}
\left(\mathrm{X}_{\mathrm{i}}-\mathrm{X}_{\text {med }}\right) /\left(\mathrm{X}_{9 \text { th }}-\mathrm{X}_{1 \mathrm{st}}\right) \\
\text { Where: } & \mathrm{X}_{\mathrm{i}}=\text { value for TL3 } \mathrm{i} \\
& \mathrm{X}_{\text {med }}=\text { median } \\
& \mathrm{X}_{9 \mathrm{th}}=9^{\text {th }} \text { decile } \\
& \mathrm{X}_{1 \mathrm{st}}=1^{\text {st }} \text { decile }
\end{array}
$$

\section{Defining the years of analysis}

The project has aimed to collect the same data for several years in order to track trends. For the three countries involved in the project the year 2001 has been chosen as a 'starting point' in the analysis and results for this year have been compared with the most recent year available.

\section{Data collection at local level}

In most countries, the data sought to substantiate the diagnostic model is available through the Census and the Labour Force Survey (LFS); other surveys provide more country-specific information which can be used to gather additional data. It is generally necessary to combine more than one source in order to acquire enough data for the model. On the supply of skills side, education levels are generally measured using the ISCED classification (International Standard Classification of Education). Information about vocational training at sub-regional level is not easily available. On the demand-side information on occupational structure of the working population can be collected using the LFS, which provides accurate and timely data in most countries on employment, unemployment and labour market characteristics. Data on productivity and incomes is sometimes harder to find. Overall, data at local level (TL3) is not often published by national statistics offices, in some cases due to confidentiality clauses, which makes data gathering at this level a relatively complicated process.

\section{Building benchmarking groups}

It is important that policy makers are able to compare regions with similar overall characteristics. The data analysis in each country therefore started with an exploration of the industrial base and degree of urbanisation of the chosen sub-regional areas. In particular the basic elements which can assist in comparisons between similar regions are:

- Employment by industry. This variable identifies the percentage of the population in the labour force working in three main industrial categories: primary, secondary and services. Ideally data at a more disaggregated level would be utilised but this is not uniformly available.

- Degree of urbanisation. The OECD‘s Directorate for Public Governance and Territorial Development has created a regional typology classification based on criteria of population density and size of the urban centres located within a region. The three regional typologies identified are: predominantly urban, intermediate and predominantly rural. 
- Differentiating cities. As large urban centres have particularly complex skills ecosystems, they have been separated from other urban areas in the analysis in the three countries. Metropolitan areas have been identified following the classification of the OECD Directorate for Public Governance and Territorial Development.

Drawing on the above information, sub-regions have been classified into three profiles; predominant primary, secondary or services sectors. Within these categories, sub- regions have been categorised according to their level of urbanisation.

After identifying the benchmarking groups it is possible to compute the supply and demand indices in two separate ways - either by comparing sub-regions within their benchmarking groups (alongside subregions with similar industrial characteristics and degree of urbanisation) or by comparing sub-regions across a country. In the first case the formula shown above applies only to the sub-regions belonging to the benchmarking group (e.g. sub-regions having a dominant primary sector); in the second case it applies to all sub-regions in the country.

\section{Data summary}

The data which has been collected for the identification of benchmarking groups and implementation of the diagnostic tool and the correspondent sources are summarised in Table 3 below.

Table 3. Data and Sources

\begin{tabular}{|c|c|c|c|c|c|c|c|}
\hline & Year & $\begin{array}{l}\text { Population } \\
\text { structure }\end{array}$ & $\begin{array}{l}\text { Degree of } \\
\text { urbanisation }\end{array}$ & $\begin{array}{l}\text { Employment } \\
\text { by industry }\end{array}$ & Education & $\begin{array}{l}\text { Employment in } \\
\text { medium high } \\
\text { skilled } \\
\text { occupations }\end{array}$ & $\begin{array}{l}\text { GVA per } \\
\text { worker }\end{array}$ \\
\hline \multirow[t]{2}{*}{ Italy } & 2001 & \multirow{2}{*}{$\begin{array}{l}\text { ISTAT from } \\
\text { population } \\
\text { registers }\end{array}$} & \multirow{2}{*}{$\begin{array}{l}\text { OECD } \\
\text { Regional } \\
\text { typology }\end{array}$} & \multirow{2}{*}{\multicolumn{3}{|c|}{ Labour force survey }} & \multirow{2}{*}{$\begin{array}{l}\text { ISTAT from } \\
\text { National Account }\end{array}$} \\
\hline & 2009 & & & & & & \\
\hline \multirow{2}{*}{ Canada } & 2001 & \multirow{2}{*}{\multicolumn{6}{|c|}{ All variables are from the Census and grouped into EI regions by HRSDC }} \\
\hline & 2006 & & & & & & \\
\hline \multirow{2}{*}{$\begin{array}{l}\text { United } \\
\text { Kingdom }\end{array}$} & 2001 & \multirow{2}{*}{$\begin{array}{l}\text { ONS mid - } \\
\text { year } \\
\text { population } \\
\text { estimates }\end{array}$} & \multirow{2}{*}{$\begin{array}{l}\text { OECD } \\
\text { Regional } \\
\text { typology }\end{array}$} & $\begin{array}{l}\text { Local area } \\
\text { labour force } \\
\text { survey }\end{array}$ & $\begin{array}{l}\text { Local area } \\
\text { labour force } \\
\text { survey }\end{array}$ & $\begin{array}{l}\text { Local area labour } \\
\text { force survey }\end{array}$ & \multirow{2}{*}{$\begin{array}{l}\text { GVA divided by } \\
\text { ABI employment. } \\
\text { Workplace based }\end{array}$} \\
\hline & 2009 & & & $\begin{array}{l}\text { Annual } \\
\text { population } \\
\text { survey }\end{array}$ & $\begin{array}{l}\text { Annual } \\
\text { population } \\
\text { survey }\end{array}$ & $\begin{array}{c}\text { Annual } \\
\text { population survey }\end{array}$ & \\
\hline
\end{tabular}

The data used for the implementation of the diagnostic tool is broadly comparable across countries. In particular, data for Italy and the United Kingdom is collected from the same sources (LFS and National Accounts). Data from Canada is from the population census which was the only available source for the chosen indicators at the appropriate geographical level. Because census data is only collected every 5 years, it was not possible to include data for later than 2006. Data on GVA at the local level was also not available, meaning that income per worker was used as a proxy for labour productivity in Canada. These differences should be born in mind when interpreting the data findings. 


\section{Findings from the diagnostic tool}

A full set of graphs representing the findings and trends for each country is available on the Skills.OECD website. Results for all sub-regions in each country are available, organised by region and by benchmarking group for two different years (2001 and 2009 in the United Kingdom and Italy and 2001 and 2006 in Canada). In the following section we highlight selected graphs to illustrate the different ways in which the findings can be analysed and presented, and to identify the situation of the seven case study regions which were used as a basis for the policy research for this project.

In all the graphs, sub-regions are plotted according to their levels of supply of skills (x axis) and demand for skills (y axis), computed using the inter-decile method identified above. The four quadrants correspond to the four regional types presented in Figure 1: high-skilled equilibrium (positive $\mathrm{x}$ and positive $\mathrm{y}$ ), low-skilled equilibrium (negative $\mathrm{x}$ and negative $\mathrm{y}$ ), skills surplus (positive $\mathrm{x}$ and negative $\mathrm{y}$ ) and skills shortages (negative $\mathrm{x}$ and positive $\mathrm{y}$ ). Sub-regions which are outliers (having values greater than 1 or lower than -1) are placed in a box and their value noted.

For ease of presentation, the graphs represent metropolitan and urban; and rural and intermediate areas separately.

\section{Italy}

The following two graphs highlight the overall position of the provinces in (Figure 2) urban and metropolitan areas and (Figure 3) intermediate and rural areas in Italy in 2009. The X axis (supply side) represents the percentage of the population having post secondary education. The $\mathrm{Y}$ axis (demand side) identifies the demand index which is realised by combining GVA per worker (weight $=0.75$ ) and percentage of employed in medium-high skilled occupations (weight=0.25). 
Figure 2. Urban and metropolitan regions in Italy in 2009

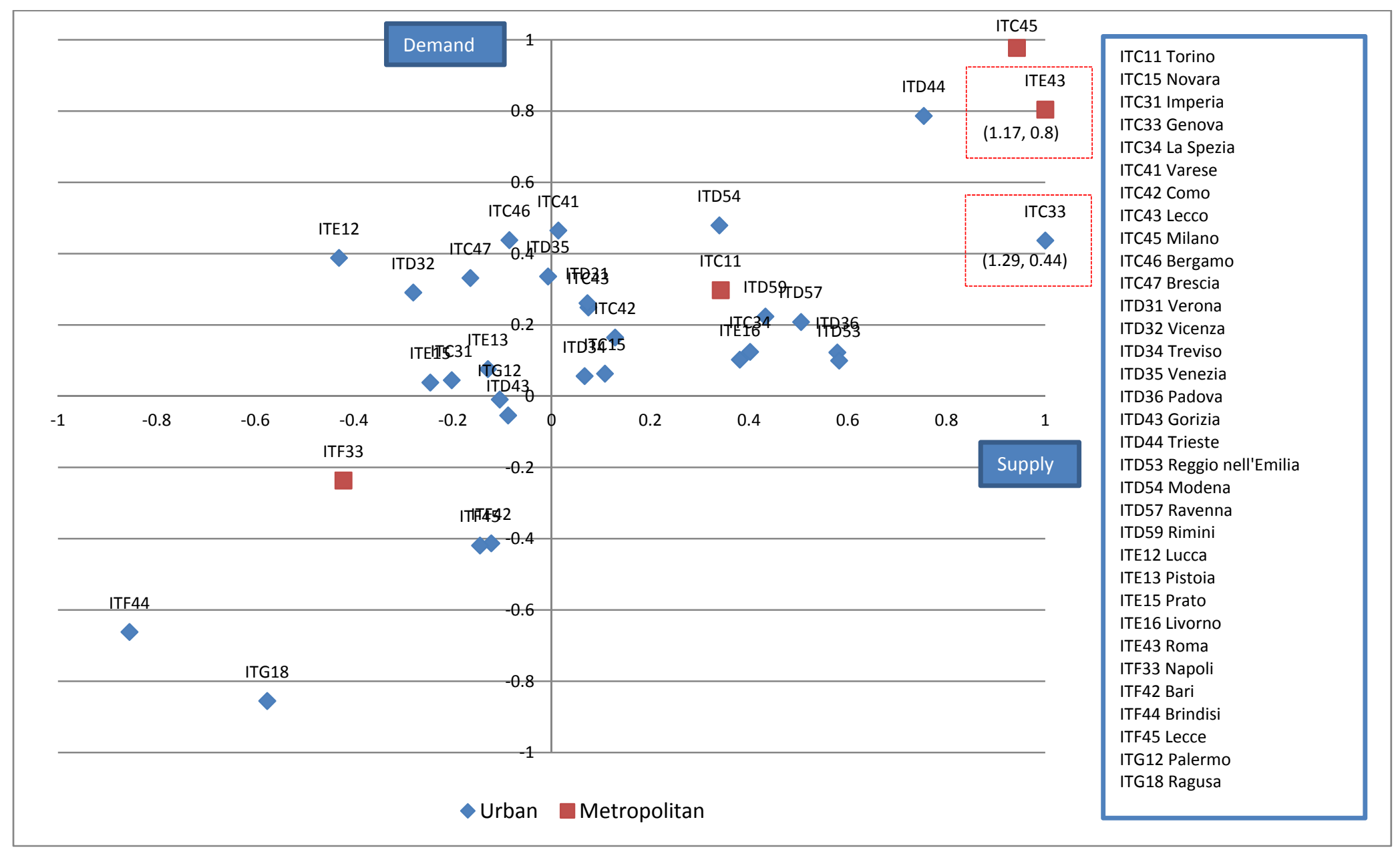


Figure 3. Rural and Intermediate urban regions in Italy in 2009

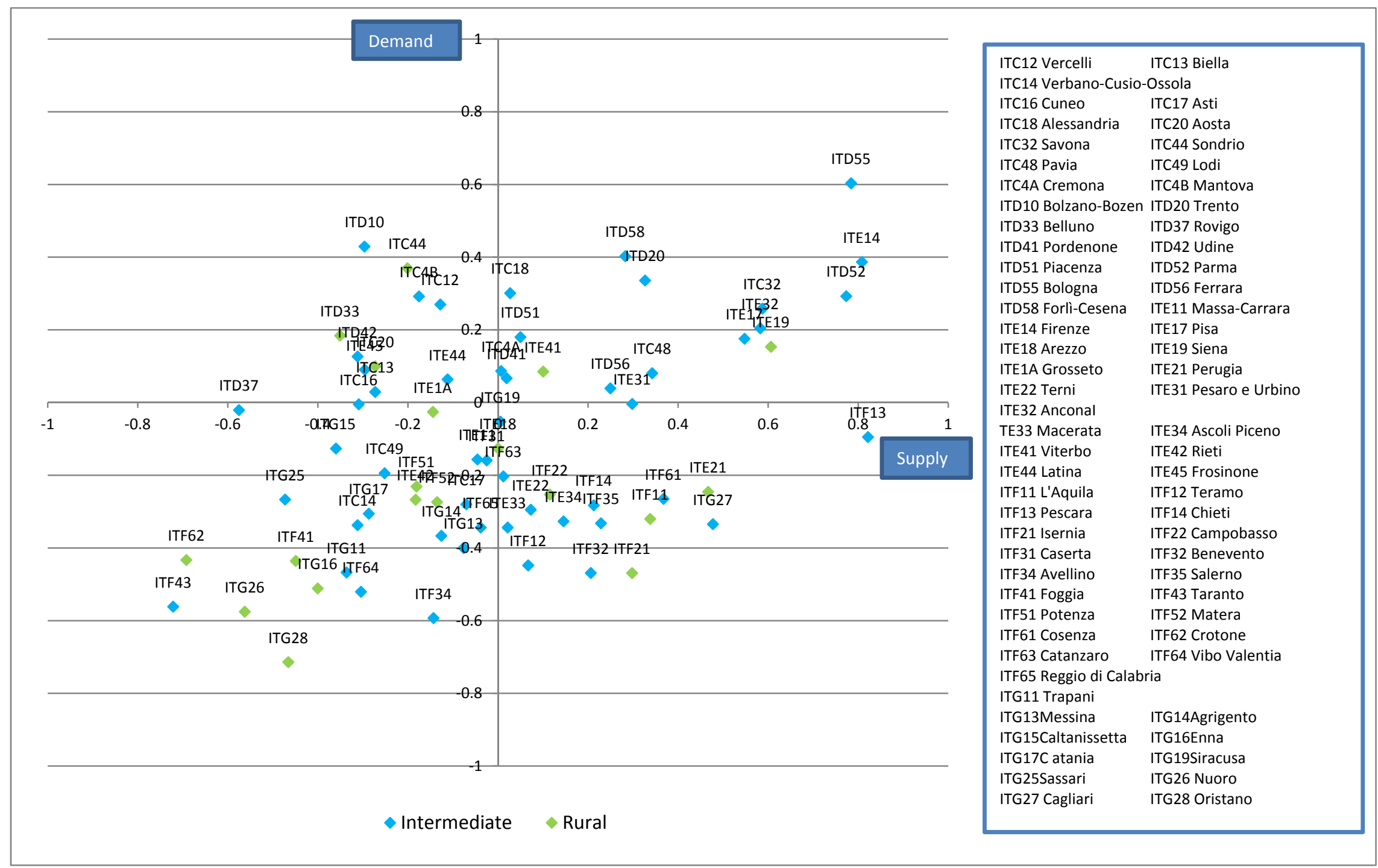


It is evident that metropolitan, urban, rural and intermediate areas are well distributed across the graphs, however it is notable that those provinces in the top two quadrants are more likely to be from the north of Italy than the south.

It is also possible to track how the relative performance of individual provinces has changed over time. The following two graphs show the distribution of Italian provinces in Veneto and Campania for 2001 and 2009 - these provinces were the focus of the field work for this study, with Treviso and Riviera del Brenta in Veneto being two case study areas. The Riviera del Brenta district is located across the provinces of Venezia (Venice) and Padova.

Figure 4. Skills supply and demand in Campania and Veneto, 2001

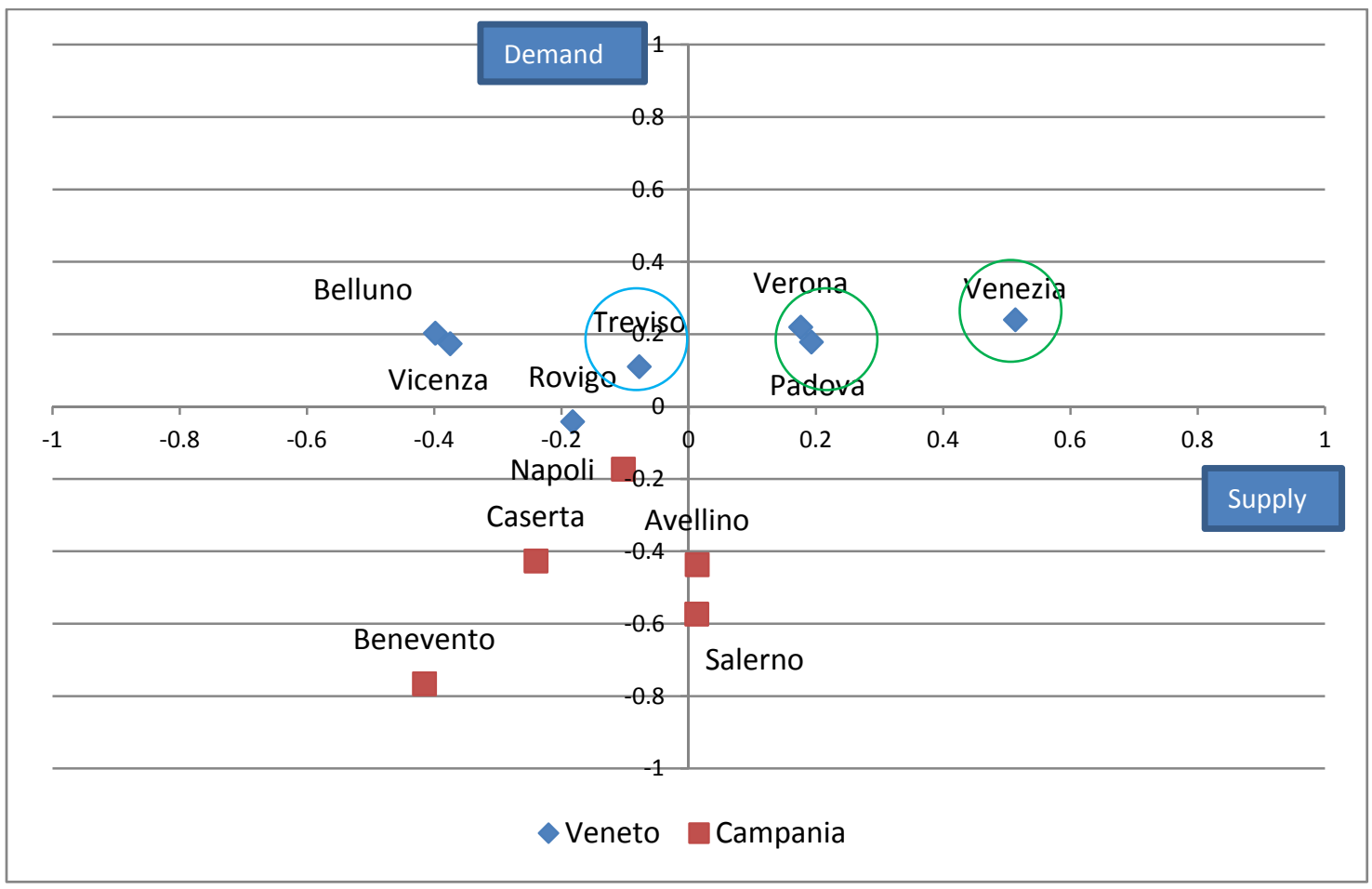

Sub-regions in both Veneto and Campania have changed their position during the period, especially in relation to the supply of skills (X axis). In 2009 Venezia and Napoli are performing less well than in 2001 in terms of their level of skills supply against the national median. In contrast Treviso, Padova and Benevento have improved their relative position in terms of skills supply over time. 
Figure 5. Skills supply and demand in Campania and Veneto, 2009

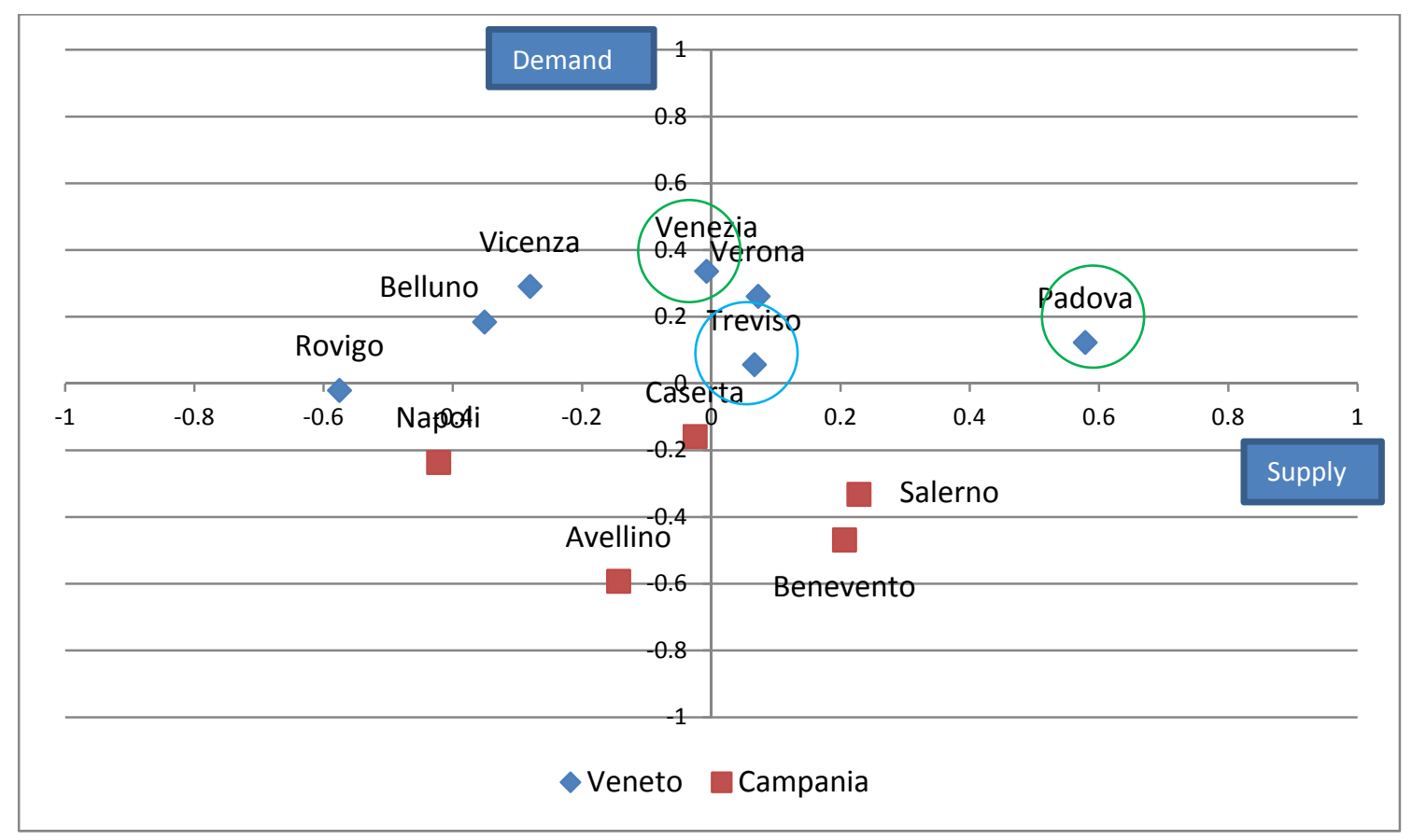

The above graphs record relative changes for provinces in the supply and demand for skills against the national median. In order to understand the absolute changes in skills supply and demand, Figure 6 shows the percentage changes over time for the indicators used in the diagnostic tool. It corroborates the assumptions made in relation to the differences across sub-regions. Overall the share of people having post-secondary education has increased to a greater extent than both medium- high skilled occupations and GVA per worker, however in the case study region of Venezia skills levels have not increased to the same degree. It is interesting to note that in the three case study regions (Venezia, Padova and Treviso) mediumhigh skilled occupations and GVA have increased at a different pace. For example, in Treviso GVA has not changed significantly but the percentage of medium-skilled occupations have increased over time, whereas Venezia and Padova have experienced the opposite trend. 
Figure 6. Percentage change over time (2001-2009) for the variables used in the diagnostic tool

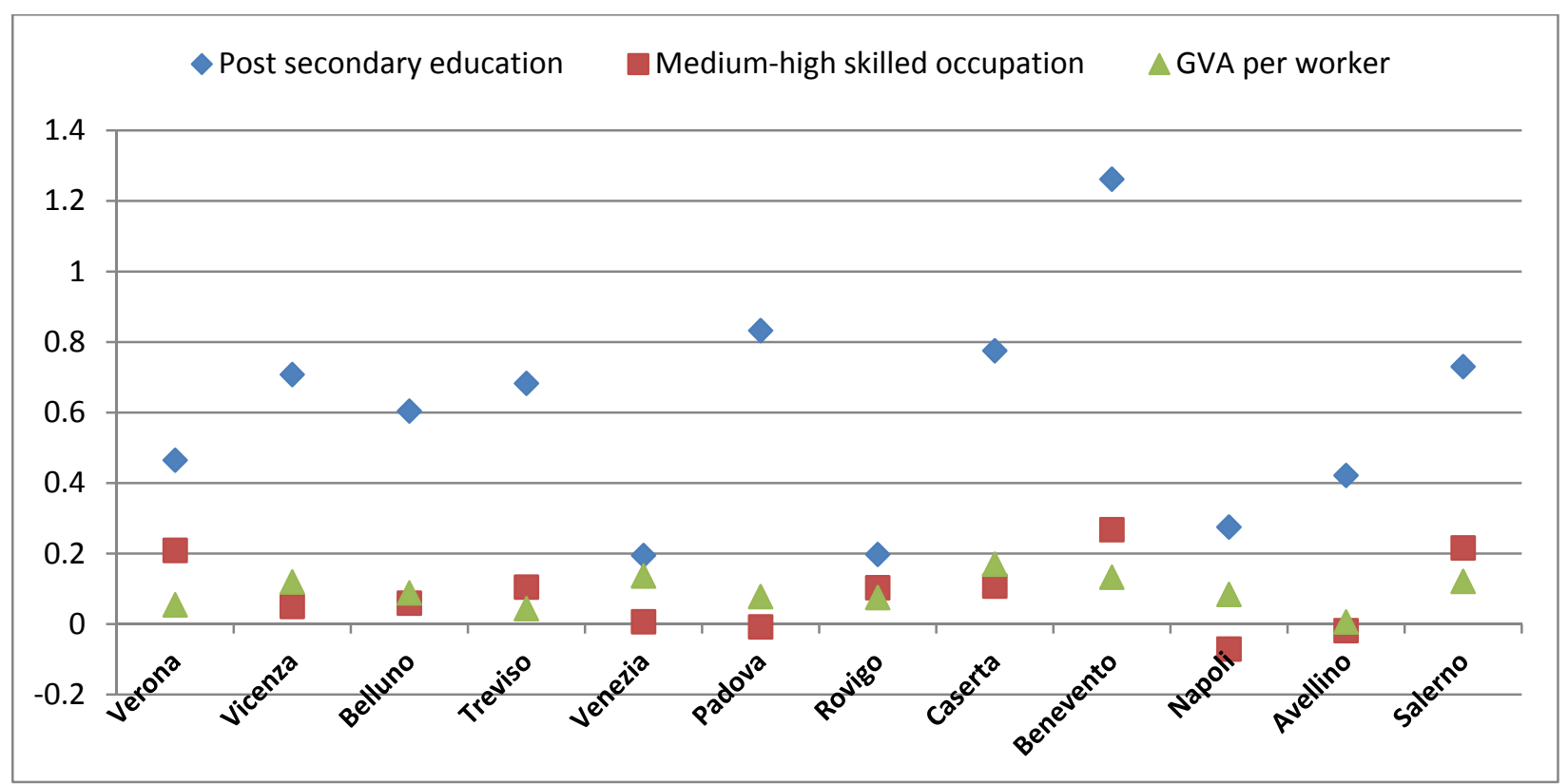

\section{Canada}

The following two graphs highlight the overall position of the EI regions in (Figure 7) urban and metropolitan areas and (Figure 8) rural areas in Canada in 2006. The $\mathrm{X}$ axis (supply side) represents the percentage of the population having post secondary education. The $\mathrm{Y}$ axis (demand side) identifies the demand index which is realised by combining income from employment (weight $=0.75$ ) and percentage of employed in medium-high skilled occupations (weight $=0.25$ ). 
Figure 7. Urban and metropolitan regions in Canada in 2006

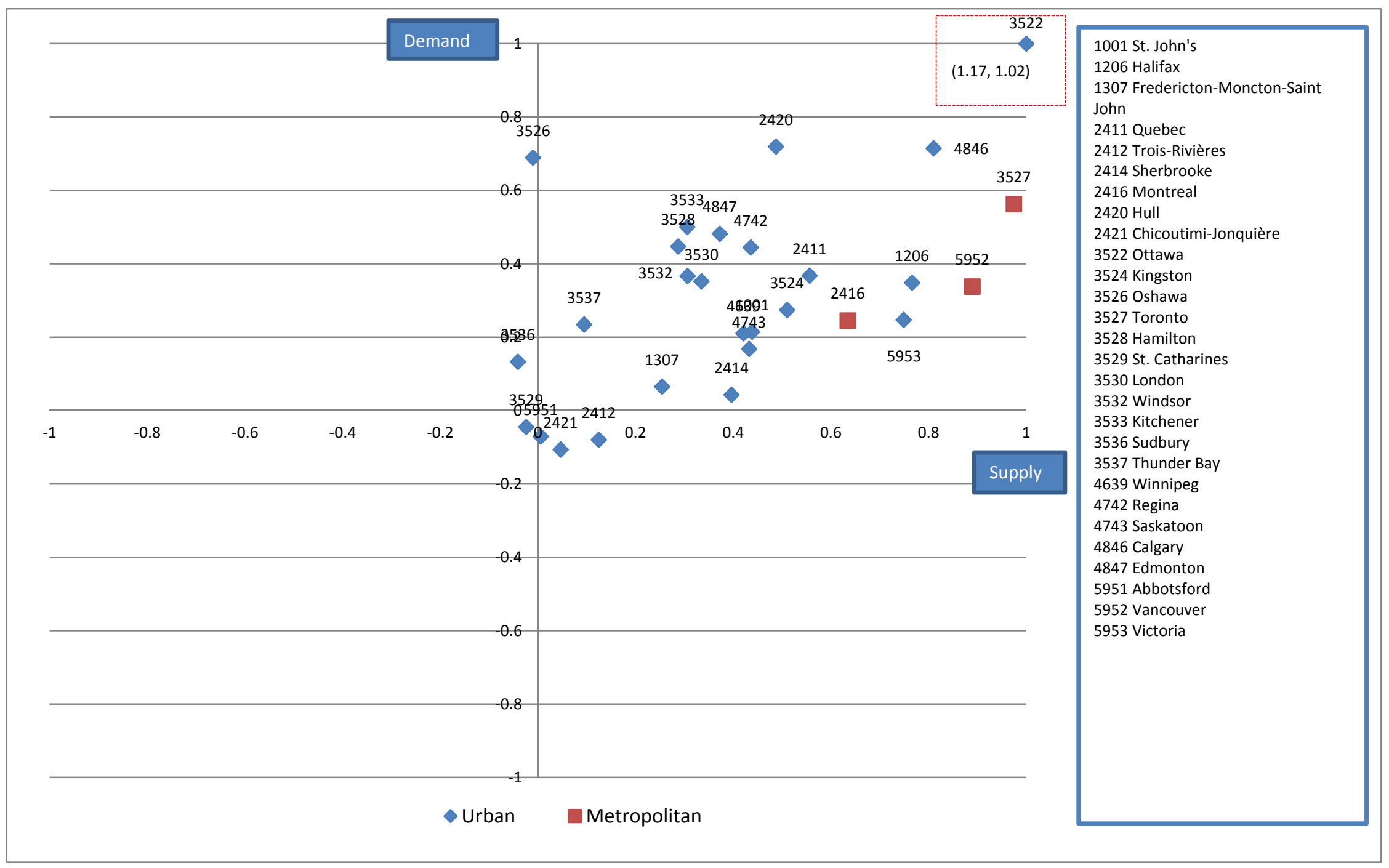


Figure 8. Rural regions in Canada in 2006

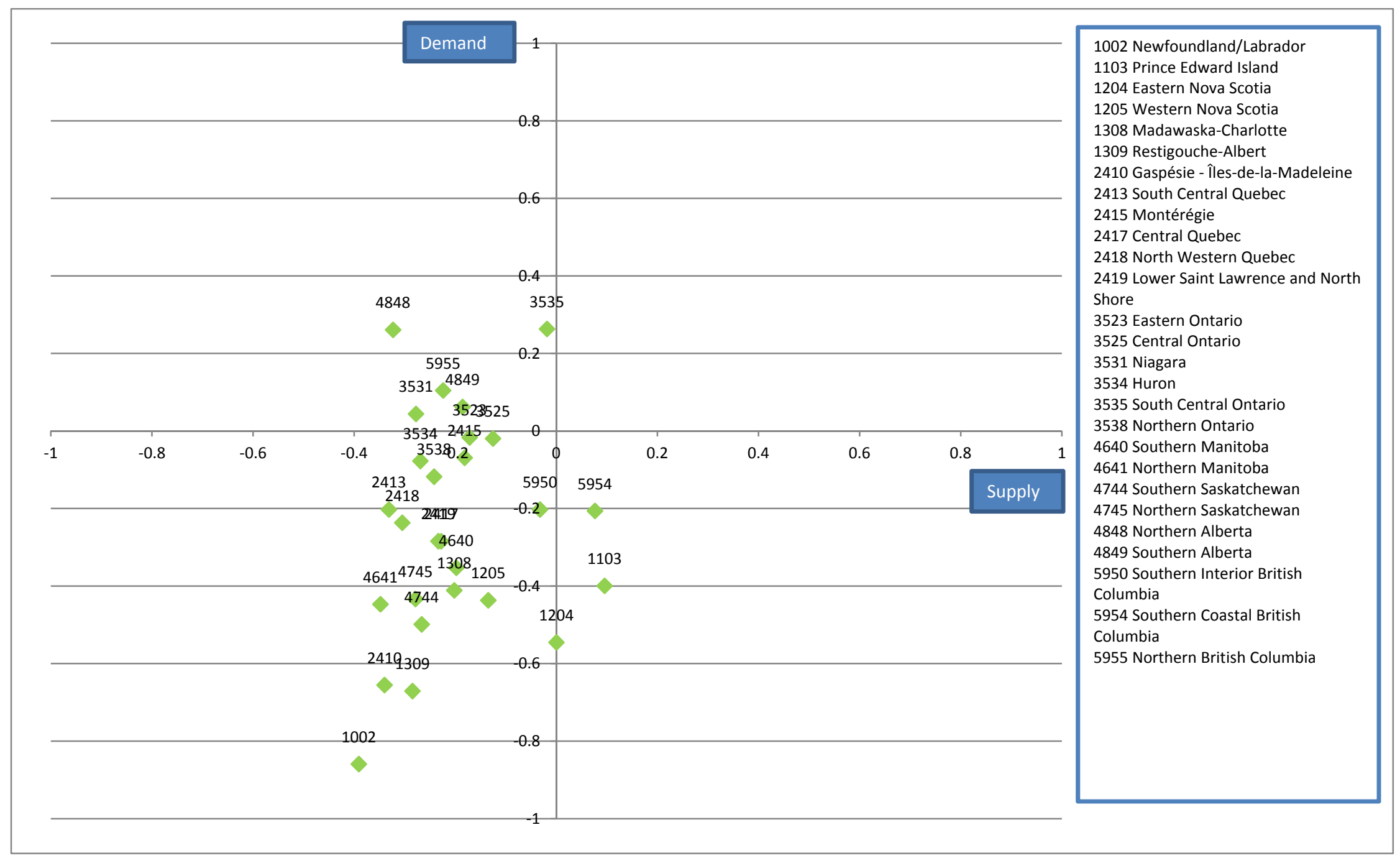


It is clear that rural regions in Canada are more likely to be in the low-skills equilibrium quadrant, while urban regions are more likely to be in the high skills equilibrium quadrant.

In Canada, the province of Ontario was chosen as a case study region. The following graph shows the distribution of EI regions within the province of Ontario in Canada in 2006.

Figure 9. El regions in Ontario, Canada 2006

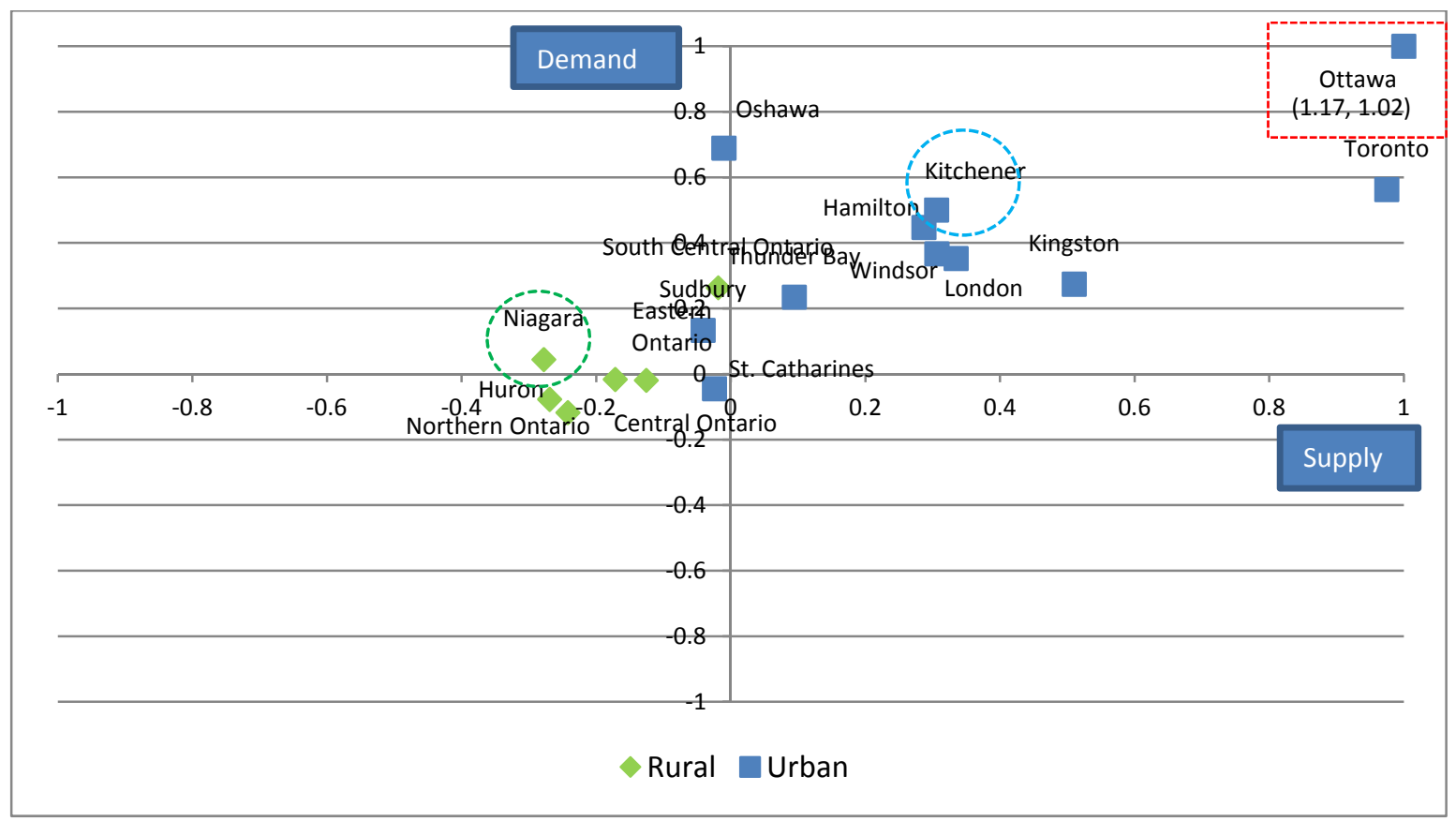

In the graph above it is possible to identify Niagara and Kitchener which are two case study areas in the context of this project. Niagara is on the borderline between low-skills equilibrium and skills shortages when compared with other EI regions in Canada. Kitchener is in the high-skilled equilibrium quadrant and is characterised by relatively good levels of both skills supply and demand.

Indeed, when Kitchener is compared with other EI regions across Canada with a concentration of employment in the secondary sector, it is clear that the region is performing particularly well in comparison with other region of its type. The following graph compares EI regions across Canada with a high percentage of employment in the secondary sectors in 2006. The predominant sector has been determined by comparing employment by sector in each EI region with the figure for Canada and the indicators have been computed within the benchmarking group. 
Figure 10. El regions characterised by high \% employment in secondary sector, Canada, 2006

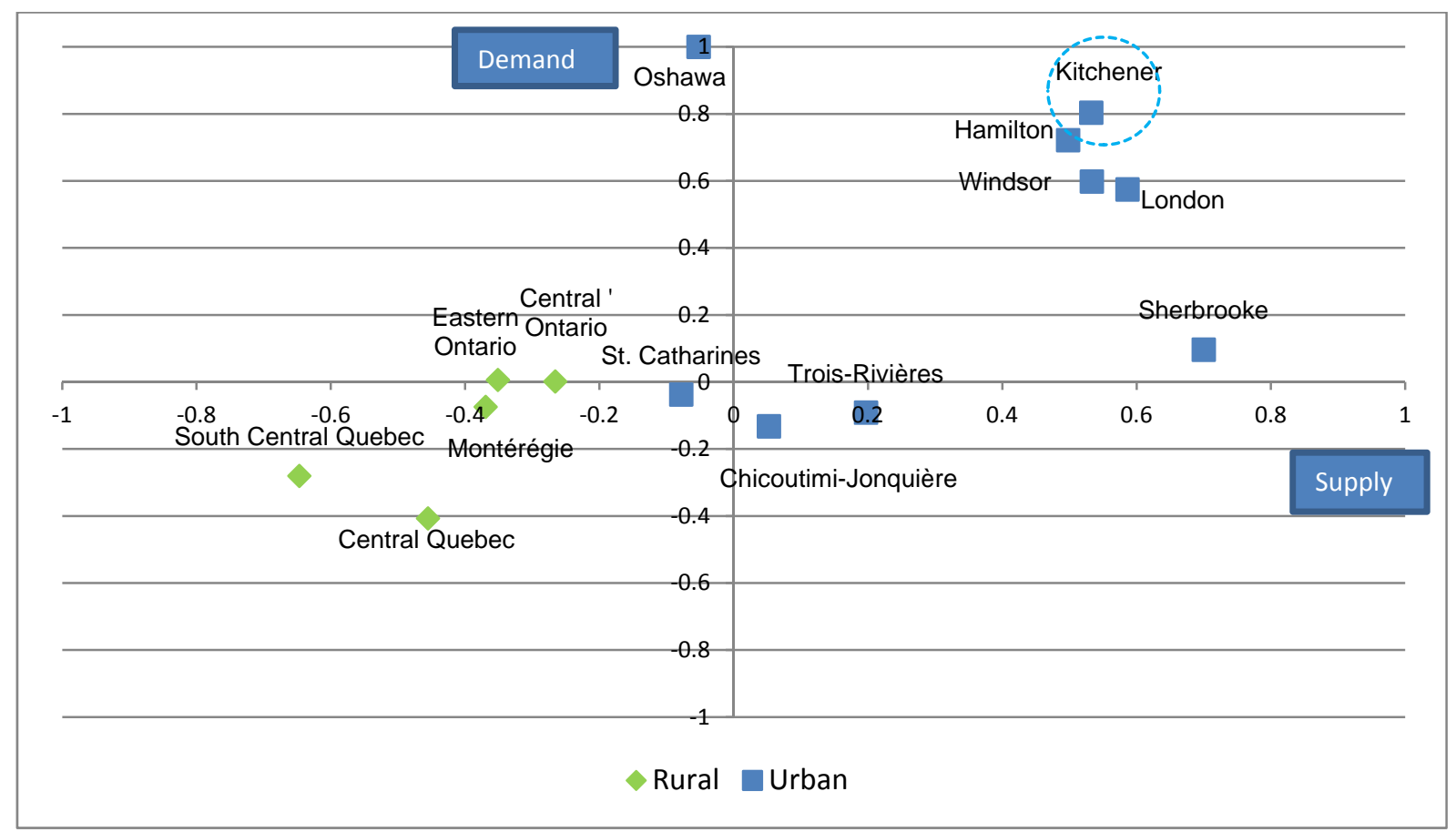

\section{United Kingdom}

The following two graphs highlight the overall position of the TL3 areas in (Figure 11) urban and metropolitan areas and (Figure 12.) rural areas in the United Kingdom in 2009. The X axis (supply side) represents the percentage of the population having post secondary education (NVQ3 and over). The Y axis (demand side) identifies the demand index which is realised by combining GVA per worker (weight $=0.75$ ) and percentage of employed in medium-high skilled occupations (weight $=0.25$ ). The legend of the two graphs is presented in Tables 4 . and 5. 
Figure 11. Urban and metropolitan regions in the United Kingdom in 2009

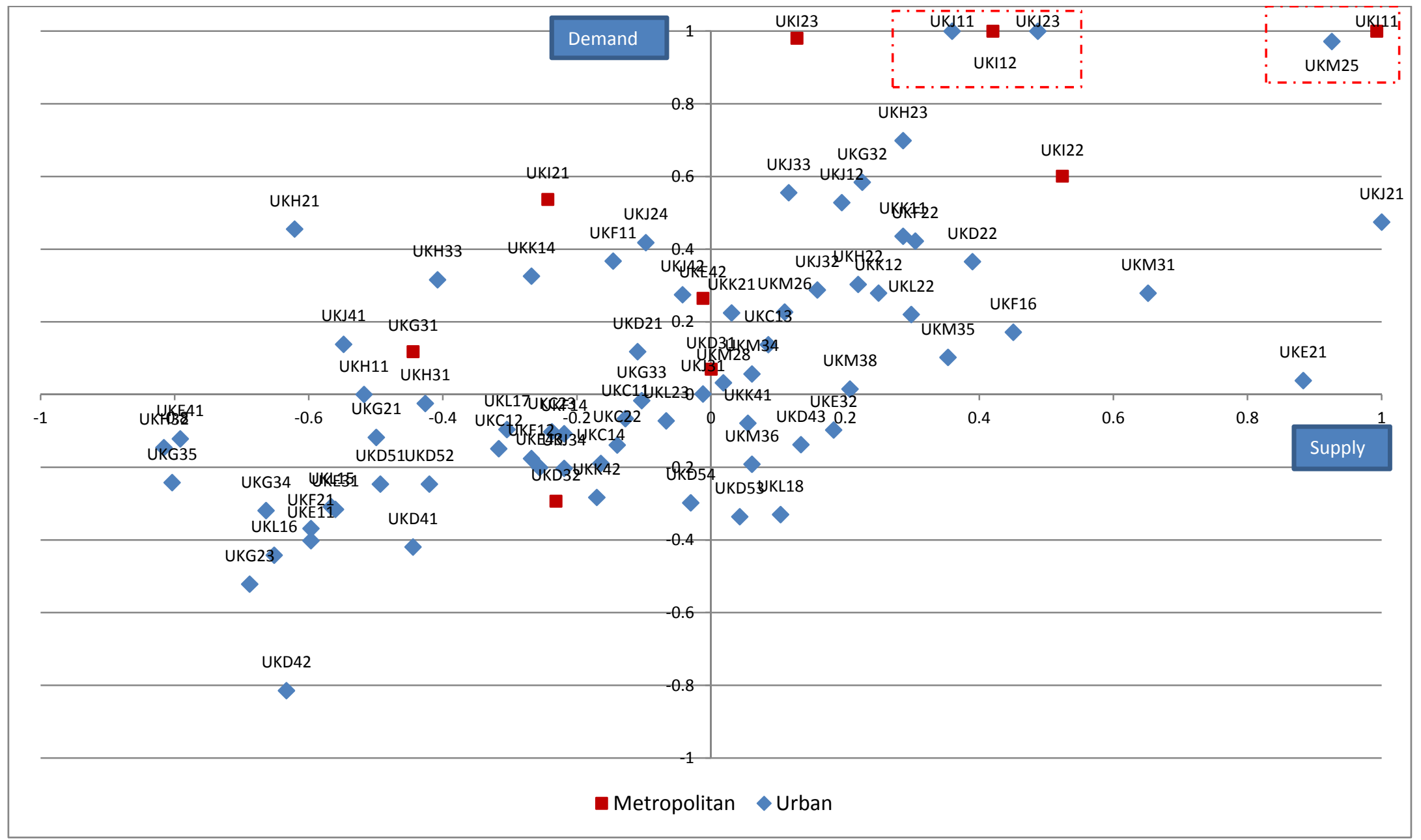

Note: Real values for the areas circled in red are: UKI11 $(0.99,2.66)$, UKI12 $(0.42,1.74)$, UKJ11 $(0.36,1.23)$, UKJ21 $(1.2,0.47)$, UKJ23 (0.48, 1.07$)$ 
Figure 12. Rural and intermediate urban regions in the United Kingdom in 2009

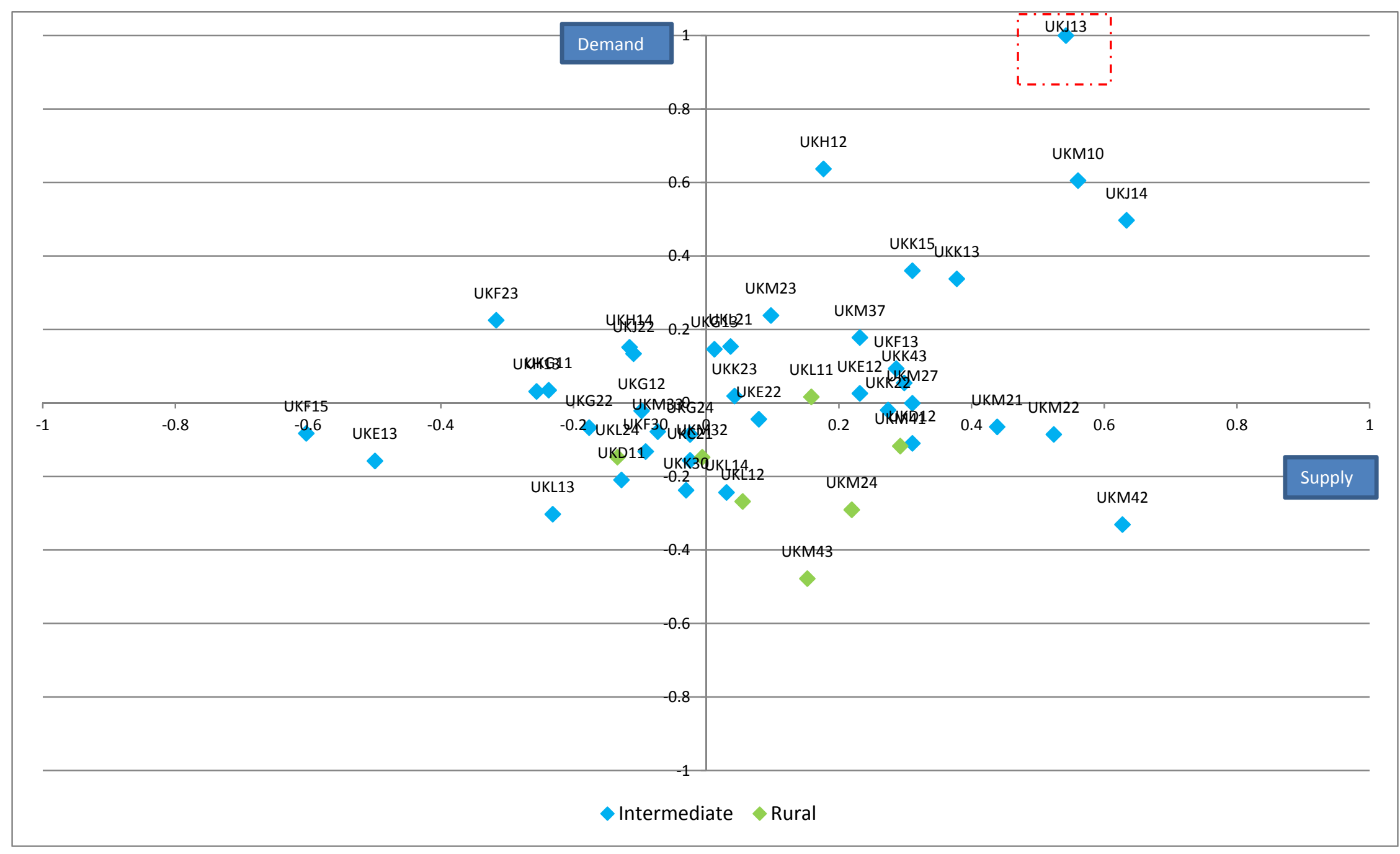

Note: Real values for the area circled in red is: UKJ13 $(0.54,1.06)$ 
Table 4. Urban and metropolitan regions in the United Kingdom

\begin{tabular}{|c|c|c|c|}
\hline UKC11 & Hartlepool and Stockton-on-Tees & UKH23 & Hertfordshire \\
\hline UKC12 & South Teesside & UKH31 & Southend-on-Sea \\
\hline UKC13 & Darlington & UKH32 & Thurrock \\
\hline UKC14 & Durham CC & UKH33 & Essex CC \\
\hline UKC22 & Tyneside & UKI11 & Inner London - West \\
\hline UKC23 & Sunderland & UKI12 & Inner London - East \\
\hline UKD21 & Halton and Warrington & UKI21 & Outer London - East and North East \\
\hline UKD22 & Cheshire CC & UKI22 & Outer London - South \\
\hline UKD31 & Greater Manchester South & UKI23 & Outer London - West and North West \\
\hline UKD32 & Greater Manchester North & UKJ11 & Berkshire \\
\hline UKD41 & Blackburn with Darwen & UKJ12 & Milton Keynes \\
\hline UKD42 & Blackpool & UKJ21 & Brighton and Hove \\
\hline UKD43 & Lancashire CC & UKJ23 & Surrey \\
\hline UKD51 & East Merseyside & UKJ24 & West Sussex \\
\hline UKD52 & Liverpool & UKJ31 & Portsmouth \\
\hline UKD53 & Sefton & UKJ32 & Southampton \\
\hline UKD54 & Wirral & UKJ33 & Hampshire CC \\
\hline UKE11 & Kingston upon Hull, City of & UKJ34 & Isle of Wight \\
\hline UKE21 & York & UKJ41 & Medway \\
\hline UKE31 & Barnsley, Doncaster and Rotherham & UKJ42 & Kent CC \\
\hline UKE32 & Sheffield & UKK11 & Bristol, City of \\
\hline UKE41 & Bradford & UKK12 & $\begin{array}{l}\text { North and North East Somerset, South } \\
\text { Gloucestershire }\end{array}$ \\
\hline UKE42 & Leeds & UKK14 & Swindon \\
\hline UKE43 & Calderdale, Kirklees and Wakefield & UKK21 & Bournemouth and Poole \\
\hline UKF11 & Derby & UKK41 & Plymouth \\
\hline UKF12 & East Derbyshire & UKK42 & Torbay \\
\hline UKF14 & Nottingham & UKL15 & Central Valleys \\
\hline UKF16 & South Nottinghamshire & UKL16 & Gwent Valleys \\
\hline UKF21 & Leicester & UKL17 & Bridgend and Neath Port Talbot \\
\hline UKF22 & Leicestershire CC and Rutland & UKL18 & Swansea \\
\hline UKG21 & Telford and Wrekin & UKL22 & Cardiff and Vale of Glamaorgan \\
\hline UKG23 & Stoke-on-Trent & UKL23 & Flintshire and Wrexham \\
\hline UKG31 & Birmingham & UKM25 & Edinburgh, City of \\
\hline UKG32 & Solihull & UKM26 & Falkirk \\
\hline UKG33 & Coventry & UKM28 & West Lothian \\
\hline UKG34 & Dudley and Sandwell & UKM31 & $\begin{array}{l}\text { East and West Dunbartonshire, } \\
\text { Helensburgh and Lomond }\end{array}$ \\
\hline UKG35 & Walsall and Wolverhampton & UKM34 & Glasgow City \\
\hline UKH11 & Peterborough & UKM35 & $\begin{array}{l}\text { Inverclyde, East Renfrewshire and } \\
\text { Renfrewshire }\end{array}$ \\
\hline UKH21 & Luton & UKM36 & North Lanarkshire \\
\hline UKH22 & Bedfordshire CC & UKM38 & South Lanarkshire \\
\hline
\end{tabular}


Table 5. Rural and intermediate urban regions in the United Kingdom

\begin{tabular}{|c|c|c|c|}
\hline UKC21 & Northumberland & UKK22 & Dorset CC \\
\hline UKD11 & West Cumbria & UKK23 & Somerset \\
\hline UKD12 & East Cumbria & UKK30 & Cornwall and Isles of Scilly \\
\hline UKE12 & East Riding of Yorkshire & UKK43 & Devon CC \\
\hline UKE13 & North and North East Lincolnshire & UKL11 & Isle of Anglesey \\
\hline UKE22 & North Yorkshire CC & UKL12 & Gwynedd \\
\hline UKF13 & South and West Derbyshire & UKL13 & Conwy and Denbeighshire \\
\hline UKF15 & North Nottinghamshire & UKL14 & South West Wales \\
\hline UKF23 & Northamptonshire & UKL21 & Monmouthshire and Newport \\
\hline UKF30 & Lincolnshire & UKL24 & Powys \\
\hline UKG11 & Herefordshire, County of & UKM10 & $\begin{array}{l}\text { Aberdeen City, Aberdeenshire and North East } \\
\text { Moray }\end{array}$ \\
\hline UKG12 & Worcestershire & UKM21 & Angus and Dundee City \\
\hline UKG13 & Warwickshire & UKM22 & Clackmannanshire and Fife \\
\hline UKG22 & Shropshire CC & UKM23 & East Lothian and Midlothian \\
\hline UKG24 & Staffordshire CC & UKM24 & Scottish Borders, The \\
\hline UKH12 & Cambridgeshire CC & UKM27 & Perth and Kinross and Stirling \\
\hline UKH13 & Norfolk & UKM32 & Dumfries and Galloway \\
\hline UKH14 & Suffolk & UKM33 & East Ayrshire and North Ayrshire Mainland \\
\hline UKJ13 & Buckinghamshire CC & UKM37 & South Ayrshire \\
\hline UKJ14 & Oxfordshire & UKM41 & Caithness and Sutherland and Ross and Cromarty \\
\hline UKJ22 & East Sussex CC & UKM42 & $\begin{array}{l}\text { Inverness and Nairn and Moray, Badenoch and } \\
\text { Strathspey }\end{array}$ \\
\hline UKK13 & Gloucestershire & UKM43 & $\begin{array}{l}\text { Lochaber, Skye and Lochalsh and Argyll and the } \\
\text { Islands }\end{array}$ \\
\hline UKK15 & Wiltshire CC & & \\
\hline
\end{tabular}


In the United Kingdom metropolitan, urban, rural and intermediate regions are, as for Italy, welldistributed across the different quadrants. The North West of England and Wales were chosen as focus regions. The following two graphs show the distribution of TL3 areas in the North West of England for 2009 and TL3 areas with a dominant services sector. Blackpool and Manchester are case study areas for the project. The $\mathrm{X}$ axis (supply side) represents the percentage of the population having post secondary education (NVQ 3 and 4). The Y axis (demand side) identifies the demand index which is realised by combining GVA per worker (weight=0.75) and percentage of employed in medium-high skilled occupations (weight=0.25).

Figure 13. TL3 areas in the North West, 2009

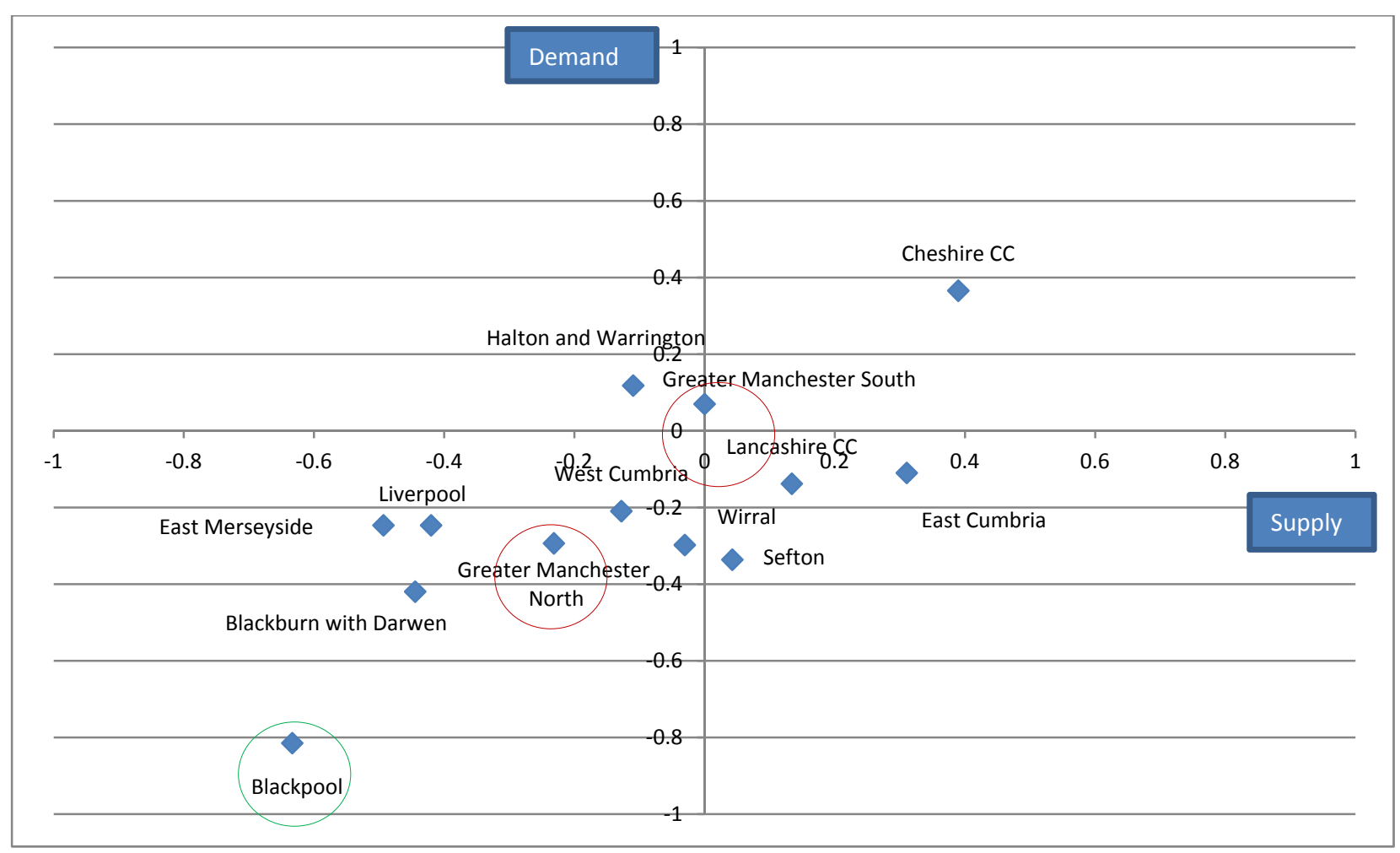

It is interesting to note that the Greater Manchester' sub-region is split into two TL3 areas - Greater Manchester South and Greater Manchester North, which are classified as metropolitan areas. These two sub-regions falls in two different quadrants, a result which was not found surprising by local stakeholders who recognise a strong divide in the economic fortunes of the north and south of their city. Blackpool falls in the low-skilled equilibrium quadrant, both when compared with the national median and also when compared to other sub-regions in the United Kingdom with a strong services sector (see Figure 14. below). 
Figure 14. TL3 areas in the United Kingdom with a dominant services sector, 2009

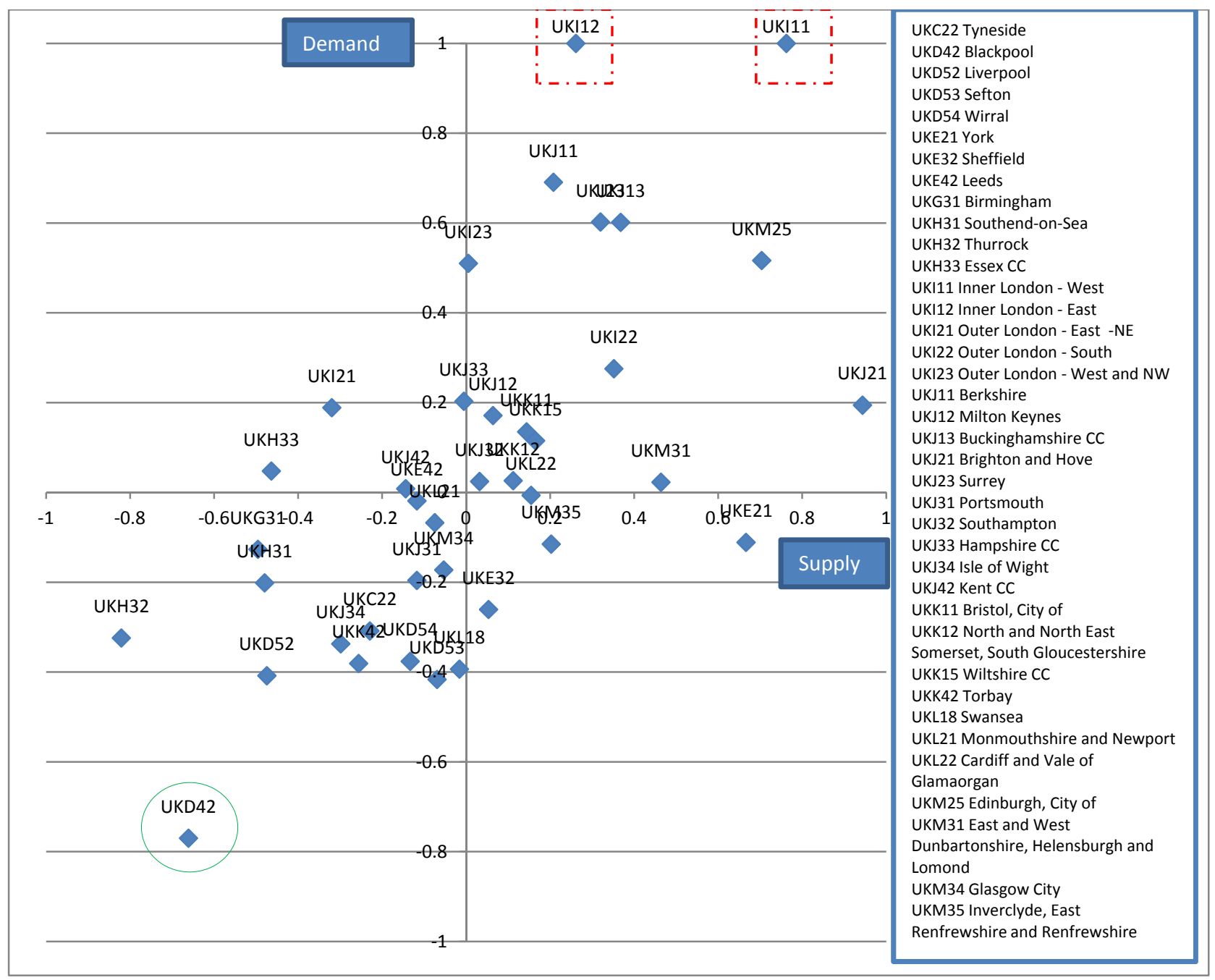

Note: Real values for the areas circled in red are: UKI11 $(0.76,1.72)$ and UKI12 $(0.26,1.04)$

A third case study area in the United Kingdom was Rhyl in Wales, another seaside town in the subregion of Conwy and Denbeighshire also falls within the low-skills equilibrium quadrant. Trend data for the United Kingdom (between 2001-2009) shows that while Rhyl, Blackpool and Manchester (North and South) all experienced a small relative change in position in this period, they did not move between the four quadrants. 
Figure 15. TL3 areas in Wales, 2009

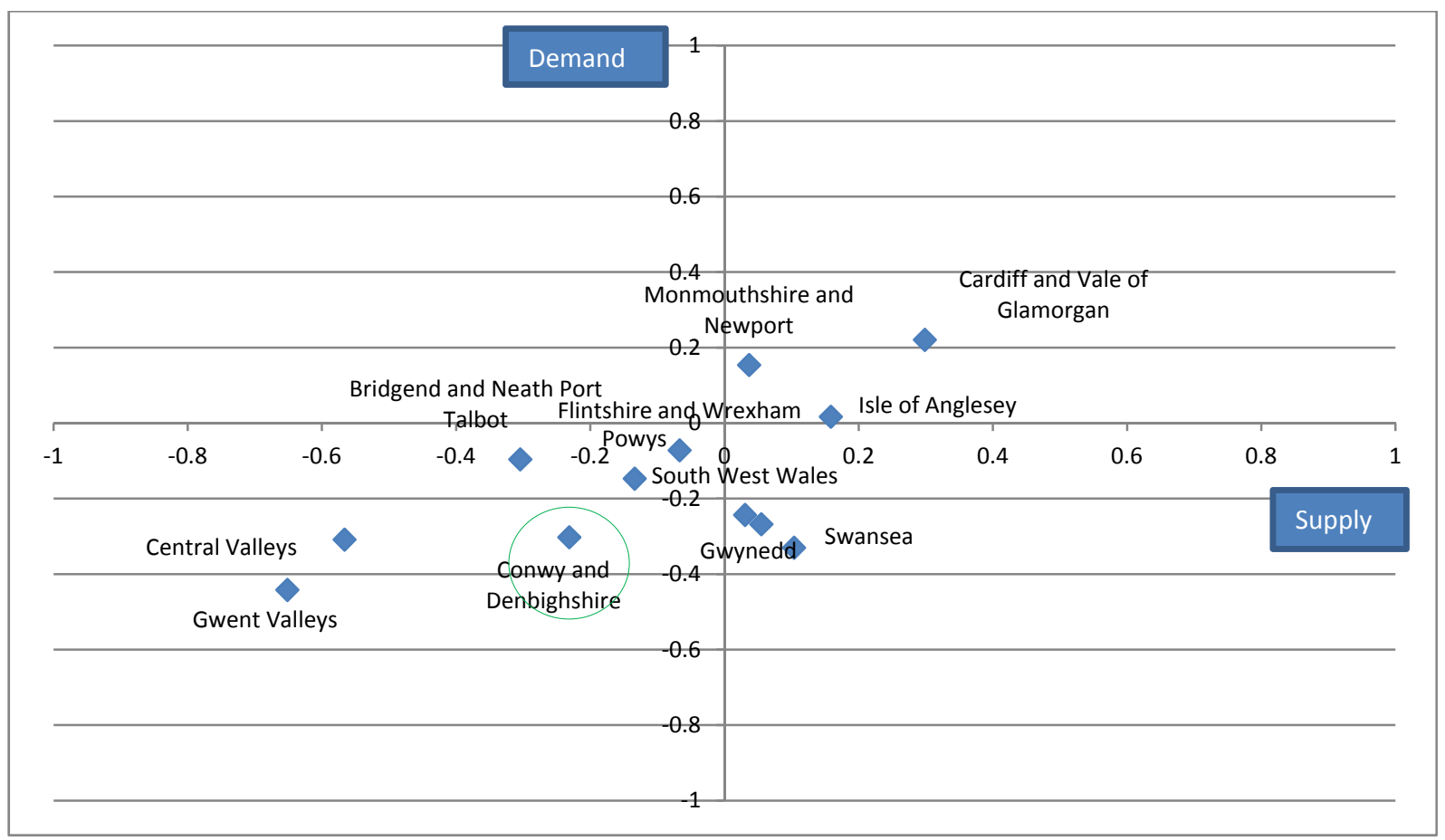

\section{Plotting the findings against other available indicators}

\section{Combining with one indicator}

It is useful to understand how indicators of skills demand and supply relate to other indicators at local level. When data on employment rates and unemployment rates were compared with the results of the diagnostic tool, they appeared to have a relatively weak relationship to the four quadrant types, illustrating that employment and unemployment rates are influenced by a host of other factors in addition to skills supply and demand, including accessibility of jobs, existence of particularly disadvantaged groups in the labour market, and the effectiveness of skills matching services. For example, local labour markets in the low-skills equilibrium quadrant in the North West of the United Kingdom had similar employment rates to other sub-regions in the North West. In Italy, the employment rate was higher for those sub-regions in the top two quadrants of the diagram with higher skills demand. 
Figure 16. Employment rates in North West of England against the statistical diagnostic tool, 2009

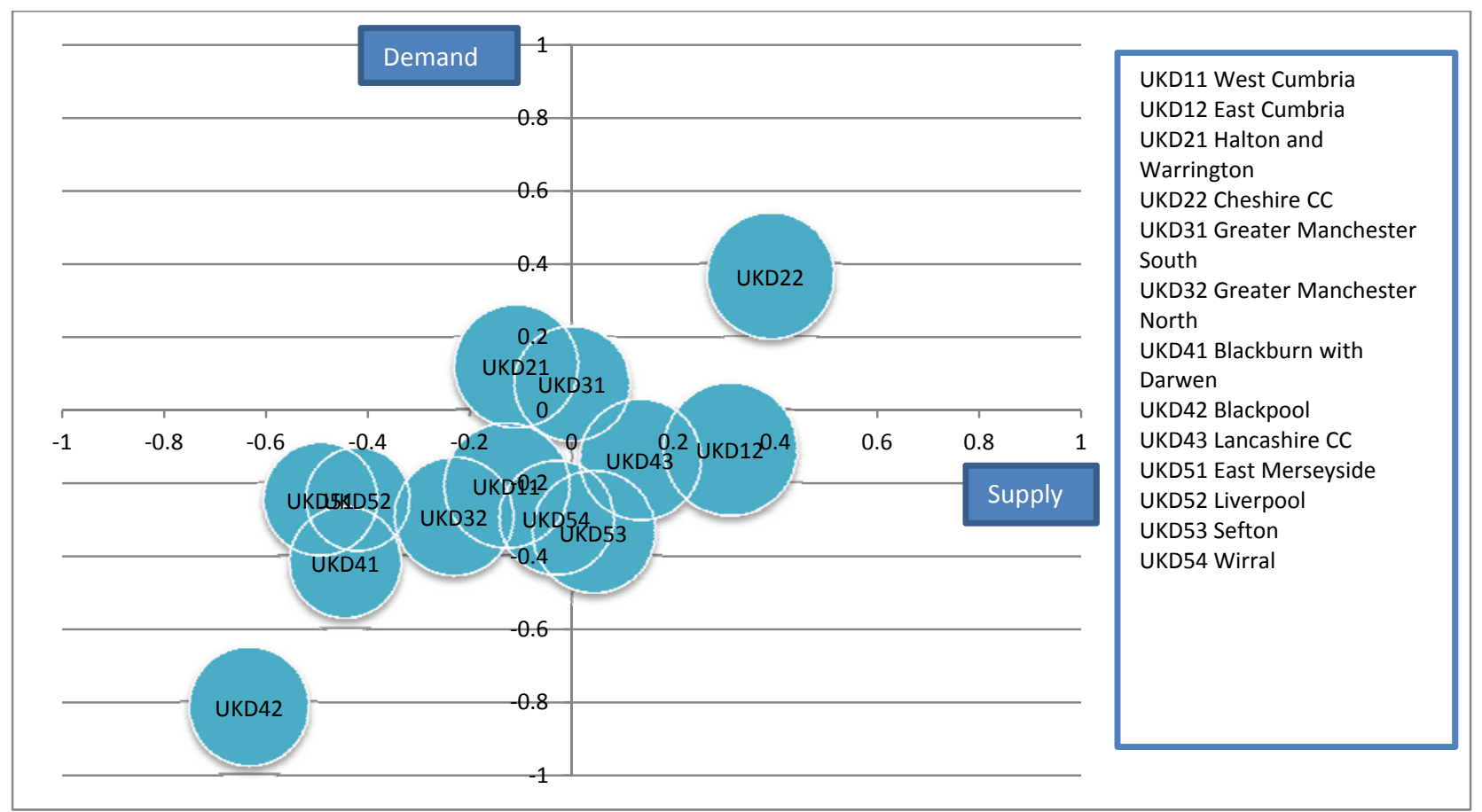

Note: The size of the bubble relates to the employment rate in the sub-region.

Table 6. Employment rates in the North West of England, 2009

\begin{tabular}{|clc|}
\hline TL3 code & \multicolumn{1}{c|}{ TL3 area } & Employment rate \\
\hline UKD11 & West Cumbria & 71.7 \\
\hline UKD12 & East Cumbria & 76.4 \\
\hline UKD21 & Halton and Warrington & 70.7 \\
\hline UKD22 & Cheshire CC & 72.6 \\
\hline UKD31 & Greater Manchester South & 66.0 \\
\hline UKD32 & Greater Manchester North & 68.0 \\
\hline UKD41 & Blackburn with Darwen & 63.9 \\
\hline UKD42 & Blackpool & 68.4 \\
\hline UKD43 & Lancashire CC & 69.5 \\
\hline UKD51 & East Merseyside & 65.0 \\
\hline UKD52 & Liverpool & 59.4 \\
\hline UKD53 & Sefton & 70.2 \\
\hline UKD54 & Wirral & 65.5 \\
\hline
\end{tabular}


Figure 17. Employment rates for provinces in Veneto and Campania against the statistical diagnostic tool, 2009

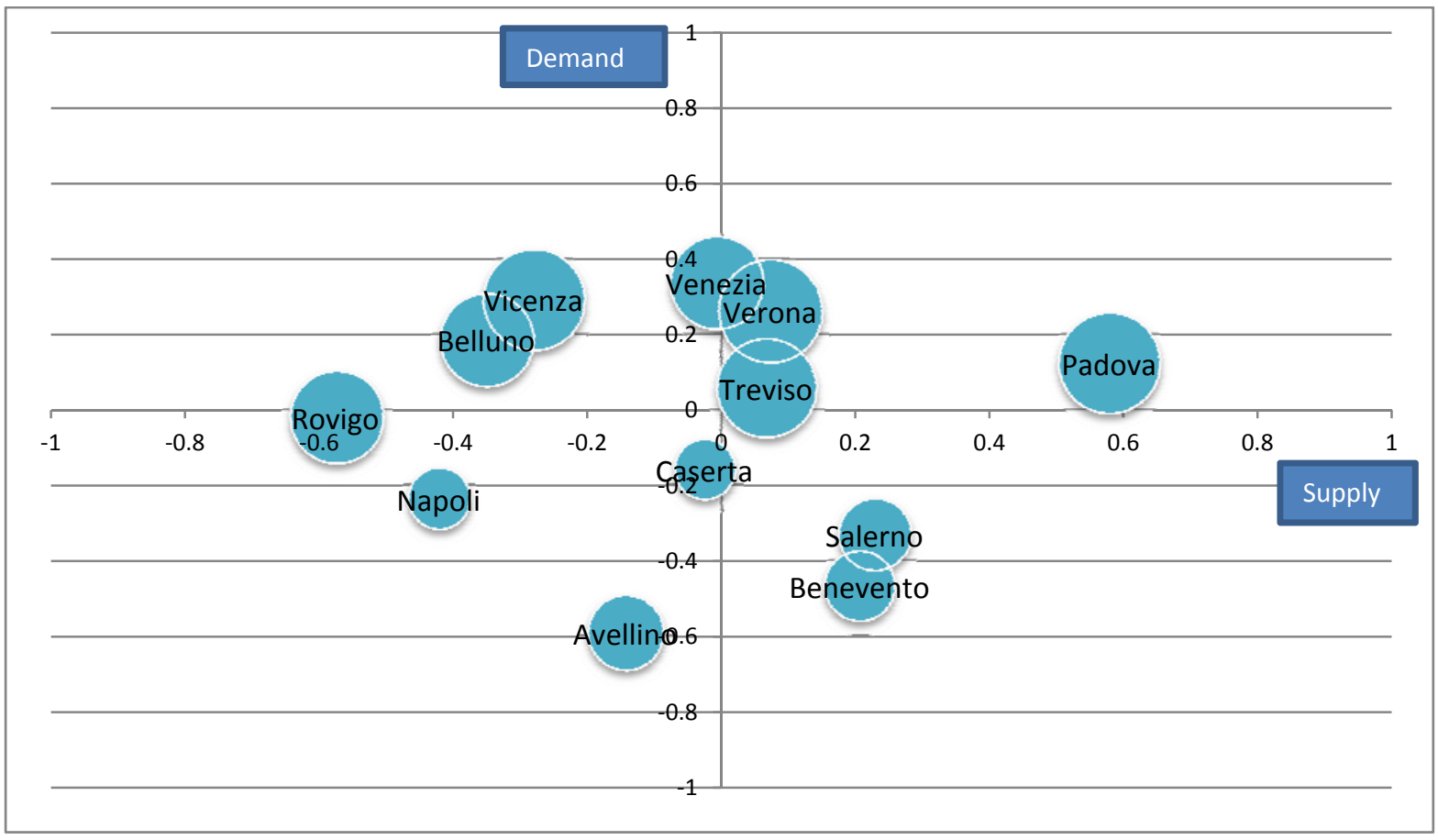

Note: The size of the bubble relates to the employment rate in the sub-region.

Table 7. Employment rates for provinces in Veneto and Campania, 2009

\begin{tabular}{|ccc|}
\hline TL3 code & TL3 area & Employment rate \\
\hline ITD31 & Verona & 67.4 \\
\hline ITD32 & Vicenza & 65.0 \\
\hline ITD33 & Belluno & 63.3 \\
\hline ITD34 & Treviso & 63.8 \\
\hline ITD35 & Venezia & 62.0 \\
\hline ITD36 & Padova & 65.6 \\
\hline ITD37 & Rovigo & 62.9 \\
\hline ITF31 & Caserta & 37.4 \\
\hline ITF32 & Benevento & 46.4 \\
\hline ITF33 & Napoli & 38.1 \\
\hline ITF34 & Avellino & 49.5 \\
\hline ITF35 & Salerno & 46.4 \\
\hline
\end{tabular}




\section{Comparing with multiple indicators}

In Italy, additional factors were incorporated into the tool through a regression analysis (Destefanis, 2012). A multinomial logit model was trialled to predict the probability of each province falling in to one of the four quadrants and to ascertain which factors had a strong impact in determining this placement (Destefanis, 2012). A number of relevant proxies related to the main features of the Italian economy and labour market were used as regressors, including employment by sector, geographical region, union density, female employment rates, youth employment rates, the share of the foreign population, the share of part-time and temporary workers, the presence of a university, the presence of industrial districts or clusters, population size, firm size and the number of patent applications.

Results suggested that being in the northern and central provinces of Italy highly increased the odds of being in the high-skill, rather than low-skill, equilibrium. Being from one of the central provinces also had a marginally positive impact on being in a situation of skills surplus. When employment by sector and other structural characteristics were included in the model, the results were slightly different and geographical location had a much weaker effect. A strong secondary sector is associated to a higher probability of being in the skill-shortage quadrant rather than in low-skill equilibrium. Provinces having a large population are more likely to be in a high-skill, rather than low-skill, equilibrium. Having a larger population also increases the odds of being in the skill-shortage quadrant rather than in low-skill equilibrium. Surprisingly, being a metropolitan area did not increase the odds of being in a high-skills equilibrium region.

The average firm size in a province was not found to have a significant impact on placement within the four quadrants, and interestingly, hosting industrial clusters or districts (known in Italy as distretti) also had no significance for being within one or other of the quadrants. On the other hand, hosting an attractive university was likely to have a significant positive impact on skills supply. The regression analysis found an inverse relationship between the level of skill demand and the share of temporary workers. However no significant relationship was identified in relation to the percentage of part-time workers.

\section{Overall findings}

Overall, the diagnostic tool was found to be useful in identifying the variation between different local areas in terms of their supply and demand for skills. It is also illustrative of the fact that local labour markets have different relative trajectories over time for sub-regions within regions. This result stresses the importance of analysing local level data in order to capture trends that otherwise would be lost, while also emphasizing that skills policies need to be sensitive to the overriding conditions facing individual places.

Sub-regions in Italy and in the United Kingdom have moved over time more than EI regions in Canada. Two reasons might explain this difference. First of all, the time lag studied in Canada is shorter than in Italy and in the UK - 5 years vs. 7 years. Secondly, in Canada, income from employment has been used as a proxy for GVA per worker, which may have varied less over time. Ideally it would be necessary to collect data on GVA per worker for Canada at the level of the Employment Insurance regions in order to undertake a strict comparison with the other two countries, but this data is currently unavailable at the subregional level.

In Canada and in the UK sub-regions have a tendency to fall on the line of equilibrium, showing either a low-skills or high-skills equilibrium. However, in the UK the TL3 regions are relatively clustered but there are a high number of outliers in comparison to the other two countries. In Italy, sub-regions are more dispersed, reflecting a greater heterogeneity in the Italian labour market. 
In general, urban areas have improved their situation over time to a greater extent than rural areas in Canada and in the United Kingdom. However this is not the case in Italy. Here rural regions seem to have improved their position more than urban regions in the recent years. In Canada the difference between rural and urban areas in both skills supply and demand is more prominent than in Italy or in the United Kingdom.

In terms of the relative performance of regions with different industrial bases (primary, secondary and tertiary sectors), Italy shows the most significant differences. Here sub-regions with dominant employment in the services sector have decreased their levels of skills demand over time whereas those with predominant employment in the secondary sector seem to have improved.

\section{Responses to the diagnostic tool from policy makers}

As part of the field work for this study, local, regional and national policy makers were asked for their feedback on the model. The main findings are set out in Box 2. below.

\section{Box 2. Feedback from policy makers on the statistical diagnostic tool}

Policy makers in participating countries gave the following feedback on the statistical diagnostic tool:

- The concept framework is useful: The concept of considering skills supply and demand alongside each other, and the categories of 'low-skills equilibrium', 'high skills equilibrium', 'skills surplus' and 'skills gaps and shortages' are of interest.

- The results make sense: Generally there were few surprises for policy makers at national and local level as to where places were on the quadrants and how they had moved over time.

- $\quad$ Timely data is important: The year for which information was available was very important for the credibility of the tool, especially given the impact of recession.

- The geography has to be right. For example in both Canada and the United Kingdom, it was noted that in some instances the TL3 areas did not accord with functional economic areas, and so could give a 'false impression' of the situation of the local economy. This highlights the importance of implementing the diagnostic tool for meaningful geographical areas.

- $\quad$ There are limitations with the indicators chosen. Some questions were raised about the indicators used, especially with regard to skills supply - it was felt that level of qualifications is not an accurate guide to the skills levels in a locality - skills and aptitudes gained through work are also important. When data on adult competences is made available through the OECD PIIAC study it may be possible to approximate adult skills in different ways however it will be difficult to disaggregate this information to lower geographical levels. There were also concerns about the quality of data on GVA per worker being variable at the local level.

- The weighting of the demand indicator appears arbitrary: It was noted that the weighting of demand indicators could be done differently and concerns as to the impact that this could have on the outcome.

- $\quad$ The methods use to collect data vary over time. There were some concerns whether change over time represented 'real change' or 'noise in the data' (due to sampling variation).

- The graphs show relative rather than absolute change: The fact that changes in position on the quadrants over time measures relative rather than absolute change vis-à-vis other areas was considered to downplay progress made in absolute terms. 
Overall the tool was found to be useful in considering the supply and demand for skills alongside each other. A number of the identified limitations of the tool were based on the lack of comparable data at local level collected at regular intervals and this will be difficult to overcome in the short term. Care needs to be taken with the geographical area chosen for analysis to ensure that they reflect functional labour markets or 'travel to work' areas. The presentation of the quadrant graphs showing variation in performance at subregional level also needs to be accompanied by other analysis which shows absolute rather than relative change over time. 


\section{RESPONDING TO AND SHAPING SKILLS DEMAND: POLICY LESSONS}

In addition to the development and testing of the statistical diagnostic tool, this project has carried out fieldwork in the three countries, Canada, Italy and the United Kingdom to identify current approaches to better balancing the supply and demand for skills.

\section{The policy context}

Evesson et al (2009) and Buchanan et al (2010) have identified that policy makers have four domains of influence over skills (see Figure 18. below). On the supply side, they can increase the quality and quantity of output from education and training systems. They can also influence the flows of skills through migration and mobility, and removing obstacles to the labour market (such as intergenerational disadvantage). On the demand side, they can influence the context of skills deployment, through management practices and methods of work organisation. Further they can also influence the nature and design of products and services.

Figure 18. Four domains of influence over skills

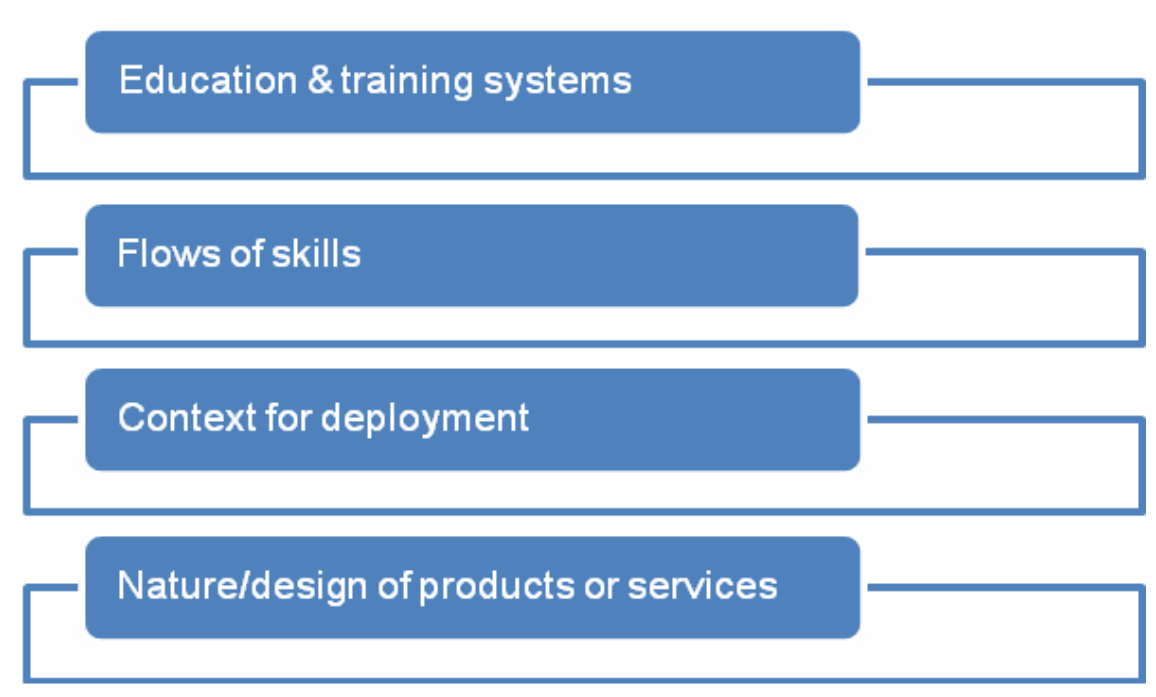

Source: Evesson et al, 2009

This latter is a particularly interesting area for policy in that it encourages policy makers to think about how skills are influenced by product market strategies, both in the private but also the public sector. Recent work by the UK Commission for Employment highlights the strong link between product market strategies and skills utilisation in the private sector. Mason (2011) analysed data from the 2001 and 2009 National Employers Skills Surveys to show that firms in England varied greatly in the extent to which they are seeking to engage in 'high-end' or high value added production, and that this degree of variation has persisted throughout the period from 2001 to 2009. The incidence of different types of product strategy differs greatly between sectors as well as within each sector. The research showed that product market strategies and the level of workforce skill in an establishment were strongly positively correlated. This means that those with high product market strategy scores were also likely to register higher levels of workforce skill, whereas those with lower product market strategy scores are more likely to register lower workforce skill scores. 


\section{Box 3. What is skills utilisation?}

What do we mean by skills utilisation? Skills utilisation has been defined as being "about ensuring the most effective application of skills in the workplace to maximise performance, through the use of a number of key agents (e.g. employers, employees, learning providers and the state) and the use of a range of HR, management and working practices." (CFE, 2010). Warhurst and Findlay (2011) define it in more simply yet specifically as being about "the better use of skills' and 'the use of better skills'.

Many companies, particularly in emerging economies, continue to compete by producing low-cost products. When companies deliver standardised products to markets and attract customers mainly on the basis of cost, they are likely to use technical means of production that are task- and routine-based (Ashton and Sung, 2011). They therefore have limited incentive to attract skilled staff or to train new staff. However, as firms move into higher-quality product markets, they are more likely to require both technical and generic skills across the workforce in order to innovate and to develop products that are unique and differentiated to meet customer needs. Adopting new technologies can be an important dimension of developing new product-market strategies, as firms think innovatively about how new technologies can help them to adapt products to new types of customer demand.

Buchanan et al (2010) illustrate the potential for the public sector to also change product market strategies through an analysis of early childhood education and care. These services can be defined in different ways. 'Day care', for example, is concerned with keeping children safe while parents work. On the other hand, there are pre-schools and kindergartens primarily concerned with the development of children. What type of service for children prevails will ultimately be determined politically (as the government plays the dominant role as funder and regulator) and will profoundly shape skill needs. If governments choose a system of long day care arrangements to primarily help working parents return to (or stay in) the labour market, the set of skill requirements will be very different to those if government is concerned with the development of children as well educated citizens.

\section{The importance of balanced approaches at the local level}

Looking at skills policy in this broader context highlights that local policy makers have a raft of different tools that they can use in order to raise skilled employment and make the transition to a more productive and successful economy (see Figure 19. below). Taking a more balanced approach to skills means that in addition to investing in education and training systems and paying attention to flows of talent, local policy makers should also think about investing in skills demand through, for example, facilitating technology transfer, and working with employers to improve work organisation. The extent to which policy makers should focus on the latter issues will depend on the nature of their local economy. 
Figure 19. Conceptual framework for skills policy in this area

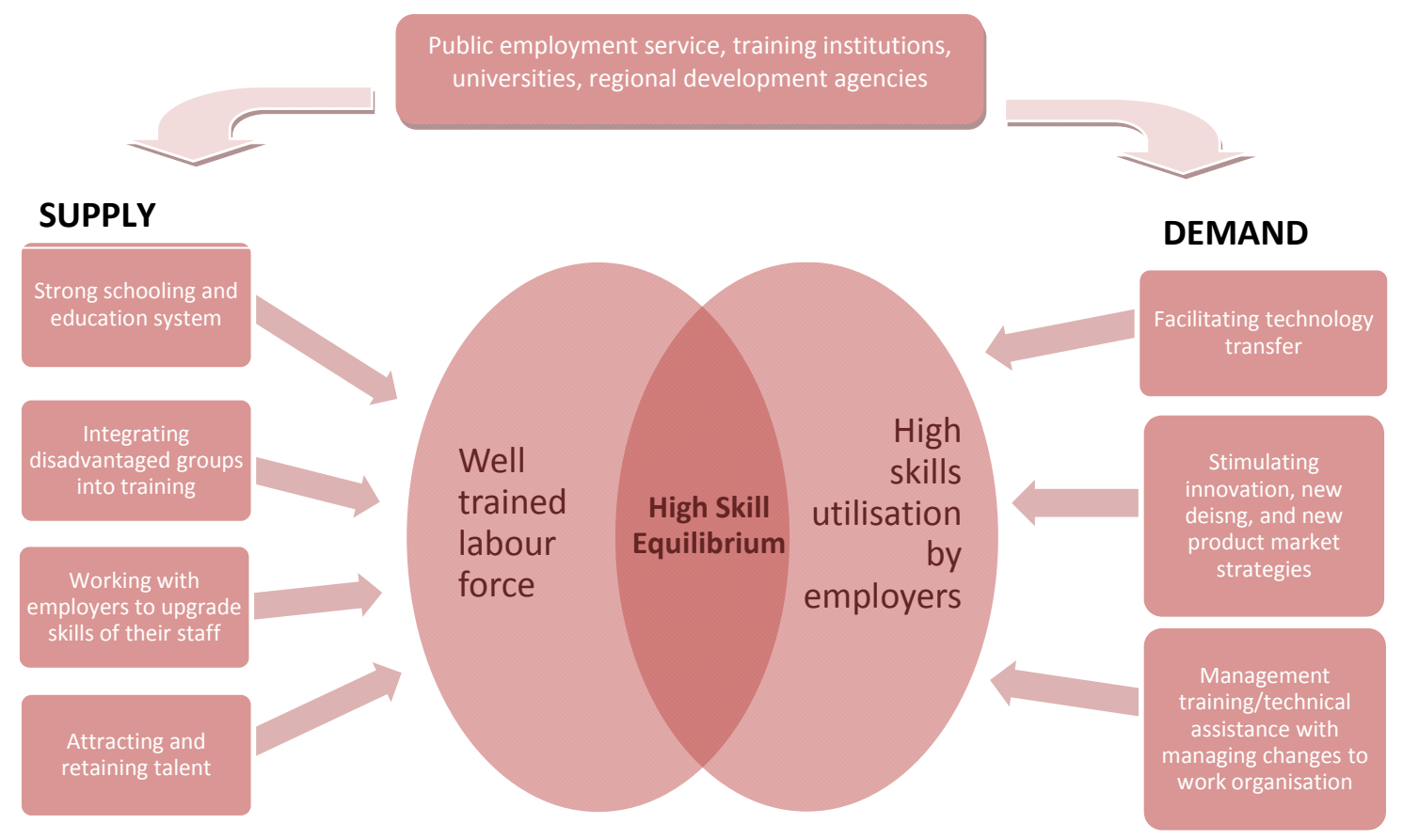

In high skills equilibrium and skills gaps regions it may make most sense to develop 'demand-led' systems which ensure that skills supply responds to the current and future demands of employers. However for low-skills equilibrium and skills surplus regions, more emphasis may need to be placed on helping to 'shape' employer demand so that the economy generates more productive and sustainable employment. While investment in skills may help to transform local employment in the longer term as people evolve and transform the work that they carry out, the inertia present in management practices and the existence of an open labour market (where skilled people can migrate elsewhere to find more appropriate employment), means that this is likely to be a slow process.

Moving towards a high-skills equilibrium is not necessarily about investing in high tech, high-skills sectors. It is also about boosting skills utilisation in sectors which traditionally have a high concentration of lower skilled jobs, such as retail, care and tourism. However, working to help shape demand is a tall order for many policy makers who do not necessarily see it as the domain of public policy to intervene in the market in this way. Although policy makers have more control over the quality of employment in public services and in public procurement there are competing obligations and goals for the management of these services, including reducing public expenditure.

\section{National policy context}

Although the body of academic work arguing for a balanced approach to skills supply and demand is strong $^{8}$, the degree to which this has permeated the thinking of national policy makers is variable.

8. See for example, Finegold and Sol,1988; Buchanan 2001, 2004, 2010; research by the ESRC Centre on Skills, Knowledge and Organisational Performance (SKOPE) at the Universities of Oxford and Cardiff 1999-2011. 
Generally there is a strong divide between policies to support skills (which are supply driven) and economic development and innovation policies, which are delivered by separate ministries. This means that the context for the deployment of skills and the impact of human resource management on productivity within diverse sectors of the economy is often neglected.

In Italy for example, skills policy has traditionally been very much supply side-based, with a current national focus on school-work transitions/apprenticeships, vocational training and life-long learning. At the same time, recent economic development policies have put more of a premium on improving productivity and innovation in firms, and European Social Funds are used to fund investment in productivity and innovation at regional level. Destefanis (2012) finds that the implementation of such demand-side policies and programmes are often beset by delays in implementation and are delivered in a fragmented way at local level. Recently a new industrial policy strategy called Industry 2015 has been established which encourages collaboration between local authorities, businesses, universities and research centres which operate under the guidance of project managers. The strategy identifies networks of firms while also providing state aid for R\&D projects and a new form of tax credit for R\&D. Destefanis (2012) also identifies a lack of policy emphasis on the effective matching of skills supply and demand at local level (for example by the Public Employment Service) in comparison with other OECD countries.

In Canada, at the federal level skills policies are developed by Human Resources and Skills Development Canada, while policies to support economic development and innovation are delivered by Industry Canada and regional bodies such as ACOA (Atlantic Canada Opportunities Agency) and Western Economic Diversification Canada (WD). At this level there is evidence of joined-up policy thinking on skills, economic development and employment with HRSDC investing in research into more demand side approaches to skills. However this approach is not always carried down to the provincial or local level (Froy and Giguère, 2010b). In Ontario (the case study region), a wide variety of policies and programmes have been put in place by the Ministry of Economic Development and Trade and the Ministry of Agriculture, Food and Rural Affairs to boost productivity and innovation, with an emphasis on identifying best practices, encouraging benchmarking to global standards, supporting internationalisation, funding technology transfer and promoting productivity practices through conferences, training programmes and publications (Verma, 2012). However, such policies are not always coordinated across at local level with the skills policies being delivered by the Ministry of Training, Colleges, Universities, which focus mainly on supply side and downside adjustments (post-secondary education, 'second career' training for areas of job growth ${ }^{9}$, apprenticeships and adult learning).

In the UK, concerns about a 'long tail of low skills' has meant that skills policies have focused primarily upon boosting the supply of skills through publicly-funded investments, as well as social inclusion/mobility. However, more recently the government appointed Commission for Employment and Skills has argued that 'the future employment and skills system will need to invest as much effort on raising employer ambition, on stimulating demand, as it does on enhancing skills supply'. As they point out, there is little value to an organisation having a skilled workforce if the skills are not used well (UKCES, 2009). While the policy focus on developing a balanced approach to the supply and demand for skills has yet to translate into substantial policy change, in Scotland, there has been a particularly strong commitment to improving skills utilisation. Despite having a highly qualified population, ${ }^{10}$ Scotland performs relatively poorly on a range of economic indicators, highlighting the shortcomings of a policy focused solely on the supply of skills (Payne, 2008). Amongst initiatives to boost demand for, and improve utilisation of, skills, a Skills Utilisation Leadership Group has been established, and a series of action

9. The Second Career programme has helped over 37,000 people displaced from their jobs in the past four years to train in a new occupation deemed to be in demand, including funding access to college and university courses (Verma, 2012).

10. Scotland tends to score better on indicators of skills supply than other parts of the UK. 
research projects have been initiated aimed at exploring the potential contribution of universities and skills to improved skills utilisation in the workplace (Payne, 2011). The Coalition Government in the UK has also established a new Growth and Innovation Fund (GIF) ${ }^{11}$ to pilot new initiatives developed by businesses to increase the contribution skills make to growth, which is managed at the national level.

\section{Box 4. What is a quality job?}

Defining a quality job is a difficult process. Participants in an ESR-funded seminar series organised by the Universities of Strathclyde and Cardiff on 'Making bad jobs better' in the United Kingdom identified that the following key elements were important in determining what was not a quality job:

- Low relative and absolute levels of pay (and associated performance management systems)

- $\quad$ Limited benefits

- $\quad$ Poor working conditions

- Uncertain levels of working time and/or poor work life balance

- Job insecurity

- $\quad$ Poor job design leading to narrow, repetitive, and boring work

- Low levels of skill required and poor training and development opportunities

- Lack of progression opportunities within the firm and/or sector

- Lack of employee voice and representation

- $\quad$ Agency worker status.

While some of these elements are clearly subjective (agency work for example can be a positive option for somebody seeking flexibility in their work in order to fit other life commitments) it is clear that it is not possible to define the quality of a job by income or wages alone. The degree to which a person's skills and potential are adequately utilised are clearly also important dimensions, as is ensuring that people have the opportunity to grow through training and career progression.

An important dimension of quality employment is that workers have the ability to problem solve and apply their own discretion while working. The IPPR (Institute for Policy Research) in the UK assert that important to a quality job is 'a sense of engagement in building a common project and mattering in the world'. Back in the 1960s, Jacobs asserted that, 'it is agonising to be capable of solving problems and have no opportunities to do so'. At the same time, jobs which fully engage members of the workforce are more likely to develop incremental innovation, as staff members 'learn by doing' and transmit this learning to others in a firm.

The ILO has also developed an employment agenda based on the assumption that productive employment and decent work are key elements to achieving a fair globalisation, the reduction of poverty and the achievement of equitable, inclusive, and sustainable development. The Decent Work concept was formulated by the ILO's constituents - governments and employers and workers - and it is now one of the organisation's major priorities. Decent work sums up the aspirations of people in their working lives. It involves work that is productive and delivers a fair income, security in the workplace and social protection for families, better prospects for personal development and social integration, freedom for people to express their concerns, organise and participate in the decisions that affect their lives and equality of opportunity and treatment for all women and men. The ILO puts the Decent Work Agenda into practice through four strategic pillars: job creation, rights at work, social protection and social dialogue, with gender equality as a crosscutting objective. See: http://www.ilo.org/global/about-the-ilo/decent-work-agenda

\section{Identifying balanced local strategies}

To analyse the potential for further developing policies to support balanced skills development at local level in the three participating countries, this study has looked at seven local case study areas (Niagara and Kitchener in Ontario, Canada; the Riviera del Brenta and Treviso in Veneto, Italy; and Blackpool, Manchester and Rhyl in the United Kingdom).

11. The GIF is adopting a sectoral approach. 
The study has also focused on three particular sectors -manufacturing (in Canada and Italy), tourism (in all three countries), and retail (in the United Kingdom). The tourism and retail sectors traditionally offer a high percentage of relatively low quality and low-skilled employment, and represent important areas of future job growth given the rising importance of services ${ }^{12}$. While manufacturing is declining in many OECD countries it still constitutes a significant percentage of local employment in some OECD regions ${ }^{13}$ and it is an area where improved product market strategies may be essential to retaining employment given global competition (OECD 2006/9; Froy and Giguère, 2010a).

\section{Local approaches in Canada}

\section{The development of a balanced approach to skills in Niagara}

As identified in the data analysis for this project (see Figure 9), the town of Niagara is currently on the border line between a low-skills equilibrium and skills shortage area. The Niagara peninsula has been known historically as the home of the Niagara Falls and while the Falls themselves attract 20 million tourists annually (on both sides of the US-Canada border), tourism in the region sees a concentration of low-medium quality jobs. In more recent decades the Niagara peninsula has become known as the seat of the wine industry in Ontario and the region hosts an important food processing industry. The region has also seen growth in knowledge-based economic activity such as information technology and other technology-driven services for industry.

There is a strong collaborative approach locally to diversifying economic development, with a clear recognition of the value of human resources and skills to this process. Broadly actions are being carried out which stimulate both skills supply and demand (see Figure 20. below).

12. In 2020, for example, almost three quarters of jobs in Europe are expected to be in services (European Commission, 2008)

13. Employment in industry constituted 15\% of employment in OECD countries in 2010 (source: OECD.Stat). 
Figure 20. Balancing supply and demand for skills in Niagara, Ontario

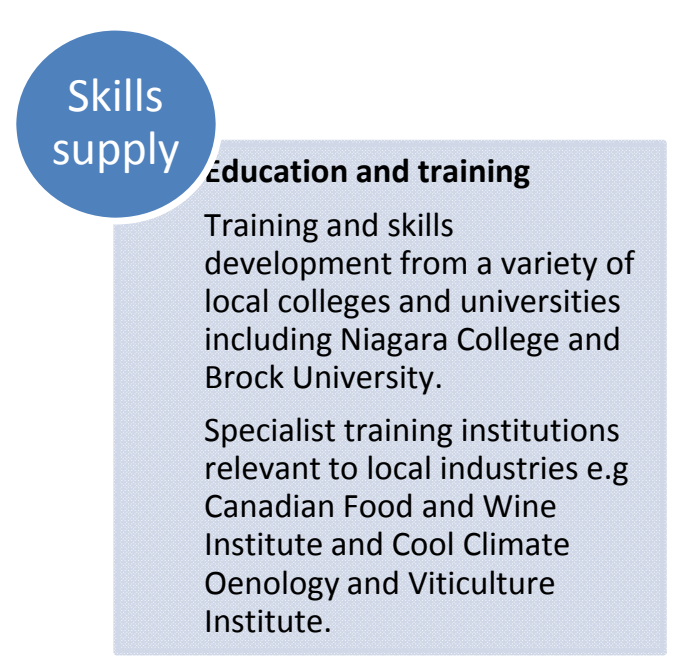

Flows of talent (offering greater choice to youth to remain in the area)

Initiatives to support youth retention for example careers fairs.

Development of Niagara Occupational profiles to make the local labour market more transparent and thereby attractive to local youth.

Trades Awareness Programme to encourage people to take up local trades.

Improving the attractiveness of the town through the 'Smarter Niagara' strategy.

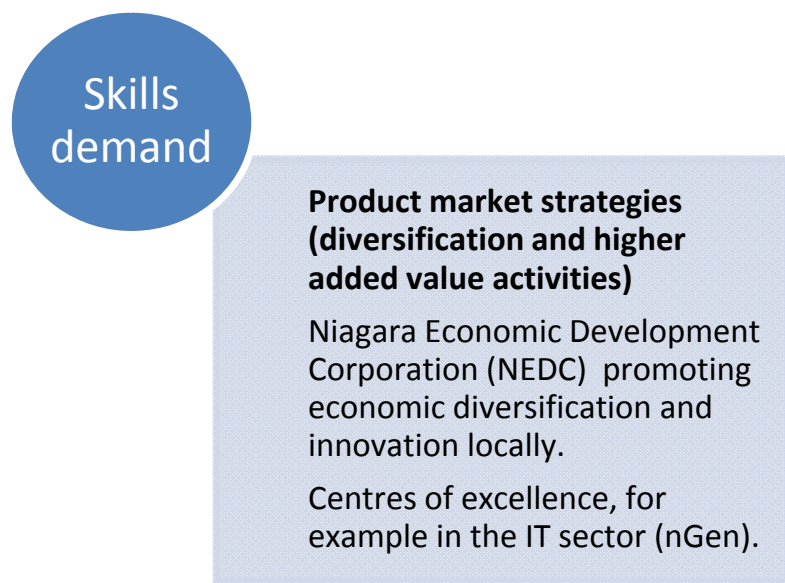

Technology transfer and management training

Investment by Niagara college in $R \& D$ with local firms

Technology transfer by CME's

SMART Manufacturing programme and the Guelph Food Technology Centre

In terms of improving skills supply, there is a range of local education provision available, for example Niagara College and Brock University. A proportion of the courses on offer are clearly aligned to the local industrial base (specialising for example in horticulture, hospitality and tourism), reflecting the fact that the Ontario Ministry of Training, Colleges and Universities (MCTU) looks favourably on new funding applications for programmes which are supported by industry. Verma (2012) finds that campuses outside of large metropolitan areas in the province are particularly likely to offer industry-specific and region-specific programmes. The Niagara Workforce Planning Board also commissions research on, and develops priorities for, workforce development in the region with recent reports emphasising the need to 
increase skills levels and better align skills with the needs of employers (although it is strictly advisory so does not have executive role in implementing these priorities).

There is a strong awareness amongst local policy makers of the way in which flows of talent affect the local labour market. As many of the regions young people leave the town to go to bigger cities such as Toronto, local policy makers seek to improve the attractiveness of local job opportunities to show residents that they can find good local employment commensurate with their skills and potential. Both Niagara College and Brock University ensure that graduates are aware of local employment opportunities, for example through the hosting of careers fairs. Occupational profiles have been mapped to improve transparency of the local labour market, and trades awareness fairs have been organised to encourage people to take up local opportunities in the skilled trades. Verma (2012) identifies that many traditional occupations, such as welding, are becoming more high-tech, offering better salaries in return for higher skills. However many local young people shy away from such choices because of traditional notions of such work. At the same time a Smarter Niagara campaign has been launched to make the town a more attractive place to live, through creating vibrant urban centres, protecting the regions natural beauty, ensuring a healthy environment and combating urban sprawl ${ }^{14}$.

On the demand side, local educational institutions in the area are also engaged actively in stimulating productivity and increasing the utilisation of skills by employers. The local community college, Niagara College, for example, has a tradition of working with local firms on R\&D and innovation projects and has recently received funding from the Federal Economic Development Agency for Southern Ontario (FedDev Ontario) to increase its capacity to support the innovation goals of regional SMEs. The research arm of the college (Niagara Research) collaborates with firms in areas that include product and process applied research; engineering design; technology development; product testing; proof of concept; piloting and problem solving. The most recent federally funded year-long programme includes partnering with 165 SMEs to develop basic business tools within the following sectors: information and communication technology, advanced manufacturing, greenhouse/viticulture/horticulture, renewable energy and environmental technologies. The local Brock University has also developed a newly-built Cairns Family Health and Bioscience Research Centre which includes, alongside scientific and technical research, a business incubator to encourage spin offs and ensure that products can be taken to market. This centre also runs a 50 million CAD research programme in areas that are funded by OMAFRA (the Ontario Ministry of Agriculture, Food and Rural Affairs).

\section{Manufacturing - food processing in Kitchener and Niagara}

The Niagara Economic Development Corporation (NEDC) is a government/industry/education partnership that promotes economic diversification and technology/innovation driven quality and productivity improvements in the Niagara Region. Together with local educational institutions and other local actors, NEDC has stimulated a number of different actions to stimulate the development of higher value-added activities in the local economy.

An industry which has a high percentage of employment in both Niagara and Kitchener is food processing. In general, food processing is not considered a high technology industry. The nature of innovation in the industry is typically characterized by incremental improvement in products, processes and niche marketing which can all add value. Interviews with local employers in these case study areas identified four key approaches to adding value to products, the first of which was 'being local'. Other important areas included maintaining consistently high quality, having a unique product, and being small enough to be responsive to changes in consumer habits/tastes. Each of these is discussed below in Box 5 .

14. See http://smarterniagara.com/ 


\section{Box 5. Key factors for driving up product market strategies in the food processing sector in Kitchener and Niagara}

Research among small firms in the food-processing sector in the region of Niagara, Ontario, found that these firms were pursuing a variety of strategies to improve quality and innovation, each of which had an impact on skills use. The four main ways through which they added value to their products were:

- $\quad$ Being local: Using local products, local personnel, and selling locally (as a primary market) enabled the firms to develop customer loyalty despite having higher prices than similar products available from 'non-local' providers.

- Maintaining consistently high quality: An insistence on quality also generated customer loyalty and longterm profitability.

- $\quad$ Producing unique goods: The majority of the companies produce unique items that allow them to capture a particular segment of the market since there was no direct competition. Although they require specialised production processes, each of these lines of items generates profits by providing something that cannot be found elsewhere.

- $\quad$ Responsiveness/Flexibility: The ability to respond quickly to consumer demands enables the companies to provide a value-added product. For these smaller firms, adapting the production line or changing an aspect of their products involves changes that can be implemented relatively quickly as they have one shift of workers, direct communication lines, and hands-on owners who can train and oversee the new process directly.

Source: Verma (2012).

The four value-added processes described above have varying impact on the workforce of these companies (Verma, 2012). The focus on being local affects the workforce in a positive manner by generating employment opportunities for local workers. Once hired, attention is placed on understanding the importance of maintaining the local focus, from raw materials through to final product. However, this is more of a mindset that a skill set. A local firm called Organic Meadow (specialising in organic dairy products and eggs) illustrates this well as they encourage a "familial" atmosphere by hiring people committed to the values of organics and co-operatives. In this way, they are able to retain their workforce without paying a high wage premium.

The attention paid to maintaining consistently high quality products impacts the workforce differently. This does require specific training and education that costs the companies and, in some cases, requires them to seek a different type of worker. For example, the company 'Sweet \& Sticky' (which produces innovative non-alcoholic syrups made from local grapes) require their employees to understand their products and be aware of potentially creative uses for it. For these reasons, they seek employees with food science background or education. TMF (which specialises in meat) provides another example of how insistence on quality impacts their labour force. Due to the nature of their processes and their products, they require more specialized, skilled and knowledgeable employees who are comfortable working under environmentally challenging conditions. TMF uses incentive programs and effective leadership focused on relational aspects in order to attract and retain the type of employee they need.

The companies who have unique products require very specific skills and education for their employees. Gunn's Hill Cheese for example will use an apprentice approach to developing their skilled labour force as there are no educational institutions that provide the requisite courses specific to their product. Sweet \& Sticky aims to hire university graduates with majors in the food sciences while Picard Foods use premium wages to retain personnel once they have been trained in the unique processes involved in producing their products. Similarly, having an adaptable workforce is a key to those organisations that want to remain responsive to the customer. This requires that the employees remain open to learning about the products and the processes (Verma, 2012). 
The food processing industry in Ontario has been given a significant level of support in terms of public policies and programmes. For example, the Niagara region plays host to the Canadian Food and Wine Institute at Niagara College (which provides education programmes in culinary skills and wine making) and the Vineland Research and Innovation Centre (a centre of excellence funded by the Government of Ontario, which both funds R\&D and works with businesses to use the latest horticultural technology and bring innovative new products to market). Brock University offers courses in oenology and viticulture through a Cool Climate Oenology and Viticulture Institute (CCOVI). Conegosta College near Kitchener runs an Institute for Food Processing Technology.

Also nearby, there is the Guelph Food Technology Centre, which was set up with the support of the government of Ontario and in particular OMAFRA, the Ministry of Agriculture, Food and Rural Affairs. The centre offers both training for employees and potential employers in the sector, alongside consultancy and advice to business. Each year GFTC advises and consults with over 1500 businesses in the food and beverage industry, while also providing training to more than 3600 professionals representing 500 agrifood companies from 26 countries. The Guelph Food Technology Centre has a Board of Directors drawn from industry, government, university and community. At the same time local networks such as the Grape Growers of Ontario lobbies on behalf of their members and set minimum prices through negotiations with the Wine Council of Ontario.

\section{Support for broader manufacturing in Niagara and Kitchener}

As part of its diversification strategy, the Niagara region has been actively supporting the development of the high-tech sector, through for example launching nGen, a multi-lateral effort to create jobs in interactive digital media and related business development in the Niagara region (see Box 6 below). Initially funded through the Ontario Media Development Corporation (OMDC), nGen's founding partners include Brock University, Niagara College, Interactive Ontario, City of St. Catharines, the Niagara Enterprise Agency, and the Niagara Economic Development Corporation. In addition, nGen is supported by a dozen private employers including large computer firms like Microsoft, Dell and Autodesk.

nGen's programs are designed to help Niagara retain fresh talent from its two post-secondary institutions, and to attract and assist new business. nGen's core programmes include tenancy, mentorship, seminars, networking, interactive digital media projects and providing access to technology which it provides in a new state of the art facility, the Generator at One.

\section{Box 6. nGEN}

By bringing together key partners in industry, economic development and post-secondary education, nGen works to create an innovative business incubation and generation model to help jump-start and grow interactive digital media enterprise in the Niagara region. nGen is unique in that it fosters synergies between interactive digital media companies, local arts and culture industries in Niagara, as well as the educational and research infrastructure at Brock University and Niagara College.

nGen in conjunction with its partners provides employment and internships to students with skills in game design using Flash, Director and other prototyping tools; 2D and 3D character and scene building; animation; game design; web design; web development; game development; writing for interactive media; sound design and music creation and editing and related areas. In addition, students enrolled in business and marketing courses are recruited to provide assistance in business development. These opportunities provide students with hands-on industry experience, which significantly improves their chances of securing a job in their field once they have graduated.

nGen recruits recent graduates who have interactive media skills and are eager to pursue an interactive media or game project of their own. Graduate/entrepreneurs are provided with a modest income support for between 6 months and a year. During this period, they are provided with space, equipment and software to enable them to develop their own project. In exchange, they are asked to contribute $50 \%$ of their time to an nGen project that gives them related 
hands-on experience.

For its business development mandate, nGen presents seminars and workshops for project innovators and business start-ups on topics such as project teams, project management, marketing, interactive media deal flow, financing, and managing intellectual property, etc. It brings start-ups together with accountants, lawyers, and other professionals who can provide much needed advice for new/young entrepreneurs. As well, nGen serves as a learning house for regional, provincial and federal services and programmes aimed to assist emerging enterprises and projects in interactive media.

There is also broader support for manufacturing firms in the region through federal and provincial funding programmes, such as the CME Smart Programme (Box 7. below identifies how this has benefitted one local firm). The Canadian Manufacturers \& Exporters (CME) organisation represents more than 10,000 companies nationwide, over $85 \%$ of which are small and medium-sized enterprises. Thanks to funding provided by the Government of Ontario and the Southern Ontario Development Programme (FedDev Ontario), CME has created the SMART Program to help small and medium-sized manufacturers in Ontario improve their productivity by transferring technology and training people in how to use this technology.

\section{Box 7. Handling Specialty Inc}

Handling Specialty is a small firm (45 employees) located in Grimsby, in the Niagara region, exclusively dedicated to the custom design and manufacture of material handling systems for demanding applications. They manufacture engineered-to-order lifting, tilting, rotating and traversing equipment for Fortune500 clients seeking innovative customised solutions. Over the past 40 years, they have built a reputation for providing innovative solutions to a wide range of original equipment manufacturers in industries such as automotive, aerospace and defense, entertainment, rail, and factory automation. Clients include firms such as GE, Boeing, and Northrup Grumman among others such well-known organizations.

Handling Specialty has carved out a niche for itself as a small but specialised producer of technology-driven solutions to high-end clients. Their success can be attributed to factors such as establishing a reputation for being reliable, working closely with the client and their ability to keep up with state-of-the-art technological capability. The latter is rooted in a "training culture" within the organisation. They used the federal tax credit program, Scientific Research \& Experimental Development (SR\&ED), to introduce new technology and to train people in its use. They also participated in CME's SMART Manufacturing programme to improve productivity by introducing technology and training people to use them. Under a dollar-matching program (costs are shared by the firm and public funds) they trained every engineer in the organisation. As a result of these training inputs engineers at Handling Specialty have state-of-the-art knowledge in 3D rendering. Every technical employee uses an iPad. Largely due to such capability the firm has recently won and completed four projects through competition at the international level.

To achieve such results on being able to attract and retain highly-skilled staff the firm works closely with other organisations in the region. A third of its engineers have been hired through co-op education programs from nearby Ontario colleges and universities. It has worked closely not only with educational institutions and the Niagara Workforce Planning Board on the supply side but also on the demand side with organisations such as Canadian Manufacturers and Exporters, the Niagara Economic Development Corporation and the Chambers of Commerce. ${ }^{15}$

While manufacturing represents a small - and declining - part of the local labour market in Niagara, the case study area of Kitchener has a much stronger employment base within the secondary sector, and (as shown in Figure 10.) is performing very well in its balance of skills supply and demand in comparison with

15. In August 2011, Handling Specialty was sold to another Niagara region firm, Whiting Equipment of Welland, ON. Under the terms of the sale it will be able to pursue its lines of business without any interruption. 
other secondary regions in Canada. Kitchener is part of a technology triangle (Kitchener-WaterlooCambridge) which hosts some of the most successful manufacturing in Canada. It benefits from local proximity to the major city of Toronto (with its markets, universities and business partners) while also being strongly connected into global markets. Blackberry maker Research in Motion (8,000 employees) is the region's largest employer while large manufacturers like Toyota Motor (4,300 employees) and ATS Automation Tooling Systems (1,800 employees) are surrounded by many small and medium size firms making parts for original equipment manufacturers. The region also benefits from the presence of a number of higher education and college institutions, including University of Waterloo, Wilfrid Laurier University, and Conestoga College.

Canada's Technology Triangle (CTT) is a not-for-profit, public-private regional economic development partnership that markets the competitive advantages of the Waterloo Region to the world, and works to attract new businesses, investment and talent to the region. At the same time it is recognised that there is a need for a culture of continuous improvement for the region to remain globally competitive. Local firms take advantage of a provincial Advanced Manufacturing Investment Strategy for innovation and technology (see Box 8 below). In addition, the Canada-wide Excellence in Manufacturing Consortium (EMC) partners with a local Waterloo Manufacturing Innovation Network and the government of the Province of Ontario to provide advice and support to local firms. The EMC also collaborates with the Yves Landry Foundation, a private foundation that funds upgrading of skills for current employees.

\section{Box 8. Funding programmes to support manufacturing in Ontario}

The Ontario Advanced Manufacturing Investment Strategy (AMIS) is a $\$ 500$ million program that was created by the Government of Ontario. The programme essentially encourages organisations to make investments in leadingedge technologies and processes. AMIS will provide a repayable loan up to $30 \%$ of the total eligible costs of a project-up to a maximum of $\$ 10$ million. The loans are interest free and principal free for five years as long as the company meets the job and investment targets that were agreed upon. After that, the rate is the province's cost of borrowing plus $1 \%$.

In advice to firms several local programmes place an emphasis on lean manufacturing, with the EMC running workshops, for example on lean management, and the application of lean in administration, and supply chain management. Lean manufacturing has long been seen as an effective model for business in both cutting waste but also in allowing shop floor workers to engage in problem solving and team working in order to lead to a culture of continuous improvement. Hence this represents an opportunity to improve the utilisation of such higher level generic skills in all areas of production.

However, the fieldwork for this study found that productivity gains by employers from the lean approach did not always translate into better jobs or higher incomes. While people working on the shop floor may be able to use more discretion, take on more responsibility and problem solve, their enhanced job descriptions do not always appear to lead to improved their salaries or conditions. One local firm manager identified that while workers reported greater job satisfaction following the implementation of the lean approach through more active engagement in their work, wages were still very much determined by the going rate for a particular type of worker within the regional labour market. Changes in job descriptions had not significantly upgraded wages.

This highlights the fact that just doing work more efficiently and improving competitiveness in producing a given product line does not necessarily lead to improved job quality for workers. If firms maintain the same product market strategy there will be a ceiling on their ability to significantly alter the rewards they are able to offer their staff or the types of job available. In fact by reducing waste in terms of 
removing any activity which does not meet customer needs ${ }^{16}$, firms may be eliminating some of the fertile ground for experimentation and innovation which lead to new products and new designs (see Jacobs, 1969). If all activities are centred on what customers will pay for, there is little opportunity to create and develop new products and services. Provincial policy makers in Ontario agreed that the ability to change and innovate the design of products would be intrinsic to the ability of their region to keep up with market developments and produce better quality and more sustainable jobs ${ }^{17}$.

\section{Local approaches in Italy}

\section{Made in Italy - a sector approach to footwear}

One area which has seen the development of design to be an intrinsic element of a sector development strategy is the Riviera del Brenta area of Veneto Italy. Here, employers have worked together on a broad shift in their product market development strategies. The Riviera del Brenta industrial district is located across the Venice and Padova provinces and centres upon the municipalities of Stra, Fiesso d'Artico, Fossò and Vigonovo. Having traditionally hosted cottage-based industries, the region is now a global centre for the production of high quality women footwear to which the major international fashion brands resort to produce and, at times, to design their leather accessories lines. The industrial district dates back to 1898 when Giovanni Luigi Voltan, on the basis of experience gained in the most important footwear industries in the US, gave birth to the first industrial shoe company in Italy in the region. Spin-offs developed from the main Voltan range, which grafted on the informal knowledge accumulated over centuries by shoemakers and cobblers of the area. As the cluster developed, technical knowledge was shared through strong social capital networks between people and businesses (Becattini, 2004). The production process remains labour intensive, with labour constituting $40 \%$ of production costs.

While from 1950 to 1985 the region exploited world markets in a range of medium-high quality products, the years from 1985 to 1995 saw a repositioning in top-of-the range products, in particular top brands. This choice was made in 1993-1994 following falling demand for middle-range products from the Northern European markets. About 50\% of the shoe manufacturers chose to reposition themselves in upper market segments, where greater value added would allow them to absorb higher costs. In doing so they reflected a movement in Italy towards privileging a high quality 'Made in Italy' brand (see Box 9 below) ${ }^{18}$. As witnessed by the growing share of high-skilled employees in R\&D, management and marketing, this process also saw an important rise in the importance of intangible services. Before the 1993-1994 repositioning almost all workers in shoe manufacturing were blue collar workers, nowadays this proportion is around $40 \%$ (with roughly $50 \%$ of designers and $10 \%$ of commercial staff).

A key factor in moving from medium to high quality products was effective global marketing. Given the barriers experienced by SMEs in accessing new global markets, a local employers association, ACRIB, the Associazione dei calzaturieri della Riviera del Brenta was crucial to expanding the global brand of the Rivera del Brenta district. ACRIB was created in 1961 on the initiative of businessmen in the district to meet the needs for representation in wage bargaining with the unions across the two provinces, Padova and Venice, and for managing the participation of a number of small-medium firms at international fairs. Over

16. For example, a poster produced by the Association of Manufacturing Excellence (www.ame.or) advised firms to Eliminate waste! Anything which does not add value in the customer's eyes is waste and must be eliminated!

17. Ministers, Deputy Ministers and senior staff from the Ministries of Labour; Training Colleges and Universities; Economic Development and Trade, and Agriculture, Food and Rural Affairs met as part of the OECD LEED study visit for this project, January 2011.

18. The remaining $50 \%$ of companies in the region chose a different strategy, which mostly meant moving production to countries with low labour costs. 
time ACRIB has become a hub for business, while maintaining its role in negotiation with unions. ACRIB is part of ANCI, the National Association of Italian Footwear Manufacturers, and has a delegation in the Industrial Associations of Vicenza, Padova and Venice.

\section{Box 9. The importance of brand - Made in Italy}

'Made in Italy' refers to the process of revaluation of the Italian industrial and handicraft production towards higher quality products, with an emphasis on the 'Made in Italy' brand. This has occurred within a diverse set of sectors known as the ' $4 \mathrm{Fs}$ ' :

- $\quad$ Food and wines;

- $\quad$ Fashion (including apparel, leather goods, footwear, jewellery, eyewear, cosmetics and perfumery);

- $\quad$ Furniture and building materials (including wood products and furniture, ornamental stones, tiles and other ceramic products);

- $\quad$ Fabricated metal products and machinery (including Ferrari cars, yachts, cruising ships and helicopters, plastic and rubber products: including all non-electronic machinery).

Source : World Bank (2009)

Two elements of the Rivieria del Brenta model are particularly important for this study - firstly the role of the unions in ensuring that improvements in productivity went hand in hand with improvements in salary and working conditions (most importantly health and safety). As productivity developed, the region ensured that wage levels rose accordingly through strong relationships with the unions, mediated by ACRIB, which generated a shared interest in the ongoing growth and adaptability of the region. For example, an agreement was made in 1995-1998 to grant an extra month of wages to reward productivity increases. High priority was also given to supporting flexible working for women with family and other commitments, and health and safety regulations (the district has the lowest rate of accidents in Italy, as certified by the INAIL (Italian Workers' Compensation Authority).

A second important element is the strong role played by a local education and training institution in the transformation to higher value-added product market strategies. The Riviera had a long tradition of craft production where knowledge was transferred informally across generations. The process of converting this informal knowledge into codified knowledge was first carried out by a School of Arts and Crafts "Ottorino Tombolan Fava", created in 1923 for professional training in various crafts, and then specialising as a school for footwear designers. In 2001 this structure had evolved to became the Politecnico Calzaturiero, a private company started by ACRIB, ANCI, Veneto Innovazione and by public and private bodies of the Veneto region to promote initiatives in training, research and technological transfer, development of quality and safety at work. The activity is characterised by the mix of four distinctive elements which make the work of the training school particularly effective:

- $\quad$ Tradition - the polytechnic, through its 80 years' history, has contributed to the training of most of the entrepreneurs, designers and shoe technicians that are working in the region today;

- Cooperation with the private sector and the unions - the synergy with ACRIB is vital to promoting the polytechnic's role in company development and growth; 
- Composition of the teaching staff - entrepreneurs, stylists, designers, experts and consultants working in shoe companies make up most of the teaching staff;

- Integration of training with activities to increase skills utilisation and demand - the polytechnic offers support with technological research and quality control of materials for firms throughout the supply chain.

The principal mission of the polytechnic is the training of entrepreneurs, managers, newly qualified young people and graduates, involving on average 1000 pupils, 100 teachers, 10000 teaching hours divided into about 100 different courses each year. The centre has proven particularly successful in recruiting the managers of local firms to give training out of hours to employees and potential employees across the whole sector. The presence of the ACRIB network and the establishment of a shared interest in developing the global brand has apparently been instrumental in reducing the fear that managers might have in sharing knowledge with the workers of other firms. The college also provides training projects for unemployed young people (funded through the European Social Fund). While engaging managers as teachers the college also provides management training back to firms, often in conjunction with universities and renowned institutions such as the Bocconi University of Milan and the Polytechnic of Milan, to ensure that firms are using up to the minute management techniques.

The polytechnic promotes and participates in numerous research and technology transfer initiatives, in Italy and abroad. Collaboration with major universities and with leading manufacturers is undertaken for the development of processes, products and innovative materials. The polytechnic also carries out research and experiments aimed at developing human resources and sponsors studies in co-operation with universities and other institutions and networks in order to develop, design and test new production technologies, testing and developing new technologies, and providing rapid prototyping (e.g. through 3D printing of new products). The polytechnic also has a quality control laboratory and carries out health and safety training.

By training both employees and managers, and investing in innovation, technology transfer and work organisation, the work of the polytechnic clearly straddles skills supply and demand (see Figure 21. below). 


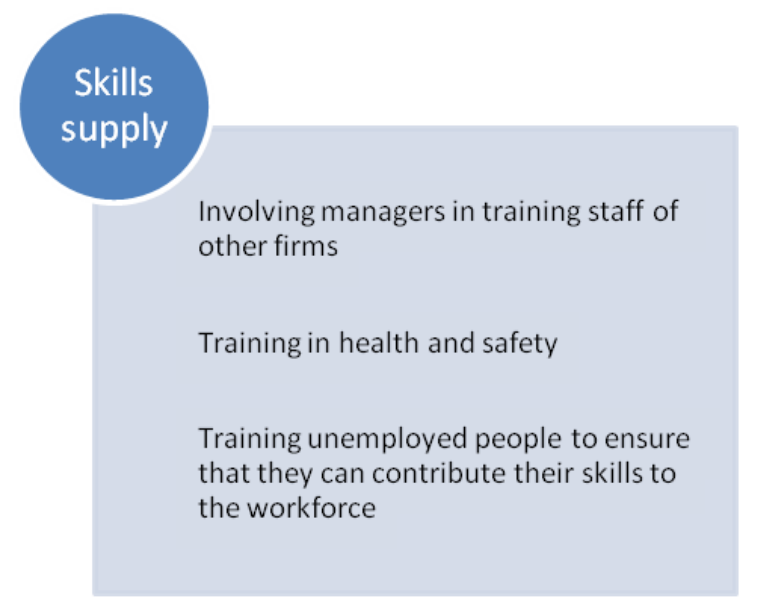

Destefanis (2012) makes the point that sustainable local skills ecosystems such as that which has developed in the Riviera del Brenta may evolve more easily when diverse aspects of the supply chain are all located in one region. In Campania, by contrast, another local industrial district analysed, which was centred around food processing, had not seen equivalent success as most local firms just undertake one part of a complex international production chain. It was therefore more difficult to evolve or innovate products and use this as a mechanism to improve skills utilisation and job quality.

\section{A cross-sector tri-partite approach}

The tripartite collaboration between firms and unions in the Riviera district also occurs elsewhere in the Veneto region, not only at the level of particular industrial districts, but also across broader territories and multiple industrial sectors. In the town of Treviso, a Local Pact for Development signed by trade unions and industry (Unindustria Treviso, CGIL, CISI and UIL) had helped to raise the quality of local jobs and salaries in a variety of industries while stimulating local economic development.

An important element in the recent evolution of the Treviso economy has been the outsourcing of manufacturing activities toward Eastern Europe, especially in Romania, and China. From 2000 onwards, outsourcing led to worrying job losses in the region. In 2004, a first pact for growth and industry among unions and the local Confederation of industries was implemented, which ultimately became a strategic pact for the province of Treviso. The main aim of that pact was to reintegrate workers that had lost jobs because of delocalisation back into the labour force. This proved challenging - although the main unions (CGIL, CISL, UIL) worked together to seek the support and assistance of a broader set of local institutions, including the Chamber of Commerce, it became clear that labour market reintegration for certain groups, especially women, youth, and the over 50s would not be easy. These problems become even more serious with the current recession, bringing in 2011 the signature of a new pact for sustainable development and 
job creation ("Patto per lo sviluppo sostenibile, la qualificazione dell'occupazione, la competitività del sistema economico locale") led by unions and the local confederation of industries.

The pact has focused not just on labour market integration but also on improving the quality of jobs locally. It has placed strong emphasis on second-level wage bargaining (over and above the national wage bargaining process) at the provincial level to ensure that improvements to productivity go hand in hand with improved working conditions and increased wages. The aim is to create an environment which favours better skill utilisation and a more stable employment relationship. However, in an area where the share of temporary workers has recently doubled, the pact has made little attempt to encourage local firms to train their labour force.

This latter point reflects a wider finding of the Italian study, that there is a strong relationship between skills training and utilisation and the nature of employment contracts. It was identified that training was almost non-existent for the significant number of employees in Veneto and in Campania who were on either temporary contracts or who work in the informal sector. The informal economy remains a significant issue in both the north and south of the country, and the Veneto region is trying to rectify this through a new initiative to measure competences gained informally.

The size of firms was also found to matter significantly. In Veneto, it was found that the large number of micro and small enterprises in the region are more reluctant to collaborate and to engage in skills development and skills formation, supporting broader LEED findings in this area (OECD, 2012 forthcoming). A bilateral agency for the Veneto craft industry called EBAV (which works with firms of less than 15 employees) has helped to overcome this by supporting collaboration and shared investment in a number of areas including training, innovation and technology, and access to credit. Through collecting membership fees from local firms it has been able to invest 100 million EURO in such areas over the last 19 years.

\section{Boosting strategic thinking around tourism}

The Veneto region is obviously not just a manufacturing centre. With the city of Venice at its heart it also has a strong tourism economy. However while the region hosts a global tourist attraction, much like Niagara, there were concerns locally about the future of this sector and its contribution to economic development. In this case the main issue is that the tourism sector involves small businesses which are family run, and there is little value given to formal qualifications or skills training. The International Centre of Studies on the Tourism Economy (CISET) based in the region identified that the main model for skills development is the transfer of knowledge from one generation to the next through 'learning by doing, ${ }^{19}$. While this can be effective in the transfer of skills and in the preservation of highly valued traditions, it does not support new strategic thinking on how to develop the sector to meet the demands of new markets or introduce new innovations. A number of local initiatives have therefore focused on training for managers.

\section{Local approaches in the United Kingdom}

\section{Attracting a new type of tourist to Blackpool}

Tourism was also central to the local economy in Blackpool, in the United Kingdom. Here it was again recognised that the local economy would benefit by raising the game in terms of the tourism offer. Having long been a seaside resort that caters for high volume but low-spending customers, Blackpool is working hard to raise its game and attract higher spending customers through offering a higher quality

19. Source: CISET, Oriago di Mira. 
'offer'. The town has been growing its branded attractions (e.g. Madame Tussauds, Nikolodean, Merlin) while also investing significantly in infrastructure (trams, cycles, buying the Blackpool tower for the public, new concert hall, refurbished front). It was recognised that capital and infrastructure investments alone will be insufficient to realising the town's vision, and that alongside them there is a need for investment in skills, particularly in the area of customer service (see Figure 22. below). This means investment in specific skills (for example through local college courses geared to the tourism industry) but also more informal learning and knowledge sharing.

Figure 22. Balancing supply and demand for skills in Blackpool
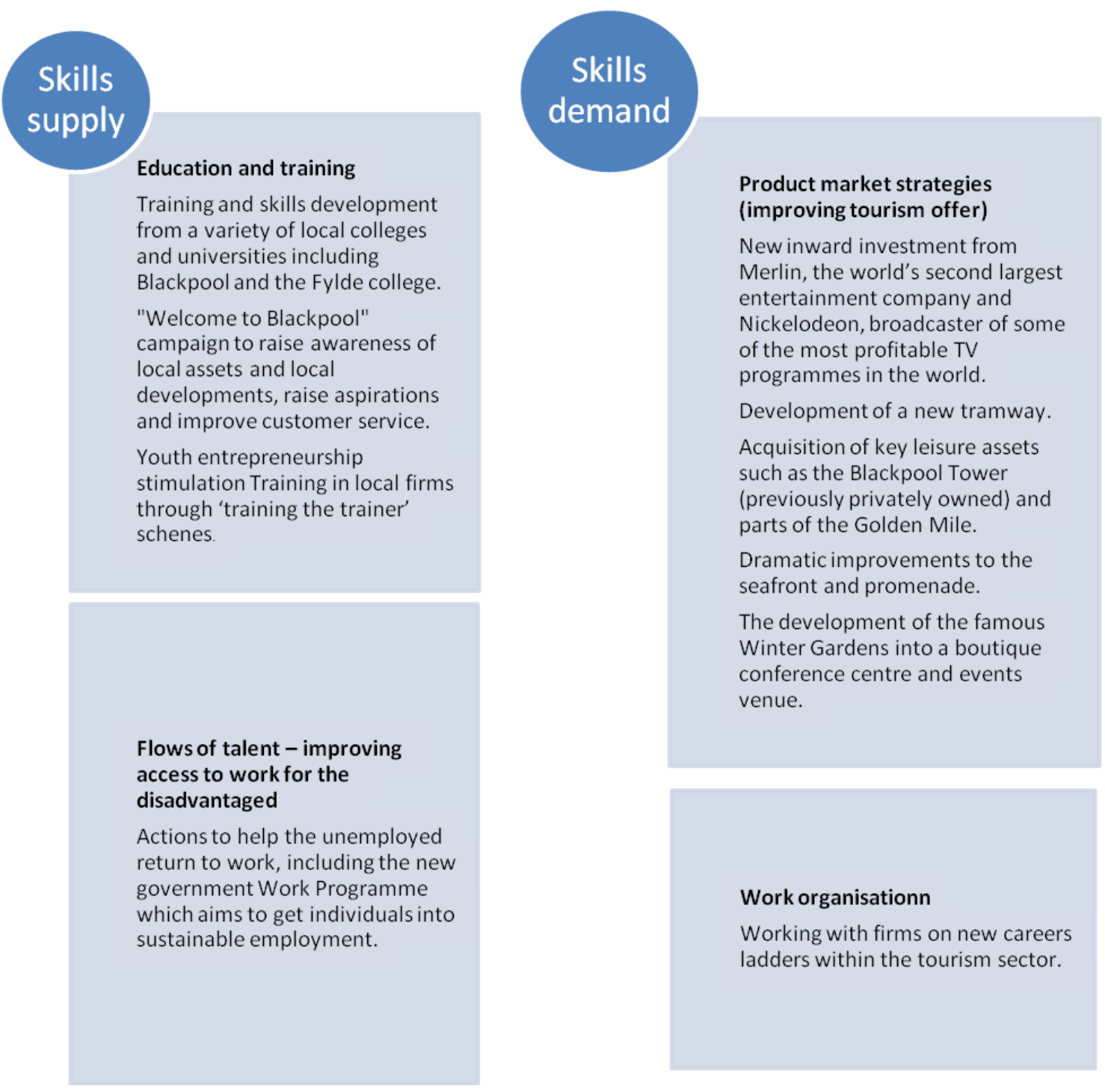

access to work for the

advantaged

Actions to help the unemployed work, including the new hich aims to get individuals into sustainable employment.

\section{Work organisationn}

Working with firms on new careers ladders within the tourism sector.

A particular emphasis has been placed on informal skills development to raise the aspirations of service personnel so that they project a better image of the town and at the same time become more committed both to Blackpool, their employers and their own personal career prospects. A good example of such an initiative is the Welcome to Blackpool initiative funded initially by the Local Enterprise Growth Initiative (LEGI) introduced by the previous UK government. This project trains local people (especially 
those working in hospitality, leisure, tourism, transport and retail sectors, but also local residents) in appreciating the history of Blackpool, current developments and future plans. Through course attendance participants learn more about Blackpool's attractions and services. The knowledge gained can then be used to enhance visitor and local residents' experience of Blackpool. Employers have reported that the short course equips staff to deliver a high standard of customer service, which in turn impresses visitors to the town and encourages word of mouth recommendations and repeat visits to Blackpool. The initiative has shown that taxi drivers, those involved in tourism, and local residents can be excellent ambassadors for Blackpool It was reported that over 3,000 people (of all ages) have attended the course in two years and that more than 250 organisations have benefited. Such initiatives have been useful in increasing staff retention in local firms, which traditionally have had high turnover rates, linked to the seasonality of tourism in the town. High turnover rates have been seen by some firms as representing a challenge in terms of investing in staff training and skills upgrading. Growing staff retention has allowed local employers such as the Sandcastle Water Park to start working with individuals on personal development plans.

\section{Raising the game in the retail sector in Rhyl}

The retail sector is another area where there are high concentrations of low-quality low-income work in the United Kingdom. Working to raise the quality of local retail jobs has been one focus for the town of Rhyl in the United Kingdom, a seaside town in North Wales (see Figure 16). West Rhyl contains the most deprived neighbourhood in the whole of Wales. A substantial number of local residents have low or no qualifications or skills needed to take up work opportunities, or have other problems that impact on their ability to work.

Skillsmart Retail, the national sector skills council working with the retail sector in the United Kingdom has developed a system for working with local town centres to improve the quality of the retail sector. The Skillsmart Retail Location Mode ${ }^{20}$ is particularly aimed at towns and cities which have a high proportion of independent retailers and where positive intervention could secure benefits. In Rhyl the Location Model research involved Skillsmart Retail, the Welsh Government and Denbeighshire Council working together to:

- create a profile of consumers in Rhyl, using geodemographic modelling data (while major retail chains conduct their own market research and often have access to such data, it is not generally accessible to small/independent retailers);

- determine the competitive position of Rhyl as a retail centre;

- $\quad$ analyse the findings from street interviews, mystery shopping, and a town centre assessment; and

- benchmark mystery shopping results against the other locations in Great Britain as a whole where Skillsmart Retail has already worked with communities of small retailers and other partners.

As part of this work, Skillsmart Retail has also established the local college, Coleg Llandrillo Cymru as the first National Retail Skills Academy in Wales, providing businesses with a unique opportunity to access a range of specialised retail training packages - including a series of masterclasses (set up by a television celebrity, Mary Portas) which aim to provide shop owners / managers and their teams with core retail management skills that are simple and easy to access. Coleg Llandrillo Rhyl has established a retail skills shop in Wales which offers free advice and information on courses and learning opportunities to businesses, their employees and learners, designed specifically for the retail industry, as part of its role to support local business to increase productivity through training and development. Coleg Llandrillo Rhyl is

20. The Skillsmart Retail Location Model research was undertaken in Rhyl in late 2010/early 2011, with support from the Welsh Sector Priorities Fund Pilot programme. 
also active in apprenticeships and in a range of other education and training at various skills levels - from pre-employment to higher education.

The Retail Skills Academy aims to target its services partly to the local retail sector in Rhyl, however it was evident that it was mainly businesses outside of Rhyl itself which took up the training and master classes on offer. The colleges and other stakeholders cited a lack of employer ambition locally as the root cause, and identified that current shop owners do not have a long term strategy within the town which would lead them to seek to get out of a model of providing low-cost products for a low income market. While there are high income earners on the outskirts of the town, they tend to go to larger and higher quality shopping centres in nearby Chester and it was not felt likely that they could be attracted to spend more of their income locally at the current time. This demonstrates that raising employer ambition will be a key dimension of any local strategy to raise skills utilisation.

Such retail-focused local strategies can also be found elsewhere in the OECD. For example, an OECD LEED study in the Netherlands (Dorenbos and Froy, 2011) found that the retail sector was also of great importance to the town of Breda and its surrounding area (see Box 10. below). Here the municipality has similarly combined investment in training with a collaborative approach to raising the quality of the local retail offer.

\section{Box 10. Work with the retail sector in the municipality of Breda, Netherlands}

Retail is an important part of the local economy of Breda in the Netherlands. The sector has 2200 establishments in the area, and is currently relatively stable. However, in the context of the ageing of the population it is expected that it will become more difficult to fill vacancies in the future. It is also acknowledged that more has to be done to increase the quality of employment in the sector and the productivity and competitiveness of local enterprises, particularly small and medium sized enterprises (SMEs). Several organisations such as the national board for retail trade, the retail platform Breda, the association of enterprises in the city centre of Breda, the Chamber of Commerce and Werkplein Breda (a service to help people to access jobs which combines the public employment service and the local municipal social service department) have taken the initiative to establish a service unit for the retail sector (Servicepunt Detailhandel). The objective of this service unit is threefold:

- Improving the inflow and outflow of workers and better managing labour market transitions within the sector: for example, by improving the match between demand for labour and supply of labour through investments in skills;

- $\quad$ Training of staff: implementing an external information and advice service on human resource management for SMEs to improve work organisation, productivity and the quality of local job opportunities;

- Improving the image of the sector: stimulating and organising extra promotion with regard to working in the retail sector, improving customer satisfaction.

The strength of the service unit is that the approach is demand driven and based on one-on-one relationships with local retailers. If action is needed this takes place immediately through individual company visits and visits to the members and board meetings of the association of retailers. Local work coaches (placing local people into work) also receive training from the national board for the retail trade. Servicepunt Detailhandel started in 2009 and in early 2010 a similar service point was established for the care and welfare sectors, with plans to develop one for technical professions. A consulted business representative felt that through this collaboration they have come a long way in a short period of time.

Source : Dorenbos and Froy, 2011 


\section{GOVERNANCE OF STRATEGIES TO RAISE SKILLS SUPPLY AND DEMAND}

A number of common issues arise from the country field work in terms of the governance of balanced approaches to skills development.

\section{Taking a sectoral or a place-based approach}

This study has looked primarily at sector approaches at the local level, and there are clearly advantages to working with individual sectors in galvanising public action and supporting public-private partnerships around a common area of interest. However there are also strong arguments for looking at the issue of skills above and beyond individual sectors. While the sector-specific approach taken in the industrial district of Riveria del Brenta has been successful, the success of policies geared at industrial districts in the rest of Italy has been more variable, and the preliminary data research carried out for this project found that being part of a distretti did not increase the likelihood that a province would be in a 'high-skills equilibrium' quadrant within the LEED data analysis (Destefanis, 2012).

Focusing on one sector can be risky if production in that sector becomes unsustainable within the global market place. Knowledge sharing and the cross-fertilising of ideas can also be particularly successful in producing innovation when this occurs between as well as within sectors (Jacobs 1969, 2000). At the same time, certain sectors may have a ceiling in the degree to which they can upgrade their product market strategies based on the same market demands. Lloyd (submitted) for example points out that while the local labour market of Blackpool is heavily tourist focused, ultimately there will be a limit to the degree to which it can add value to this particular sector. In particular, seaside resorts in the United Kingdom suffer from the fact that at a certain income level people are more likely to take seaside holidays abroad where the climate is more predictable. Similarly in Rhyl, while the retail offer can be improved, the degree to which it can corner a market share of higher income customers depends not only on its own success in raising quality but also on the extent to which it can compete with nearby established quality retail centres such as Chester.

In Greater Manchester, local policy makers had recently shifted from a sector approach to economic development to a focus on 'broad diversity', reflecting the strength of Greater Manchester in a range of sectors, rather than pursuing a narrower approach foregrounding certain sectors as drivers of global competitiveness. The Treviso Local Pact for Development also focused on raising skills utilisation across a broad range of local sectors. On the supply side, taking a multi-sector approach can also be valuable. In Blackpool, local stakeholders discussed the value of creating transversal training programmes and apprenticeships in customer care, which would be relevant to both the local tourist and the local care sectors (indeed many workers share their time between both these sectors).

\section{Defining functional labour markets}

This study has highlighted that defining functional local labour markets is a difficult process. Conventional mechanisms for establishing local administrative regions (such as the NUTS III regions in European nomenclature) do not necessarily cover homogenous local labour markets. In Canada, the decision was taken by HRSDC to determine Employment Insurance regional boundaries based, to a large degree, on areas with similar labour market conditions. However the EI region of Kitchener, for example, saw little value in being excluded from the neighbouring areas of Cambridge and Waterloo in this analysis in terms of being a functional labour market (see Figure 23. below). Similarly it was argued that taking Blackpool as a functional labour market in the United Kingdom ignored the fact that there were several large and highly productive employers (such as BAE systems and AXA) just outside the town boundaries. 
Figure 23. Employment Insurance regions bordering on Kitchener in Ontario

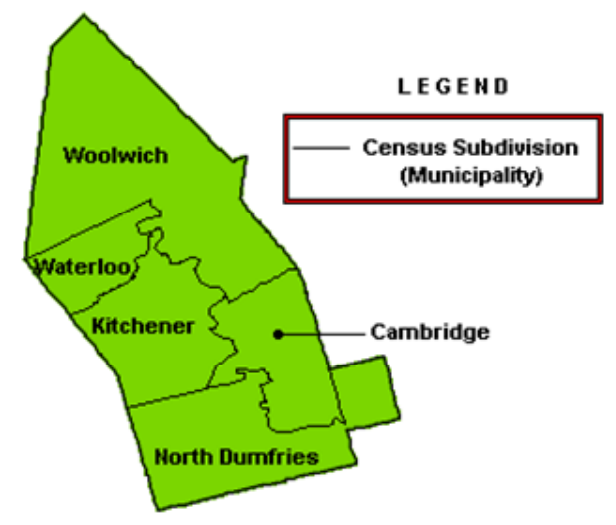

\section{Source: HRSDC}

It is not just researchers who make such distinctions, but also policy makers, who often define policies purely within their own set of administrative boundaries. Lloyd for example, argues that as there is a limit to which the local employment sectors present within Blackpool can add value and improve job quality, local stakeholders needs to consider further how the town is situated within a broader labour market region and link local people more effectively to other regional jobs. This was a practice enabled under the previous Labour government by the establishment of multi-area agreements (see Box 11 below) which allowed local councils to cooperate with each other on issues which ran broader than their own local area. Blackpool was able to cooperate with other local councils on the production of an employment and skills strategy for the Fylde Coast which looked at issues of both skills supply and skills utilisation. Such 'soft' delineations of boundaries can be very useful in helping policy makers to work together on broader labour market areas (Allmendinger and Haughton, 2009). In Manchester, multi-area agreements were used to establish a city level strategy which enables them to tackle for example issues of exclusion and low skills in one part of the city (the north) by improving transport and mobility to growth sectors in the south of the city. In the Riviera del Brenta example in Italy also, flexible working between employers and unions from two different provinces was one reason for the success of the strategy to upgrade the local footwear sector.

\section{Box 11. Multi-area agreements}

The 2007 the Review of Sub-national Economic Development and Regeneration (HM Treasury, Department for Business, Enterprise and Regulatory Reform and Department for Communities and Local Government, 2007) outlined proposals for Multi-Area Agreements (MAAs) which would allow groups of local authorities or sub-regions to agree collective targets for issues of economic development. While MAAs were first set out as voluntary agreements, the government also proposed working with interested sub-regions to explore allowing groups of local authorities to establish statutory sub-regional arrangements to enable a permanent pooling of responsibilities for economic development policy areas. In some sub-regions - including Greater Manchester - pre-existing City Strategy Partnerships (which had been established to tackle worklessness) worked towards developing into the Employment and Skills arm of MAAs, alongside concerns with transport, housing, regeneration, etc. Elsewhere, neighbouring local authorities came together in new sub-regional partnership - as in the case of Blackpool, Fylde and Wyre in the Fylde Coast MAA (signed in October 2009).

Under the Coalition government, local actors have also been encouraged to come together across municipal boundaries through the Local Enterprise Partnerships (LEPS) which are expected to cover functional economic areas. While some LEPs cover the same geographical footprint as MAAs (as in Greater Manchester), in other instances the 
LEP boundaries do not accord with the MAAs. Blackpool is now part of a LEP, for example, for the whole of Lancashire.

Source : Green (2012)

\section{Which stakeholders should be involved?}

This study has highlighted that there are a wide variety of stakeholders with potential to play an important role in raising skills demand and utilisation (see Figure 24. below).

Figure 24. The stakeholders involved at local level

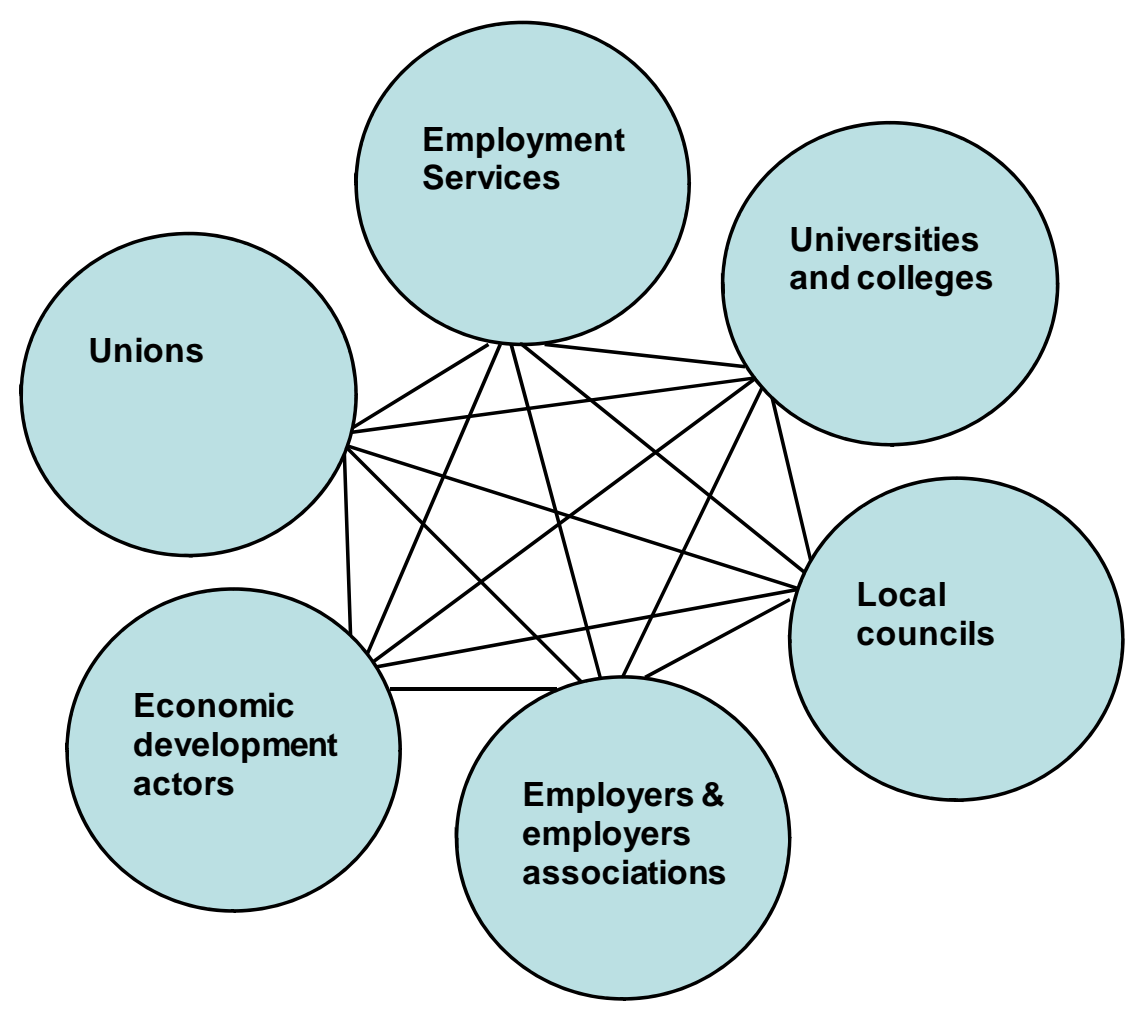

Source: LEED Skills for Competitiveness project.

\section{Vocational training institutions, community colleges and universities}

Colleges and vocational training institutions, in particular, appear to already be acting in ways which bridge the supply and demand sides of the labour market. In areas of traditional low-skills low-wage employment, the role played by colleges in stimulating innovation in the local economy may be just as, if not more, important as that played by local universities. Their potential to work with local employers to help produce incremental innovation in lower-tech sectors, and in local SMEs, should be further recognised by governments. In Niagara College in Ontario, for example, curricula are geared at best matching local industrial demands in a way that is also attractive to students. The local college hosts an applied research unit which serves local firms and organises internships of students in firms. The college also features an employment office which facilitates placement of graduates in the firms of the region 
thereby improving the retention of young people. In the Riviera del Brenta in Italy, the local Politecnico Calzaturiero has been integral to helping local companies move towards higher-value added manufacturing. In Rhyl in North Wales, likewise, the local college was both engaging in training and providing advice and support to managers to upgrade the retail sector in the town. In his recent work on the need to improve the quality of work in the United States, Osterman (2011) also highlights the community colleges as having the critical mass to contribute significantly to this policy area in the United States.

The explanations for this degree of engagement may be multiple - traditionally vocational training colleges and community colleges offer training which is more applied and therefore involves strong industry linkages. At the same time, although such colleges often had a reach far beyond their local area ${ }^{21}$ they often have a significant proportion of local residents amongst their students and therefore are particularly locally embedded.

The Skills Utilisation pilots in Scotland (cited above) also show the value of public sector funding to seed fund collaboration between local colleges and training institutions and local firms. A review by SKOPE in the UK (Payne, 2011) highlights a pilot project in Glasgow which enlisted the help of Glasgow School of Art in instilling new management approaches amongst local employers from a variety of different sectors (see Box 12 below). The firms found the drive by the college to better capitalise on workforce skills refreshing - as one local manager from the manufacturing firm Scott and Fyfe identified, "We've had the contribution of people from the shop floor and that's been crucial. Normally, they wouldn't have been part of the process and that's made us more aware of their strengths and capabilities. The input of some people in terms of the ideas they've contributed has been outstanding." The project had in particular helped the organisation to move from a 'reactive approach' of simply responding to customer inquiries to a proactive one based on 'opportunity spotting' (Payne, 2011).

\section{Box 12. Creating Cultures of Innovation through Creativity and Design - Glasgow}

Led by the Glasgow School of Art (GSA), this project seeks to help business leaders learn 'how to use the knowledge and expertise of their workforce in applied creative projects which have the benefit of generating innovations for the business or service'. Leadership is defined as a 'collective skill across the organisation' and active employee engagement is a sine qua non of finding an organisation's creative potential. A group is selected to participate in a series of workshops based upon 'a diagonal slice of the organisation', with members broadly representative in terms of their position within the firm, gender, function, age and length of service.

The GSA acts in a facilitating role, using design tools to open up 'a learning space' and help structure a creative thinking process, where ideas and experiences can be freely shared. In this process, tension and argument are considered to be a positive spur to creativity as the group must be able to hear all views without pre-judgement. As the project manager explained, 'friction is good. You can feel the tensions between the different functions and hierarchies. Our role is to allow it space to be exposed.' Workshop participants are not expected, however, to work in isolation from the rest of the organisation. Rather the aim is to create a 'ripple effect', with members expected to take their ideas back to their work colleagues and engage them in the process. The GSA team is currently using this approach with three organisations; a well established manufacturing company (Scott and Fyfe), a service retailer and a ski resort.

Source : Payne (2011)

21. Politecnicio Calzaturiero is recognised as a national centre for footwear design, Rhyl college caters for retail within the whole of Wales, and Blackpool and Fylde college offers casino training for people coming from across the UK seeking work in the cruise ship industry 
While universities often see their role as contributing to national, rather than local, prosperity, they can also contribute significantly to improving local economic development where they are locally embedded. Brock University in Niagara, for example, has played a strong role locally in both providing training of relevance to the local economy and stimulating innovation and entrepreneurship. Another OECD LEED study (Froy et al 2009) highlighted the role of the Holbeach campus of the University of Lincolnshire in the United Kingdom, which established a Centre of Excellence in the Food Industry (now the National Centre of Food Manufacturing), co-funded by Lincolnshire County Council, Lincolnshire Enterprise and the former regional development agency emda ${ }^{22}$. This centre not only provided targeted training for potential and actual workers in the food industry (including immigrants with the help of English as a Second Language training) but provides testing and analysis services to employers, technical consultancy, general business advice, master classes and joint technical projects with local companies to tackle challenges around new product development (Green,2008).

In the Riviera del Brenta, it was the local polytechnic which succeeded in bringing the Bocconi University of Milan, the Politecnico of Milan and the University of Padova into the region to work with firms in the footwear sector. This shows the value of local partnerships between these two types of institutions in relation to offering services to employers.

\section{Unions}

In the Italian examples cited in Veneto above, the unions have shown themselves to be valuable partners in working alongside firms in tripartite agreements to raise labour productivity while also improving wage levels and working conditions. A further example of the potential role of the unions in this area is the "Better not cheaper" campaign initiated in the metalworking industry in North-Rhine Westphalia in Germany. Here unions promoted new forms of production that actively used the skills of the workers and which produced new and innovative products with high standards of quality (Haipeter, 2011). Indeed without union involvement it is clear that employers may just raise the requirements associated with job roles without necessarily increasing rewards ${ }^{23}$. As improvements to productivity and market share in many sectors in OECD countries depend on the quality of human resources this is an area where unions and employers have a shared agenda. The fact that unions are also often involved in training of staff also makes this a natural area of engagement for them.

\section{Employers and employers associations}

Bringing employers on board with public sector generated projects is not easy, and the Rhyl example above clearly demonstrates the old adage that 'you can lead a horse to water but you cannot make him drink'. Indeed in several of the above examples, employers managed to raise their game through working mostly with each other, the unions and privately run institutions as opposed to collaborating directly with the public sector. In some cases the role of local and national stakeholders may just be to create the right framework conditions for such interaction, provide funding support where necessary and prevent obstacles and perverse incentives which can restrict cooperation. While working with individual employers may be challenging, this study has highlighted the value of employers associations such as EBAV and ACRIB in Italy, particularly when it comes to helping SMEs to share the costs of training and investments in innovation and technological development. This study has also highlighted the role that publically-funded sector councils and other sectoral bodies (such as the Sector Skills councils in the UK and the Sector Councils in Canada) can play in stimulating innovative approaches to raising both skills supply and

22. The regional development agencies in the United Kingdom have now been disbanded.

23. A number of commentators point to a decoupling of productivity and wages for example associated with trends in the minimum wage, decreasing unionisation and other factors (see e.g. Plunkett, 2011) 
demand, particularly when these organisations reach down to the local level through engaging in joined-up local initiatives.

In some cases, local agencies are attempting to award employers that become actively engaged in improving job quality and wages locally through charter marks and kite marks. In the United Kingdom for example, Islington Council has developed a kite mark with local firms that offer fair pay, provide work experience to young people, offer family friendly working practices and make contributions to local community groups. At the national level the United Kingdom Investors in People programme provides a similar mark of recognition for employers engaged in positive working practices that both train and reward the contributions of staff. Others (such as the charity Oxfam) advocate for a 'name and shame' approach, highlighting an employer 'poverty footprint', helping firms to understand their poverty impact and producing platforms for dialogue and innovation.

The public sector itself is also significant employer in many local areas. While a focus on the public sector was beyond the scope of this current study, evidence from elsewhere in the OECD shows the value of regional activities to improve skills utilisation in this sector. In Queensland in Australia, policy makers have developed balanced approaches to the demand and supply of skills called Skills Formation Strategies $^{24}$ (see Froy and Giguère, 2010a). Currently 60 strategies have been developed in 20 different industry sectors. While it has been difficult to acquire private sector buy in, the public sector strategies have been more successful. A central theme for the Skills Formation Strategies is the view that local skills shortages may not just represent a lack of training supply, but also a potential problem in work organisation and management strategies.

Figure 25. The thinking behind the Australian Skills Ecosystems approach

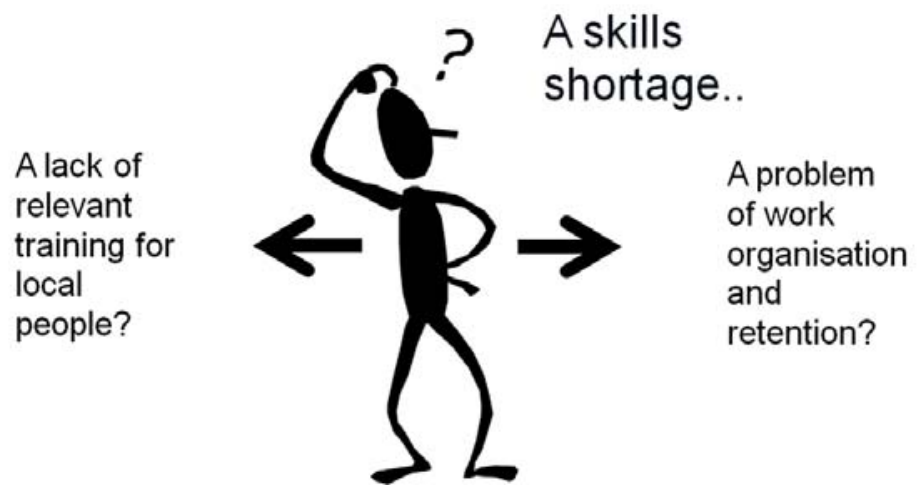

Source: LEED Skills for Competitiveness project.

For example, in the Health and Community Services sector in Queensland, concern arose due to skills shortages and hence long waiting list in community health. On further investigation it was found that the sector had low job satisfaction leading to difficulties in recruitment and retention. A scheme was developed to change work organisation in the sector, in particular by building better allocation of tasks between Allied Health Professionals and their assistants. A time and motion study showed that both of these roles were not utilising the full gamut of their skills, with assistants mainly undertaking administrative tasks and not helping professionals with the more base level work that was distracting them from higher level activity. Following consultation with the unions, both roles were redesigned with both roles taking on new roles. Greater training was provided to assistants in technical skills and to

24. This programme developed on the back of national pilot of skills ecosystem projects in Australia 2003-7. 
professionals in delegation and supervision. Due to some resistance amongst workers a period of change management was required, so a worker was taken on to manage this process - this proved critical to success. As a result of the intervention, skills shortages and waiting times have been reduced and the process used has been introduced incrementally across Queensland (Eddington, 2012).

\section{Local and regional councils and similar public bodies}

In European countries municipal governments often have an overview role which makes them natural brokers and catalysts for bring those involved in both skills supply and skills demand in a local economy. The local council, for example, was instrumental in generating such approaches in Blackpool and in Breda (see Box 10.). In addition to making use of their important capacity to influence change within the employment of their own workforce, it is also important that local authorities and other regional bodies do not forget their role as a purchaser of services. In the city of Manchester, for example, public procurement is being used to gain a variety of community advantages including the greening of the supply chain through the clauses written into sub-contracts. Awarding ' patient capital' and providing longer contracting periods can be a useful way of developing a quality driven supply chain and encouraging sub-contractors to invest in their staff and upgrade their production processes in the context of long-term investment security. Awarding contracts to social enterprises can also be beneficial, as in the absence of shareholders, such enterprises can avoid the short-term pressures and take a long-term perspective to developing and training their staff. However, in the context of budget cuts, local stakeholders stressed that prioritising quality over efficiency can be difficult to achieve.

In some places, not-for-profit agencies and local government bodies have worked together to create a 'living wage' for a particular town or city, which both encourages fairer remuneration for workers but also requires employers to utilise peoples skills better in order to justify such wage increases. An example is the London Living Wage outlined in Box 13. below.

\section{Box 13. The London Living Wage Campaign}

Raising wage levels locally can encourage employers to make more use of the skills of their staff and move away from low-wage/low-skill models of production and service delivery. The latest phase of the living wage movement started in the USA - in Baltimore in 1994 - and it has since spread to the UK. In 2001, a living wage campaign was launched in London, led by a coalition of community, faith-based organisations and trade unions called London Citizens. The campaign has spread from hospitals, to the finance houses of Canary Wharf and the City of London, to Universities, art galleries and hotels. Its current focus is on retailing and government. The campaign has focused on raising wage levels amongst workers employed under sub-contracting arrangements for cleaning, security and other such services. The campaign has also secured agreements that all the new jobs at the 2012 Olympic site will be living wage. Since 2005, the Mayors of London (Ken Livingstone, followed by Boris Johnson) have put resources into a living wage unit at the Greater London Authority, where a team of researchers establish the living wage figure for London each year (set at $£ 8.30$ per hour in 2011). The campaign has secured gains for more than 8000 workers in London, many of them working for contractors, and there are now over 100 London-based employers signed up. A Living Wage Foundation was established in May 2011 in order to properly accredit living wage firms and to promote the living wage to clients, employers and workers across the United Kingdom.

Source : Professor Jane Wills, Queen Mary, University of London

\section{Economic development actors and agencies}

Economic development agencies and other actors clearly have a key role to play in supporting the development of local economies and improving both productivity and competitiveness. However it is not always clear that they fully take into account the importance of human resources and skills to that growth in the context of the knowledge economy. While economic development agencies are often encouraged to 
think in terms of 'job outcomes', this study has highlighted that they do not always consider the quality of the employment produced or the degree to which productivity improvements bring real impacts in terms of salaries and living conditions. At the same time, economic development strategies often focus on 'winning sectors' which may bring high added value and highly skilled employment, but often constitute only a small percentage of local employment.

Ewart Keep from the SKOPE centre in the United Kingdom argues that economic development policy frequently uses an old fashioned idea of innovation which is based in science and R\&D, as opposed to also recognising the value of incremental innovation created bottom up by a skilled and effectively engaged workforce. The OECD innovation strategy has also highlighted the value of incremental innovation in leading to greater product and service innovations and hence growth and productivity (OECD, 2010; Toner 2011). Local stakeholders in Niagara, Canada emphasized that in many of the industries important to their local region (tourism, hospitality, food processing, farming and light manufacturing) adding more value to products involved incremental innovation in processes as opposed to giant leaps in new product introduction driven by high technology. They did not feel that this was fully reflected in policy making (Verma, 2012). Bottom up incremental innovation can be developed in many different sectors locally, contributing to improved employment in a larger set of employment sectors, including those characterised by a concentration of low-skilled, low income employment.

\section{Employment services}

Employment services (both public, not-for-profit and private) can also play a role in helping employers shift towards offering more sustainable employment with better opportunities for progression. In particular, action in this area can reduce labour market churn of people going and out of short-term lower-skilled employment. Generating sustainable employment is, for example, one of the goals of the new Work Programme in the United Kingdom which aims to better integrate the long-term unemployed into work through a network of private contractors. Payments to private contractors are linked to helping individuals 'sustain employment', rather than just 'enter a job'. Local contractors for the programme in Blackpool foresee that their new targets would encourage them to work more closely with employers on retaining staff in a context of rapid turnover and high temporary employment.

Elsewhere in the OECD, the province of New Brunswick in Canada has taken a particularly ambitious approach to tackling poor quality employment locally (Wood, 2011). The Department of Post Secondary Education, Training and Labour (PETL) has developed a two-fold approach to tackling the prevalence of low-skilled low-paid employment in the province. Firstly they have employed a series of 'labour market development officers', locating these positions within a network of local enterprise agencies. The task of these officers is, among other things, to work with companies on improving human resource management and raising productivity. At the same time, the province has developed a definition of underemployment and (in collaboration with federal government) can advise people who fall within this definition to quit their current employment if returning to school would improve their overall career prospects. Such actions encourage local employers (who have traditionally always had a large pool of willing workers) to improve their employment conditions.

\section{Tackling fragmentation}

Understanding the bigger picture of how skills supply relates to skills demand can be made more difficult when different public agencies do not work together and operate in silos. While there was evidence of bottom up cooperation, all the countries studied here lacked a consistent set of local strategic platforms which could sufficiently bring together local actors to tackle supply and demand issues. In the province of Ontario, for example, workforce planning boards and exist but they have no decision making powers and cannot therefore coordinate local bodies to achieve identified priorities. Verma (2012) also 
found there were no local level taskforces able to target a specific industry group or region with all available government programmes. In the United Kingdom the labour government set up business-led Employment and Skills Boards in major cities such as London, Manchester and Nottingham. These were discontinued by the current coalition government and stripped of their statutory powers. However it is notable that local stakeholders were seeking to prolong the existence of these platforms under different names, and the new Local Enterprise Partnerships (LEPs) may help to facilitate such collaboration. In Italy there is very little decision making power at the provincial level so most policy design takes place at the regional level.

It is clear that performance management targets act as important barrier to individual sectors getting involved in transversal policy areas such as this. Each sector has its own set of targets which are frequently more aligned to their core delivery area. This is a particular problem in this case because of difficulties in measuring the outcomes from investment in job quality and skills utilisation. It is much easier to measure training course delivered, as opposed to skills shortages eliminated through work with employers on work organisation. This was a problem which affected the Queensland Skills Formation strategies, for example, with state policy makers having to set about finding new ways of measuring public policy investment in this area in order to keep drawing down vocational training funds (Eddington and Eddington, 2010).

A further problem is that each of these policy areas has its own agenda which may take attention away from skills supply and utilisation issues. In the local case study areas in the United Kingdom for example employment and skills policy is strongly focused on tackling disadvantage, particularly in the context of rising unemployment in the economic downturn. Speaking of quality jobs was felt to some extent to be a luxury in the context of a situation where 'any job is a good job' given rising unemployment and declining labour market attachment. There was also a reluctance to damage relations with employers that were continuing to recruit through an insistence on the quality and sustainability of the jobs on offer.

Dismissing job quality and issues of employment progression in this way was seen by Lloyd (submitted) to miss the interconnectedness of these issues with labour market exclusion. Lloyd highlights the paths or ladders which normally exist within the labour market from inactivity through employment in secondary or dependent jobs through to better quality jobs. Through supporting progression and improvement in job quality policy makers can not only support skills utilisation but also free up more entry-level positions for unemployed workers and reduce labour market churn. During times of economic downturn these ladders reverse, with more highly skilled people losing their jobs and being bumped down into lower quality employment. In this context, it can be argued that the solution will not be necessarily to focus on matching increasingly less competitive people to a diminishing pool of jobs but rather focusing on increasing prosperity and productivity so that more high-end and low-end jobs are created and there is less retrenchment in the labour market. While a focus on tackling the immediate poverty created by exclusion may be useful in the short-term, building prosperity and productivity locally will be important to prepare routes out of the recession in the medium to longer-term.

\section{The importance of local leverage and flexibility}

A key dimension in supporting the development and delivery of balanced local skills strategies is injecting local flexibility into the management of employment and skills policies (Froy et al, 2009, Froy and Giguère, 2010b). Within the countries participating in this study local stakeholders acting at the level of functional labour markets had limited strategic flexibility and influence over the delivery of employment and skills programmes. In Manchester in the United Kingdom, for example, there was frustration that despite having brought local councils together to create a common vision for the development of the city, they had not been delegated the authority to play anything more than an influencing role in relation to local employment and skills provision. 
Local stakeholders also voiced concerns in all three countries as to the slowness of training systems in responding to their needs and adapt to changing skills requirements. In particular training is often perceived as overly bureaucratic and there is not enough flexibility at local level to design training programmes. In Italy, for example, the provinces generally have a minimal role in this area, with training policy mostly being designed at the national and regional levels. The relevance of training was found to be more important than the resources available for training - indeed in many cases training budgets were found to go unspent, partly due to the lack of a prompt and flexible response to employers' needs. A lack of reciprocal trust between employers and the public sector, and a lack of capacity within the private sector to fully articulate common skills needs was also found to be to blame (Destefanis, 2012).

What was particularly missed amongst employers in each country was modular 'bite sized' training which would allow workers to quickly upskill. Such training is clearly important in the context of the rapid skills obsolescence generated by today's pace of technological change. In generating training that is relevant to local needs, however, it is important that policy makers keep an eye on the need to develop broader educational strategies which will equip local people with the ability to be both mobile within a country, but also to be more adaptable and transferable locally. While in the Veneto region in Italy, employers were often seeking school leavers as opposed to graduates, and quick mechanisms to upgrade their skills, it was recognised at regional level that ultimately higher level skills will be required to create the innovation and strategic development of regional sectors for the medium-long term. While employers may prioritise short-term skills needs, ultimately they may benefit more from people who are equipped with broader and deeper training which allows them to participate in the longer-term evolution of both individual sectors and the wider economy.

\section{Data availability}

Finally, a lack of local level data is also challenging for this policy area. Given that many areas characterised by low-skills equilibrium often have relatively high employment rates, they can fall beneath the radar of policy concern. While many local policy makers collect information on skills supply and skills shortages locally, it is less common to collect information regarding the stock of skills locally (for example present within the local workforce) and local incomes and how this may vary by sector. This makes the development of evidence based policy particularly difficult. Where data is available, local policy makers need to think carefully how they use the data and how it influences public policy. Data on local skills shortages and unfilled vacancies for example can encourage policy makers to focus on the 'quick fix' of filling local jobs, while not looking at the bigger picture on whether skills are effectively utilised in the local economy to raise the quality of local jobs and incomes. 


\section{CONCLUSIONS AND ISSUES FOR CONSIDERATION}

The findings of this study help to support previous research by the LEED Programme (Froy et al, 2009) on the importance of local skills strategies, through highlighting sub-regional variation in the supply and demand for skills. The classification of local economies into the relative categories of low- and highskills equilibrium, skills shortage and skills surplus areas was found to be useful by policy makers in identifying the 'bigger picture' regarding the balance of skills demand and supply at local level.

The study has also highlighted the many 'on the ground' actions which are taking place at the local level in OECD countries to better link skills supply with skills demand. It is clear that while in some regions (especially those with skills shortages) there is justification for public policy makers to take a 'demand-led' approach to skills, in low-skills equilibrium and skills surplus regions it may also be appropriate to help 'shape demand', to move economies towards higher value-added activities which offer better quality jobs. Such actions will be important not only in improving living conditions but also in making local jobs more sustainable in an increasingly competitive global economy. A number of issues for consideration by Governments flow from this work, at both national and local level:

\section{Developing balanced local skills strategies}

It is increasingly obvious that local actors need to take a joined-up approach to skills locally, linking educational investment with longer-term economic development, particularly in areas facing low-skilled equilibrium. In order to develop such strategies, area-based partnerships can be beneficial at the level of functional labour markets which take a broad overview of employment, skills and economic development issues. Allowing local actors to come together around 'soft' boundaries (as promoted by the multi- area agreements in the United Kingdom) can be beneficial in allowing policy makers to fully take into account the different geographical dimensions of local labour markets.

As work to help 'shape demand' and move local economies up the supply chain is largely an untested area for public policy governments could benefit from seed-funding local experimentation in this area to understand what works and what doesn't in their own particular governance context. The 'action research' skills utilisation projects implemented in Scotland since 2009 have for example been valuable in aiding policy learning not only in their host regions, but also elsewhere.

\section{Promoting local flexibility in responding to skills demand....}

Employers who were interviewed for this study clearly signalled the importance of skills and training policies that are more responsive to employer needs. The study findings suggest that local policy makers need to urgently develop flexible life-long learning systems at local level which include both modular 'bite size chunks' of training adapted to local needs, while also delivering courses which build the broader skills required for the strategic development of the local economy. Governments can assist local actors in creating training which meets local employer demand by promoting flexibility in the management and implementation of training and skills systems, and related policy areas including employment and economic development. Policy makers in low-skills equilibrium regions can also benefit from supporting more informal training and knowledge sharing activities to build aspirations and increase commitment to local place and local firms (as took place in Blackpool in the UK).

A further important dimension of better matching skills to demand is providing better information to local people on local job opportunities. Making local employment opportunities more visible through mapping local employment job profiles and providing careers advice will improve the retention of talented people, and give skilled people greater choice in terms of whether they stay or leave a region to seek 
employment commensurate with their skills. The mapping of new job opportunities in trades in Niagara, Canada is a good example of this. The career clusters and career ladder schemes of the United States also provide a useful model which other countries can follow (Froy and Giguère, 2010b, Hamilton, 2012). In the context of today labour market where jobs are rarely 'jobs for life' such systems need to cater as much for older adults as for young people. Of course, in a global and knowledge-based economy, national and international labour markets benefit considerably from labour mobility. It is therefore important that careers advice systems create spring-boards for local residents to travel and use their skills wherever they are most likely to lead to productive and rewarding careers.

\section{.....but also where necessary helping to 'shape demand'}

In low-skills equilibrium regions policy makers in the field of workforce development and training can also play a role in joined-up strategies to help 'shape demand', steering the local economy towards higher value-added production which raises skills demand and utilisation. In many cases, economic development approaches in such regions focus on supporting economic diversification, inward investment and entrepreneurship, and education and training institutions can play an important role in supporting such strategies. Niagara College in Ontario for example was active in providing relevant training courses, sharing information and relevant careers advice to students, helping students to access business incubation facilities and promoting relevant $\mathrm{R} \& \mathrm{D}$ and technological transfer.

The case studies for this project also underline the value of actions to boost productivity and skills demand in local sectors which have traditionally hosted low-skilled jobs (for example tourism, retail, lower-tech manufacturing), particularly where such sectors are likely to remain an important source for employment in the future. In the absence of a strong public sector push in this area, in many cases it is local employer networks, unions and colleges that are collaborating on supporting incremental innovation in such sectors. It is important that the public sector capitalises on such 'bottom up' collaboration through supporting clusters of enterprises and supply chains. Public support can be useful in a number of areas:

Stimulating employer networks, particularly amongst smaller companies can help in the development of quality local brands and support effective marketing to niche and higher value markets. Bringing employers together can also promote technology transfer, and support the sharing of training resources and co-operation on the development and testing of new product innovations.

An important finding of this study was the extensive involvement of vocational training colleges in in working with firms to improve local skills utilisation and improve productivity through management training and the (co-) development and dissemination of relevant R\&D, and product testing and technology transfer. The local polytechnic in the Riviera del Brenta in Italy is a good example of a private college taking on such a role, with the support of regional government resources and European Social Fund monies. Governments could do more to support and enhance the capacity of colleges to take a lead in this area, while also supporting partnership working between colleges and local universities in this field.

Providing management training and technical assistance to firms is a particularly important area for investment by both colleges and universities, in order to improve work organisation and skills utilisation. Better trained managers are likely to create more productive working environments for their staff. This may mean helping employers to prioritise creativity and innovation over simple efficiency, as creativity is more likely to lead to changes in product market strategy which will significantly change employment opportunities. The Skills Utilisation pilot in Glasgow, Scotland is an example of such an approach. Local firms will benefit not just from formal management training but also networks and partnerships which share innovations and new knowledge and ideas at local level. LEED research has recently demonstrated the particular importance of such networks in supporting skills upgrading in SMEs (OECD, 2012 forthcoming), which often have little time to participate in formal training. 
It was evident from the study that increasing skills utilisation and productivity in firms does not automatically translate into better incomes and better working conditions for local people. The importance of unions and other employee representative bodies in working with employers to ensure that workers benefit from improvements to productivity is clear and it is important that unions are involved in local partners to promote more effective skills utilisation. The Local Pact for Development in Treviso, Italy, is a good example of such an approach. At the same time it is important that economic development actors consider the influence of their initiatives on local working conditions and job quality.

\section{Considering the role of the public sector as an employer, purchaser and funder}

Finally, it is important to remember that the public sector can play an important role in helping to shape skills demand and utilisation locally not only as a policy maker, but also as an employer, standard setter and purchaser:

As an employer: When seeking to help local economies to move up the value chain it is important that public actors start in their own back yard. The public sector is frequently an important employer at the local level, particularly in low-skills equilibrium economies, and it is also frequently responsible for employment sectors where have traditionally offered poor quality and low-skills jobs, such as the care sector. The Queensland Skills Formation Strategies in Australia are a good example of how actions taken by the public sector to improve work organisation in sectors such as community health sector can improve job quality while also reducing skills shortages and better delivering services. Despite the pressures associated with austerity measures, it is important that governments maintain a longer term goal to improve the quality of work in the public sector and its supply chain through, for example, establishing regulations around minimum quality of service and setting in place minimum training requirements. Governments could also benefit from screening their broader policies for their impacts on skills and job quality. Ideally public services should be designed in a way which creates not only good quality services but also good quality jobs.

In setting incentives and standards: Governments can play a strong role in setting occupational standards which drive up both skills training and skills utilisation, particularly within the public sector. Developing systems for rewarding employer ambition (such as the Investors in People in the United Kingdom) can be useful. Setting standards locally, for example by awarding charter marks to local businesses that are effective in managing and rewarding their staff, is another option. Governments can also change the incentive structures for local employment agencies so that they concentrate on the quality and not just the quantity of job-matches, as has been seen with the United Kingdom's new work programme.

As a purchaser: public procurement can also be used to develop a quality-driven supply chain, for example by awarding longer-term contracts which encourage local firms to invest further in their staff and/or requiring a certain level of training, salary levels and working conditions in tendering processes. Given that social enterprises can avoid some of the short-term pressures associated with satisfying private shareholders, they can often be a useful partner in developing and training their staff and promoting local job quality. 


\section{BIBLIOGRAPHY}

Allmendinger P, Haughton G, 2009, "Soft spaces, fuzzy boundaries, and metagovernance: the new spatial planning in the Thames Gateway" Environment and Planning A 41(3) 617 - 633, UK

Beatty C., Fotthergill S., Gore T. and Wilson I. (2010) The Seaside Tourism Industry in England and Wales: Employment, Economic Output, Location and Trends, CRESR, Sheffield Hallam University, UK.

Becattini G. (2004), Industrial districts: A new approach to industrial change, Edward Elgar, Cheltenam, UK.

Buchanan, J. et al., (2010), Skills demand and utilisation, An International Review of Approaches to Measurement and Policy Development, OECD LEED Working Paper 2010/4

Buchanan, J., and Evesson, J (2004) "Creating markets or decent jobs? Group training and the future of work', NCVER, Adelaide, South Australia (published at http://www.ncver.edu.au/publications/1468.html)

Buchanan, J., Schofield, K., Briggs, C., Considine, G., Hager, P., Hawke, G., Kitay, J., Meagher, G., Macintyre, J., Mounier, A., and R., (2001) 'Beyond Flexibility: skills and work in the future', Board of Vocational Education and Training (NSW), Sydney, 2001 (published at http://www.bvet.nsw.gov.au/pdf/beyondflex.pdf)

CFE (2010), ‘Skills Utilisation Literature Review’, Scottish Government, Glasgow.

Coyle, D. (2001), Paradoxes of Prosperity: Why the New Capitalism Benefits All, Texere, New York.

Destefanis, S. (2012) 'Skills for Competitiveness: Country Report for Italy', OECD LEED Programme Working Paper 2012/4, OECD Publishing.

Dotti N.F., Fratesi U., Lenzi C., Percoco M. (2010), Local labour markets and the interregional mobility of Italian university students, AISRE

Dorenbos, R. and F. Froy (2011), "Managing Accountability and Flexibility in the Netherlands: Country Report”, OECD LEED Working Paper, Paris.

Eddington, Noela and Eddington, Ian (2010) Methods and instruments for evaluation and monitoring of VET systems. Working Paper. Economic and Social Research Council on Skills, Knowledge and Organisational Performance, Cardiff, United Kingdom.

Eddington, N. (2012) "Queensland Skills Formation Strategies: a Case Study”, OECD LEED Programme Working Paper, forthcoming, OECD Publishing.

European Commission (2008), 'New Skills for New Jobs. Anticipating and matching labour market and skills needs', Communication from the Commission to the European Parliament, the Council, the European Economic and Social Committee and the committee of the regions, SEC(2008) 3058

Evesson, J. Jakubauskas, M. \& Buchanan, J. (2009) 'Choosing a sustainable future in Victorian Primary Industries’, Workplace Research Centre, University of Sydney 
Finegold, D. \& Soskice, D. (1988) ‘The Failure of Training in Britain: Analysis and Prescription’, Oxford Review of Economic Policy, 4:3, pp. 21-53

Froy, F and S. Giguère (2010a), Putting in place jobs that last: a guide to rebuilding quality employment at local level, OECD Publishing, Paris

Froy, F. and S. Giguère (2010b), Breaking Out of Policy Silos, OECD Publishing, Paris.

Froy, F., S.Giguère and A.Hofer (2009), Designing local skills strategies, OECD Publishing, Paris

Green A. E., C. Hasluck, T. Hogarth and C. Reynolds (2003), "East Midlands FRESA Targets Project Final Report", report for East Midlands Development Agency, Institute for Employment Research, University of Warwick, and Pera.

Green, A. (2012), 'Skills for Competitiveness: Country Report for the United Kingdom', OECD LEED Programme Working Paper 2012/3, OECD Publishing.

Green, A (2008) ‘Designing Local Skill Strategies: The Case of South East Lincolnshire’, OECD, Paris.

Haipeter, T (2011), 'Better not cheaper - a German trade union campaign and the problems of union revitalisation. Working paper presented at the 32nd Annual Conference of the International Working Party on Labour Market Segmentation (IWPLMS) "Education and Training, Skills and the Labour Market", Bamberg University (Germany) on 11th - 13th July 2011

Hamilton, V. (2012), “United States Career Pathway and Cluster Skill Development: Promising Models”, OECD LEED Programme Working Paper 2012/6, OECD Publishing.

HM Treasury, Department for Business Enterprise and Regulatory Reform, Department for Communities and Local Government (2007) Review of sub-national economic development and regeneration, HM Treasury, BERR, CLG, London.

Keep, E., Mayhew, K. and Payne, J. (2006) From skills revolution to productivity measure - not as easy as it sounds? Oxford review of economic policy, 22:4, pp. 539-559

Keep, E. (2009) 'The limits of the possible: shaping the learning and skills landscape through a shared policy narrative’, SKOPE Research Paper No. 86.

Jacobs, J (1969) The economy of cities Vintage Books, Random House

Jacobs, J (2000) The nature of economies, Modern Library.

Lloyd, P (submitted) comments on the Country Report for Skills for Competitiveness: the UK, OECD, Paris

Mason, G (2011) Product strategies, skills shortages and skill updating needs in England: New evidence from the National Employer Skills Survey, 2009 Evidence Report 30

OECD (2006) The Changing Nature of Manufacturing in OECD Economies (STI Working Paper 2006/9)

OECD (2008), Skills for Competitiveness: tackling the low-skilled equilibrium conceptual framework, OECD Paris 
OECD (2010) The OECD Innovation Strategy: Getting a Head Start on Tomorrow, OECD Publishing, Paris

OECD (2012), Better Skills, Better Jobs, Better Lives: The OECD Skills Strategy, OECD Publishing, Paris

OECD (2012 forthcoming), Innovation in Training and Skills Development. OECD Publishing, Paris

ONS (2000), Standard Occupational Classification 2000 Volume 1

Osterman, P, (2011) Good Jobs America: Making Work Better For Everyone, Russell Sage Foundation

Payne, J (2011) 'Scotland's skills utilisation programme - an interim evaluation', SKOPE Research Paper No. 101 June 2011, University of Cardiff

Plunkett, J (2011), 'Growth without gain?: The faltering living standards of people on low-to-middle incomes,' Resolution Foundation Commission on Living Standards

Toner, P (2011), Workforce Skills and Innovation: an overview of major themes in the literature'OECD Science, Technology and Industry Working Papers. 2011/01, OECD Publishing

UK Commission for Employment and Skills (2009) Ambition 2020: World Class Skills and Jobs for the UK. Wath-upon-Dearne: UKCES.

Verma, A. (2012), 'Skills for Competitiveness: Country Report for Canada', OECD LEED Programme Working Paper 2012/5, OECD Publishing.

Warhurst, C. and Findlay, P. (2011) 'More effective skills utilisation: the shifting terrain/shifting the terrain of skills policy in Scotland’, Universities of Sydney and Strathclyde.

Wills, J (2009) 'Subcontracted Employment and its Challenge to Labor', Labor Studies Journal 2009; 34; 441, SAGE publications

Wood, D. (2011), “Balancing Flexibility with Accountability: governing active labour market policy in post-devolution Canada: Country Report”, OECD LEED Working Paper, Paris.

World Bank (2009), World Development Indicators, World Bank 


\section{Skills for Competitiveness}

A Synthesis Report 